\title{
Three essays in environmental markets: Dynamic behavior, market interactions, policy implications
}

Irene Margaret Xiarchos

West Virginia University

Follow this and additional works at: https://researchrepository.wvu.edu/etd

\section{Recommended Citation}

Xiarchos, Irene Margaret, "Three essays in environmental markets: Dynamic behavior, market interactions, policy implications" (2006). Graduate Theses, Dissertations, and Problem Reports. 2493.

https://researchrepository.wvu.edu/etd/2493

This Dissertation is protected by copyright and/or related rights. It has been brought to you by the The Research Repository @ WVU with permission from the rights-holder(s). You are free to use this Dissertation in any way that is permitted by the copyright and related rights legislation that applies to your use. For other uses you must obtain permission from the rights-holder(s) directly, unless additional rights are indicated by a Creative Commons license in the record and/ or on the work itself. This Dissertation has been accepted for inclusion in WVU Graduate Theses, Dissertations, and Problem Reports collection by an authorized administrator of The Research Repository @ WVU.

For more information, please contact researchrepository@mail.wvu.edu. 


\title{
Three Essays in Environmental Markets: \\ Dynamic Behavior, Market Interactions, Policy Implications
}

\author{
Irene Margaret Xiarchos
}

Dissertation Submitted to the Davis College of Agriculture, Forestry, and Consumer Sciences in West Virginia University in partial fulfillment of the requirements for the degree of

\author{
Doctor of Philosophy \\ in \\ Natural Resource Economics
}

Jerald J. Fletcher, Ph.D., Chair

Alan R. Collins, Ph.D.

Walter C. Labys, Ph.D.

Tim T. Phipps, Ph.D.

Russell S. Sobel, Ph.D.

Morgantown, West Virginia

2006

Keywords: voluntary programs, environmental reputation, dynamic paths, metal markets, primary and secondary prices, price volatility, inventories, economics 


\section{ABSTRACT \\ Three Essays in Environmental Markets: Dynamic Behavior, Market Interactions, Policy Implications \\ Irene Margaret Xiarchos}

In order to induce or support voluntary environmental behavior, the mechanisms of existing and possible environmental markets must be understood. This dissertation analyzes two issues related to voluntary environmental behavior:

(i) The reactions of firms over the long term to stakeholder concerns about the environment (essay one).

(ii) Interactions between recycled and primary markets for metals (essays two and three).

Although these essays consider different phenomena, they are underlain by common factors: the exploration of behavior in environmental markets, the importance of profit as a motivation for firms' actions, the centrality of the role of information, and the necessity to look at systems in a dynamic framework.

Essay one, entitled "An Environmentally Conscious Firm: Dynamic Behavior and Policy Considerations", analyzes the environmental practices of a firm conscious that its environmental behavior influences its reputations and thus its profits. Additionally, it considers the role of and the opportunities for voluntary programs and public disclosure policies under this formulation. The analysis is undertaken using dynamic optimization. The title of essay two is "Price and Volatility Transmission between Primary and Scrap Metal Markets". This essay empirically evaluates the dynamic interactions of primary and scrap metal prices through multivariate time series methods and expands the investigation at the level of volatility transmission. In the related essay three, "Time-Varying Ratios of Primary and Scrap Metal Prices: The Importance of 
Inventories", potential short term instability between primary and scrap prices is explored through an examination of primary to scrap price ratios. A model that relates the ratio of primary and scrap prices to levels of primary metal stocks is proposed and evaluated. 


\section{ACKNOWLEDGMENTS}

Working on this document has been an academic and personal challenge, and completing the Ph.D. has taken me through a journey which has shaped my life. I thank my advisors, professors, colleagues, family and friends for all the times they granted me their support and input. I would especially like to thank my advisors Alan Collins, Jerry Fletcher, Walter Labys, Tim Phipps, and Russ Sobel for their mentoring and advice. I feel fortunate that my major advisor and committee

chair Jerry Fletcher pushed me along the the road of personal and academic growth by believing in my abilities, supporting my choices, and allowing me to gain knowledge from all my committee members. I also want to extend my thanks to Professor Alexie Egorov for his kind programming help that came when I was most in need for it, and to my friend Dennis Kamil for his moral uplift during my dissertation crises. Additionally, I must also note my appreciation for the interlibrary loan services provided by the WVU libraries, which allowed me to access distant academic resources.

\section{I am forever grateful to my parents Stavros and Bonita Xiarchos.}

It is their compassion, advice, help, and support that got me through the difficult challenge of completing my degree. 


\section{TABLE OF CONTENTS}

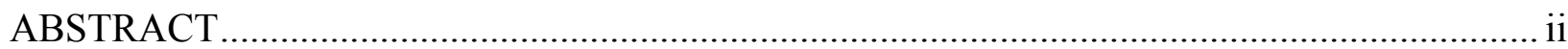

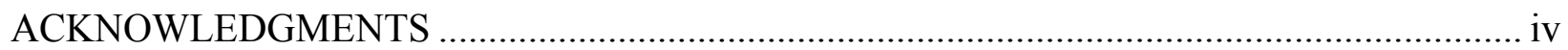

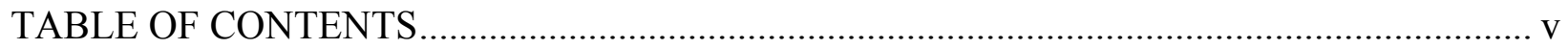

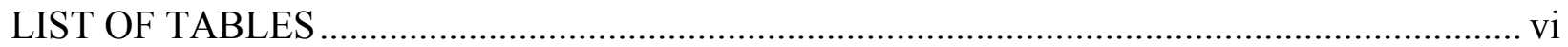

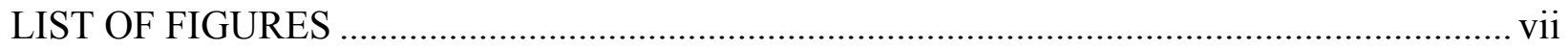

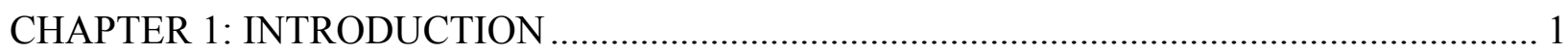

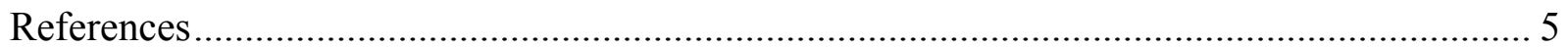

CHAPTER 2: ESSAY 1. An Environmentally Conscious Firm: Dynamic Behavior and Policy

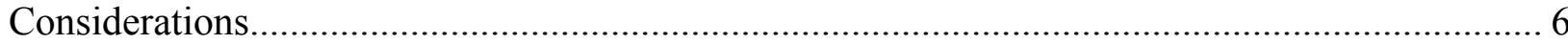

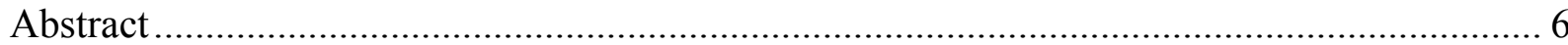

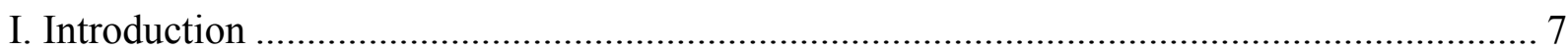

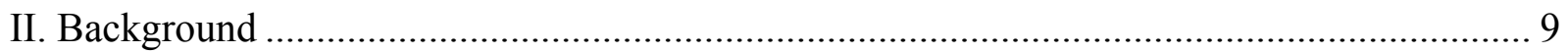

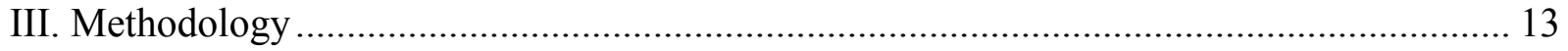

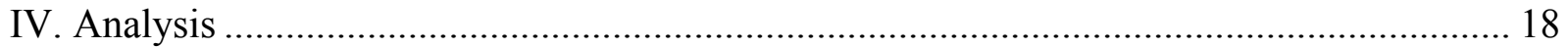

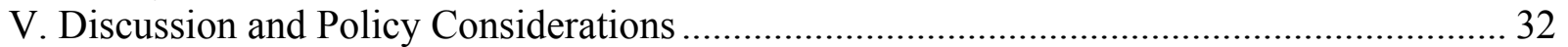

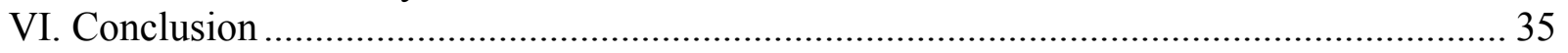

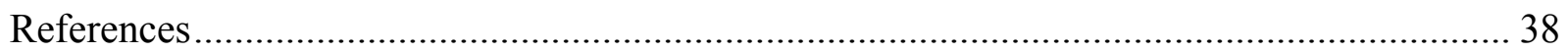

CHAPTER 3: ESSAY 2. Price and Volatility Transmission between Primary and Scrap Metal

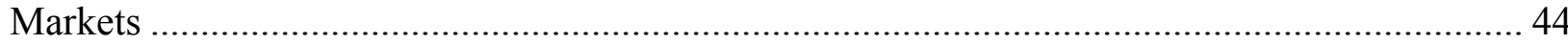

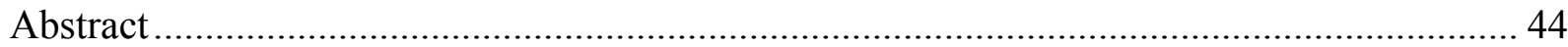

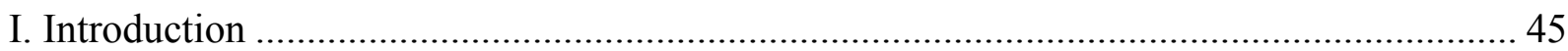

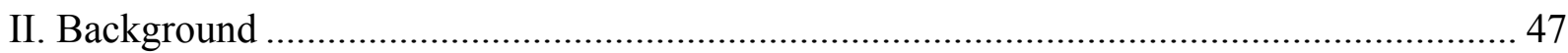

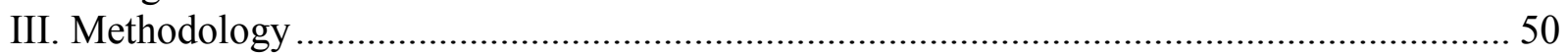

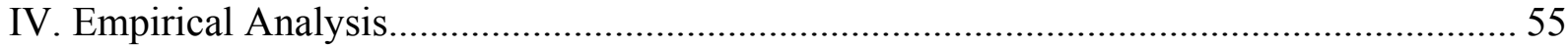

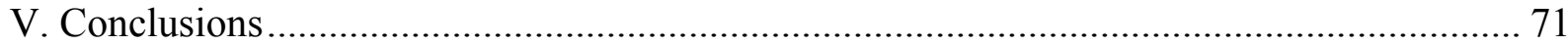

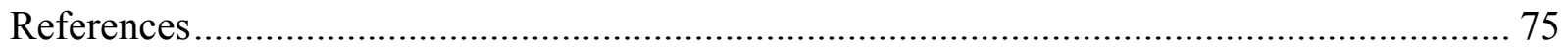

CHAPTER 4: ESSAY 3. Time-Varying Ratios of Primary and Scrap Metal Prices:

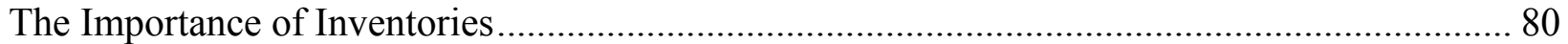

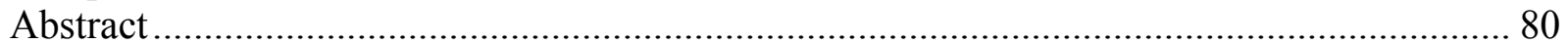

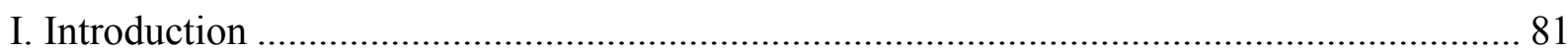

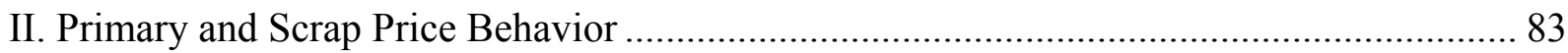

III. Primary to Scrap Price Ratios ........................................................................................... 91

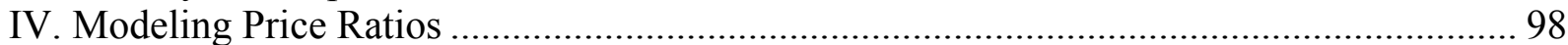

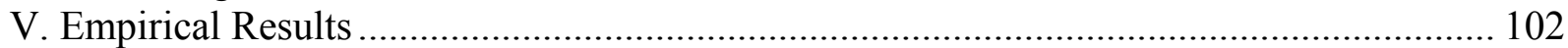

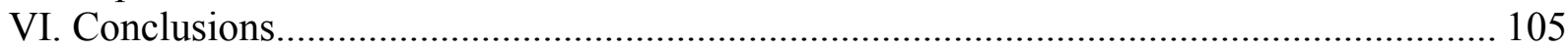

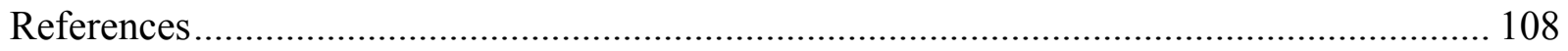

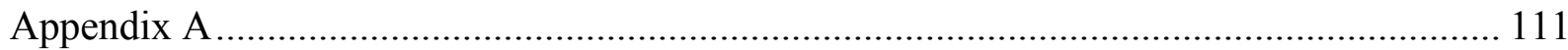

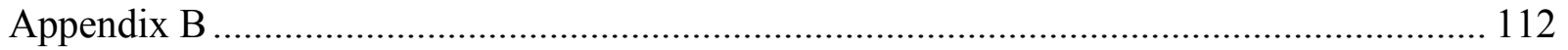

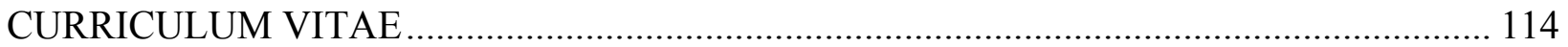




\section{LIST OF TABLES}

ESSAY 2. Price and Volatility Transmission between Primary and Scrap Metal Markets

Table 1. Recycling Rates and Old to New Scrap Ratios by Metal ........................................ 56

Table 2. Characteristics of Primary and Scrap Prices by Metal .............................................. 59

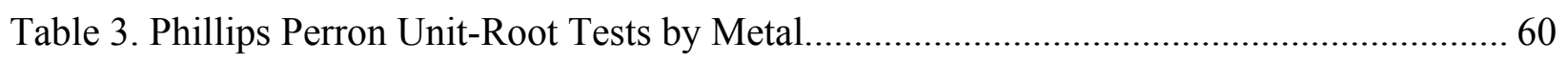

Table 4. Characteristics of Primary and Scrap Price Changes by Metal ................................. 60

Table 5. Autoregressive Conditional Heteroskedasticity Tests by Metal................................ 60

Table 6. Johansen Cointegration Tests by Metal .................................................................... 61

Table 7. Speed of Adjustment for Primary and Scrap Prices

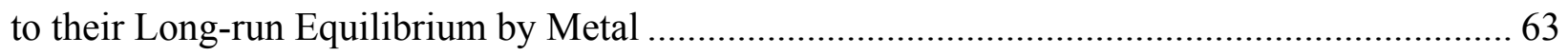

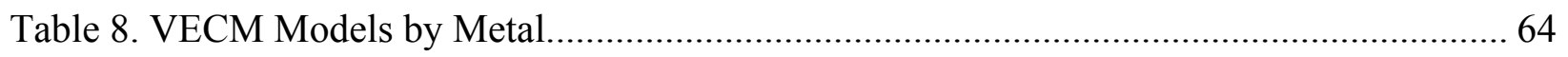

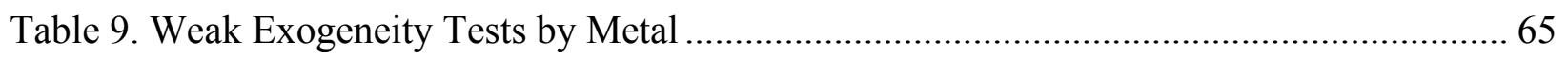

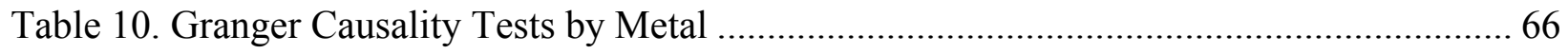

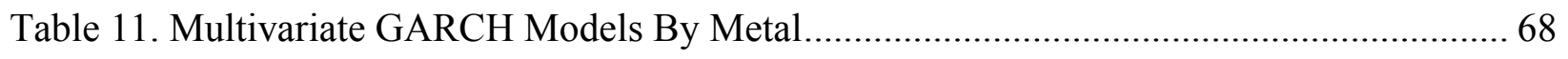

Table 12. Weak Stationarity Test for the Lead Volatility Model ......................................... 71

ESSAY 3. Time-Varying Ratios of Primary and Scrap Metal Prices: The Importance of Inventories

Table 1. Characteristics of Primary and Scrap Prices by Metal ............................................ 85

Table 2. Evidence of Cointegration between Primary and Scrap Prices by Metal .................... 90

Table 3. Characteristics of Primary to Scrap Price Ratios by Metal ....................................... 93

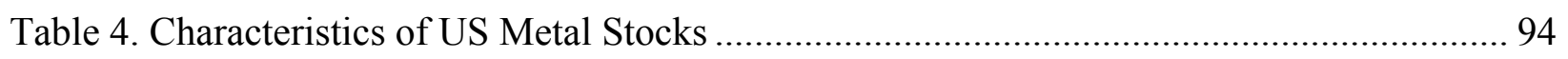

Table 5. Models of Primary to Scrap Price Ratios............................................................ 103

Table A1. Primary and Scrap Prices and Volatility by Metal (1985-1999)............................ 111

Table A2. Price Ratios by Metal for Selected Time Periods ................................................. 111

Table B1. VECM Models for Price Ratios and Inventories ............................................... 112

Table B2. Tests for Cointegration between Price Ratios and Inventories ............................. 113 


\section{LIST OF FIGURES}

ESSAY 1. An Environmentally Conscious Firm: Dynamic Behavior and Policy Considerations Figure 1. Phase Diagram for an Environmentally Conscious Firm .............................................. 22

Figure 2. Shadow Value of Environmental Reputation: Convergence to a Steady State............. 24

ESSAY 2. Price and Volatility Transmission between Primary and Scrap Metal Markets

Figure 1. Primary and Scrap Price Series by Metal .................................................................. 58

ESSAY 3. Time-Varying Ratios of Primary and Scrap Metal Prices: The Importance of Inventories

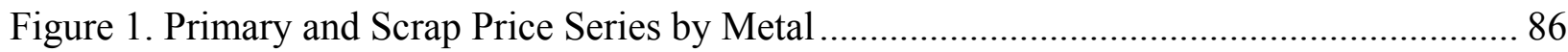

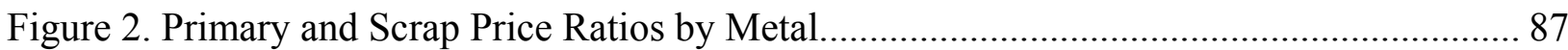

Figure 3. Metal Stocks (in logarithmic form) …………………………………………............ 95

Figure 4. Scatter Plot of the Price Ratio of Primary to Old Scrap Copper (PPC/PS2C)

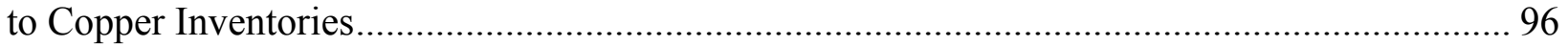

Figure 5. Scatter Plot of the Price Ratio of Primary to New Scrap Aluminum (PPA/PS1A)

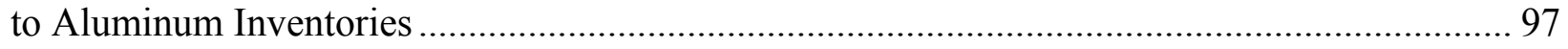

Figure 6. Scatter Plot of the Price Ratio of Primary to New Scrap Zinc (PPZ/PSZ)

to Zinc Inventories

97

Figure 7. Scatter Plot of the Price Ratio of Primary to Old Scrap Lead (PPL/PSL)

to Lead Inventories 98 


\section{CHAPTER 1: INTRODUCTION}

To induce or support voluntary environmental behavior it is necessary to understand the behavior of existing and possible environmental markets. This dissertation consists of two separate studies. The first study, essay one, is a theoretical analysis of the environmental behavior of firms when stakeholders' environmental concerns are expressed in the market. In the second study an existing environmental market, the market for recycled metals, is examined in light of its relation to the primary material market since metal market participants act in both the primary and recycled material sector. This study is separated into two essays. Essay two examines interrelationships among recycled and primary metals in terms of prices and price instability. Essay three examines short run disequilibrium forces between primary and recycled material markets, again in terms of prices. Both essays two and three provide insight into market stimuli and into a key element of fragility in many environmental markets - market instability.

Environmental policy rests on the assumption that firms can be influenced to use environmentally friendly practices. A basic question, then, relates to the method that governments choose to influence environmental behavior. Consider two extremes: (1) rely on fiat - command and control approaches - to force firms to comply with environmental standards set by government agencies; or (2) consider a situation in which firms, of their own accord, are free to choose (or not to choose) to consciously establish controls on their own activities. The first method is purely coercive. The second method is purely voluntary and leaves it to the individual firm to decrease its waste in line with its own self-interest. A middle ground would be to push firms toward compliance with government set standards by means of incentives designed 
to induce compliance. Usually such incentives proposed by economists are taxes, subsidies, or the establishment of rights that would create environmental markets.

It is not illogical to assume that firms often find it in their own self-interest to initiate environmentally-friendly practices in order to increase their profits by decreasing costs and/or increasing revenues, currently or over time. The Porter hypothesis (Porter, 1991; Porter and van der Linde, 1995) of benefits arising from controlling pollution and waste has influenced the business world. This notion has led to an increasing trend for self-initiated pollution reduction programs. In the presence of profit-making opportunities from undertaking environmentallyfriendly practices, there may be no necessity for direct government intervention. Producers themselves are quick to perceive new business opportunities. The increasing trend toward recycling, the turning of waste materials into profitable new products, exemplifies this. Metals, for example, have been recycled for many years. Recycling reduces the amount of waste to be disposed of, adds revenue, and decreases pressure on non-renewable resource stocks. While many metals markets have been producer initiated, some markets for recyclables are fragile, plagued by market instability and gaps in demand or supply (Field et al., 1994). Such markets may require government support to operate effectively.

Market opportunities for environmentally aligned actions do not necessarily negate a role for government. Government action may be needed in the background. For instance, the government may take the role of setting overall standards, providing information (a public good by nature), designing programs in ways that influence firms' actions and provide incentives towards the adoption of environmental practices, or making sure that the necessary structures are in place to assure that environmental markets not only arise but are sustainable. 
Essay one considers the fact that disclosing firms' compliance records to the general public may be sufficient to nudge firms in a "socially-responsible" direction. The environmental compliance expectations of important stakeholders may influence the firms environmental practices by changing their long-run profits prospects. Government involvement can support and induce such motives with information disclosure policies and by supporting environmentally friendly behavior through public recognition. Chief among stakeholders are consumers of the firm's output, although there may be many other concerned parties as well such as neighboring communities, investors, lending institutions, and even input suppliers.

The role of information is extremely important. In metal markets, the subject of essays two and three, information is disseminated within individual markets and among related markets by prices. In essay one the information on environmental behavior that must pass from the firm to stakeholders is not necessarily conveyed by market forces. This implies an active role for government or other intermediary agency to provide information to potential participants.

Finally, while many studies assume that actors and markets react immediately to external stimuli, these three essays explicitly consider the fact that actors do not take immediate action nor does action lead to instant reaction. Time is an important element and gives a more realistic view of markets, allowing for continuity and the linking of one time period to the next. Essay one considers the firm's dynamic path over time when the firm incorporates its environmental reputation into its profit maximization calculus. It becomes clear that the firm's past and present reputation on environmental issues affects its future profitability. The effects of time are also present in essays two and three. Action does not lead to instant reactions due to perception lags, production lags and to disequilibria. Lags that arise from in learning, production constraints, and expectation adjustments for example, mean that disequilibrium, rather than equilibrium, is the 
normal state of the market at any one time. Knowledge of this lag structure provides information on the incentives present in the secondary markets. The findings discussed in essays two and three indicate that influences between primary and secondary markets actually come through disequilibrium conditions and time lags. 


\section{References}

Field III, F., J. Ehrenfeld, D. Roos, and J. Clark. 1994. Automobile Recycling Policy: Findings and Recommendations, <http://msl1.mit.edu/TPP12399/field-1.pdf > (6 April 2006).

Porter, M. E. 1991. America’s Green Strategy. Scientific America 264:168.

Porter, M.E. and C. van der Linde. 1995. Toward a New Conception of the Environment Competitiveness Relationship. Journal of Economic Perspectives 9(4):97-118. 


\title{
CHAPTER 2: ESSAY 1 \\ An Environmentally Conscious Firm: Dynamic Behavior and Policy Considerations
}

\begin{abstract}
Voluntary programs and public disclosure policies rely on voluntary environmental behavior. This paper analyzes a firm's voluntary environmental practices undertaken in reaction to market signals; it provides a theoretical analysis of a firm which operates in the presence of consumers and other stakeholders who value environmental actions and respond to the firm's environmental history. Environmental reputation links past business behavior to future market reactions and creates business incentives for environmental involvement. The firm's voluntary environmental practices are examined in a dynamic optimization framework and implications for policy involvement are considered. The analysis shows that the firm's environmental actions decrease over time until a steady state is reached where pollution is controlled above the level expected by consumers and other stakeholders in order to compensate for depreciation. Public exposure is found to increase long run profits whereas periodic evaluations and periodic disclosure of environmental performance reduces them. The paper also shows that regulation and information based policies are complementary as regulation increases long run environmental pollution control and public exposure leads to higher investment in reputation by overcompliance.
\end{abstract}




\section{Introduction}

In the last few decades, environmental policy makers have become increasingly interested in the use of economic incentives to stimulate improvements in environmental quality. Concurrently there has been a growing awareness of the importance of voluntary environmental actions. This trend has found supporters within government and industry and among consumers. In the United States this movement has developed primarily in the form of public programs and unilateral agreements which rely on individual business efforts and contracts with public agencies or independent associations. In 1999 there were 54 voluntary programs at the federal level (National Center of Environmental Economics [NCEE], 2001), and the United States Environmental Protection Agency projected that by the year 2000 more than thirteen thousand firms and organizations would participate in EPA voluntary initiatives (Mazurek, 1999). In addition to this, two thousand companies participated in unilateral initiatives of industry associations during 1999 (Mazurek, 1999).

This new perspective focuses on incentives that stimulate firm-initiated environmental behavior. In response to this, the current essay analyzes a firm's voluntary environmental practices undertaken in reaction to market signals. The motivation for the firm's environmental behavior is assumed to be its ability to influence its profits through its own environmental actions (Labatt, 1997; Labatt and Maclaren, 1998). The link between environmental behavior and profitability is environmental reputation (Cavaliere, 2000). The firm's environmental actions affect its environmental reputation; its reputation influences its profits.

Wells (2000) and Reed (2001) indicated that participants in voluntary programs proclaimed reputation value as one of the chief benefits of participation. Specifically Wells (2000) indicated that companies perceive their participation in voluntary environmental 
programs and public environmental recognition as a way to enhance their corporate reputation, which has a real but intangible value. Public perception, which is very closely linked to reputation, has also been found to motivate participation at voluntary programs (Khanna and Damon, 1999; Videras and Alberini, 2000; Arora and Cason, 1995, 1996).

The financial effect of the intangible value of a firm's environmental reputation has been examined by linking environmental behavior to a firm's market value. Konar and Cohen (2001) and King and Lenox (2001) found that firms with better environmental records have higher market value based on their Tobin's $q$ score. ${ }^{1}$ Dowell et al. (2000) showed that multinationals that follow tighter environmental standards than the national ones have higher Tobin's $q$. Khanna and Damon (1999) examined how investors value participation in the $33 / 50$ voluntary program. They found that participation decreased the average return to investment by 1.2 percent but increased the average excess value of unit sales by 2.2 percent, indicating that the increased expenditures from participation lead to short-term losses but increase the investors' expectations for long term profitability. ${ }^{2}$ Nadeau et al. (2004) showed that participation in the Energy Star buildings voluntary program resulted in a return of $\$ 16,026$ per million dollars in assets owned (3.66 percent of the market value of the average participating company) while non-participation lead to the loss of 10 percent of the asset value of a non-participating company.

Including the element of reputation allows the utilization of a dynamic optimization framework as environmental reputation links current actions to future market reactions. In this way the paper discusses self-initiated environmental behavior in a dynamic structure whereas past literature has dealt with self-initiated behavior of the firm in either a static or a repeated

\footnotetext{
${ }^{1}$ King and Lenox (2001) measured the environmental performance of each firm relative to the performance of other firms in its industry.

${ }^{2}$ The average return to investment is a measure of the current financial performance, whereas the average excess value of unit sales is a measure of future prospects for a firm.
} 
finite game framework. Moreover the paper analyses environmental self-compliance and overcompliance of a firm which operates in a monopolistically competitive market. This is the market setting for most goods and allows for analysis under a more comprehensive form of market power than does the analysis under monopoly used by Cavaliere (2000) and that of oligopoly used by Arora and Gangopadhyay (1995).

The paper sets up a theoretical framework, explores pollution control as a firm's dynamic path decision, and discusses the implications of firm-initiated environmental behavior. Moreover, it examines policy implications and incentives for policy involvement which exist when environmental image influences business decisions. Past research on these issues has largely taken the form of empirical analysis. This study contributes to the literature by expanding the theoretical examination of voluntary environmental behavior. It is also able to reveal possibilities for the role of information provision as an environmental policy, a somewhat controversial issue.

\section{Background}

There has been a growing movement on the part of companies to voluntarily undertake environmentally-friendly actions. Some of these self-initiated efforts have taken the form of over-complying with regulations (McClelland and Horowitz, 1999), adopting Environmental Management Systems (EMS) (Khanna and Anton, 2001), or taking part in voluntary pollution reduction programs such as the Green Light program, the Energy Star Program, the Indoor Air Program, the Performance Track Programs, or the $33 / 50$ program (NCEE, 2001).

Various incentives for self-regulation and environmental over-compliance have been analyzed in the literature. A decision for environmental self-regulation can be based on efforts to avoid liability costs or stricter regulation in the future (Schmidheiny, 1992; Maxwell et al., 
1998). Environmental over-compliance has also been examined as a tool utilized by firms to maintain industry leadership or even to prompt the government to tighten environmental standards and thus raise rivals' production costs (Salop and Scheffman, 1983; Barrett, 1991; Innest and Bial, 2002). McClelland and Horowitz (1999) and Bandyopadhyay and Horowitz (2001) offer the additional possibility that plants over-comply to compensate for uncertainties in production technologies and emission randomness.

This paper addresses only overcompliance which may be related to the effects of environmental reputation on revenues and costs. Labatt and Maclaren (1998) suggest that public concerns and stakeholder pressures are significant voluntary environmental action motivators. They also note the importance of financial considerations, both in the form of costs and revenues. The effects of reputation on revenues are associated to consumer reactions. The ability of firms to extract higher product prices as an incentive for self-initiated environmental behavior has been modeled by Arora and Gangopadhyay (1995). The authors examined the issue in an oligopoly framework where firms' actions are strongly interdependent and found that in the absence of regulation, the market becomes segregated into high-income consumers buying environmentally friendly goods and low-income consumers buying goods with no positive environmental attributes. Cavaliere (2000) indicated that higher reputation means higher consumer demand.

Consumer concerns and their reactions to product and firm attributes are a major factor in influencing firms' actions. Consumer pressures were found to be a significant motivator for the adoption of an environmental plan (Henriques and Sadorsky, 1996). Firms producing final goods, in close contact with consumers, with higher advertising expenditures, and with more visible pollution were found to be more likely to participate in voluntary environmental 
programs (Khanna and Damon, 1999; Arora and Cason, 1996; Videras and Alberini, 2000; Karamanos, 2000).

Environmental reputation can also influence the costs that firms face. Higher environmental reputation can help in recruiting high quality employees (Reinhardt, 1999; Carraro and Lévêque, 1999), discourage stakeholder activism (Reinhardt, 1999), and make it easier to raise money through financial markets (Carraro and Lévêque, 1999). Investors have been found to react negatively to public disclosures about poor environmental performance as reported in the TRI (Hamilton, 1995; Khanna et al., 1998), and bankers are beginning to include environmental considerations in their lending decisions, viewing poor environmental performers as financially risky (Hoffman, 1997). In addition, supply chain partners may pay a premium to suppliers with high environmental performance (King and Lenox, 2004). The reason for this is that environmental problems at the supplier level can impose costs on buyers such as supply disruptions, spill-over reputation damages (Reinhardt, 1999), and shared liability for environmental problems caused by the supplier (Snir, 2001). King and Lenox (2004) showed that reducing information asymmetries with supply chain partners is an important motivator for businesses and organizations to gain ISO 14001 certification.

The fact that firms undertake voluntary environmental actions to increase their reputation is reflected in their efforts to obtain external certification of being environmentally-friendly such as eco-labels or ISO 1400/EMAS certification for the use of an Environmental Management System. These actions are targeted towards providing consumers with signals that affect purchasing decisions and towards other stakeholders who can influence the firm's costs or business opportunities. Consumer and other stakeholder reactions to a firm's environmental 
behavior based on the information they have in relation to its environmental actions creates opportunities for using information disclosure as a policy tool.

An increasing number of public disclosure programs have already been put into effect. These programs reveal firms' environmental performance. Examples are the TRI (Toxic Release Inventory) in the United States, the EcoWatch in the Philippines, British Columbia's List of Polluters published by the Ontario Ministry of the Environment in Canada, and the PROPER color-rating program in Indonesia. In addition, voluntary environmental programs supported by government such as those mentioned in the preceding paragraph provide a new way of promoting environmental responsibility by offering public recognition and awards to firms with environmentally-friendly practices. As is suggested throughout this paper, information disclosure about environmental performance makes it possible for firms to compete in the environmental arena for price premiums or market shares.

The role of information and public exposure in inducing environmental behavior is of special interest in this paper. Empirical evidence linking business-led environmental protection behavior to public exposure and consumer reactions is found in various sources. Arora and Cason $(1995,1996)$ argued that public awareness is crucial in inducing firms to participate in the EPA 33/50 program, a voluntary program for firms to reduce their toxic releases. Dasgupta et al. (1998) found that environmental exposure results in market retribution, and Konar and Cohen (1997) found that stock price declines from negative information exposure led subsequently to higher emission reductions. Khanna et al. (1998) showed that abnormal returns caused by public disclosure of harmful environmental behavior lead to higher pollution reductions on site. The World Bank's study of Indonesia's Proper environmental color rating program suggested that the program led to substantial improvements in environmental behavior (Afsah et al., 1996). 
On the other hand, there have been arguments in the literature which refute the effectiveness of information policies. King and Lenox (2000) found the effects of information disclosure on environmental improvements to be insignificant. Harrison and Antweiter (2003) argued that the results of information disclosure policies would not have been important if influences from traditional policies and independent time trends were not acting at the same time. Foulon et al. (2003), however, took traditional regulation effects into account and still found that, in a regulatory environment where both traditional monitoring/enforcement practices and public disclosure programs are in use, public disclosure creates additional strong incentives for pollution control.

\section{Methodology}

Information disclosure of a firm's environmental performance can influence the behavior of the firm because it affects its reputation. Cavaliere ${ }^{3}$ (2000) was the first to model reputation as a factor leading to environmental behavior and voluntary environmental agreements. Environmental reputation links present environmental actions of firms to future consumer and stakeholder reactions. Thus reputation allows the examination of firms' decisions over time.

The firm's goal is assumed to be long run profit maximization. To take into account that consumers distinguish products and firms based on the quality of the firm's environmental behavior, a monopolistic competition framework is assumed. This is a typical market for environmentally friendly products, and it also allows for the investigation of behavior over time without the use of game theory. Dynamic optimization of the firm's profits provides long-run insights as environmental reputation becomes a motivator for continuous environmental consideration.

\footnotetext{
${ }^{3}$ The analysis was based on a two-stage game between the firm and consumers for the case of monopoly. The firm's environmental strategy was chosen in relation to the profits it would produce.
} 
The analysis unfolds as follows. Self-regulation possibilities and the role of information in leading firms to take responsibility for their environmental actions are captured by a dynamic profit optimization model where voluntary environmental actions are undertaken in an effort to influence environmental reputation. The model is solved in search of the optimal paths of a firm's environmental actions. Both mathematical and graphical approaches are used. Convergence to a steady state is analyzed through a phase diagram to provide qualitative information about the firm's behavior over time. The impact of the model's variables on the long run behavior of the firm are analyzed using comparative dynamics and steady state comparative statics. Special attention is given to variables that can be affected by policy. From the solution of the model and the steady state analysis, policy inferences related to this new method of public exposure are discussed.

\section{III. a. Theoretical Model}

The firm is modeled as a profit maximizer taking into account that revenues and costs are affected by environmental reputation; environmental reputation is determined by the firm's environmentally favorable or unfavorable behavior. In a static market this is expressed as:

$$
\operatorname{Max}\{\operatorname{Revenue}(G)-\operatorname{Cost}(G)-s * i\} \text {, s.t. } G=f(i)
$$

where $G$ is environmental reputation, $i$ denotes the firm's environmental practices, and $s$ is the cost of the environmental practices. The effect of reputation on revenues and costs adheres to the law of diminishing returns ${ }^{4}$.

Under this formulation the effect of reputation on revenues and costs differs since different actors with different motives influence the firm's revenues and costs. Reputation influences revenues by changing consumer demand - either shifting the demand function or changing its shape (Sethi and Thompson, 1981). A better environmental reputation increases

\footnotetext{
${ }^{4}$ The revenue and cost functions are assumed to be strictly concave and convex respectively.
} 
demand as willingness to pay increases. Since environmental behavior affects revenues, elements of differentiation are present in the market and the demand curve that the firm faces is downward-sloping; i.e. the firm operates in a monopolistically competitive market. Reputation may also influence the firm's costs. Higher environmental reputation increases the firm's financial, supplier, and business opportunities and reduces costs that arise from community and environmental group pressures.

The problem addressed is inherently dynamic in that environmental market response and reputation depend on the firm's past behavior. Consumers and stakeholders are assumed to expect a certain behavior - amount of pollution control - from the firm and to have access to information about the firm's environmental performance. When the firm takes more actions than expected, its environmental reputation increases.

Expectations are assumed to correspond to the pollution control exerted by the average firm in the market. Khanna et al. (1998) and Lanoie et al. (1997) indicate that repeated provision of information allows investors to track the environmental performance of firms relative to that of other firms as well as to its own past performance. Their studies suggest that benchmarking creates clear signals of environmental performance and stronger investor reactions. Without a benchmark polluters do not receive statistically significant losses; a benchmark establishing lower environmental performance than other firms leads to significant negative returns (Khanna, 2001).

It is important to note that expectations may correspond to the pollution control required by regulation, but they could also be higher or lower. In cases where environmental groups target some firms, usually large and well-known corporations, expectations for their environmental behavior may be higher than that of the average firm in the market. Whatever the case, 
expectations can be expressed as a function of environmental regulation in the industry. Pollution control above the expected level provides the firm with positive reputation whereas pollution control lower than the expected level punishes firms with negative reputation.

The fact that reputation changes over time is expressed through the following equation of motion ${ }^{5}$ :

$$
\dot{G}=\partial G / \partial t=\varepsilon g(i, f(w))-a G
$$

Reputation, $G$, changes as a function of the firm's pollution abatement, $i$, relative to the pollution abatement expected, $f(w)$, and is proportional to the degree of public exposure, $\varepsilon$, present in the market. Expectations about pollution control are expressed as a function of the environmental regulation in the industry $(w)$. The degree of public exposure is assumed to be under the control of the regulatory agency. By promoting information based policies information disclosure and voluntary programs that provide signals of positive environmental performance for participating firms - the regulatory agency can increase the degree of public exposure. Reputation is also subject to oblivion ${ }^{6}-$ depreciation $^{7}$ that occurs over time. Consumer forgetfulness can be used as a policy instrument as well. For example environmental labels, certifications, and awards create a more lasting effect on memory whereas periodic evaluations reduce consumers' past memory. It should be noted that the equation of motion is concave in relation to pollution abatement and prevention actions. In most situations, strict concavity occurs, meaning that increased environmental actions increase reputation but at decreasing rates. Strict concavity is assumed in the analysis that follows.

\footnotetext{
${ }^{5}$ The environmental reputation has the same type of equation of motion as that found in the advertising literature. ${ }^{6}$ Oblivion refers to the act of forgetting.

${ }^{7}$ Reputation is subject to depreciation (Dehez and Jacquemin, 1975; Jacquemin, 1973) due the passage of time and forgetfulness.
} 
What is of interest is that the firm has control over its own reputation through its decisions on expenditures for pollution control. By failing to take into account that consumers and other stakeholders have concerns about the environment and/or have expectations about the firm's environmental actions, the firm may find its revenues falling and will, on its own, initiate actions to improve its environmental image. To the extent that the firm's environmental actions affect its revenues and costs, the firm finds it in its self-interest to become conscious of its environmental behavior relative to what consumers and other stakeholders expect and thus selfregulates its pollution.

The analysis that follows assumes that the firm does not hold inventory and can supply exactly what is demanded in the market. The firm's profits are assumed dependent only on its environmental reputation, $G$; its behavior has already been maximized in relation to all other relevant variables.

The objective of the firm is to maximize its stream of discounted profits over time by controlling its reputation through expenditures on pollution control. The state variable is reputation, $G$, and the control variable for the firm is its pollution abatement, $i$. The time framework used is infinity. This comes from the fact that environmental reputation acts as goodwill which can be sold at any time the firm decides to terminate production. A profit maximizing firm decides upon its pollution control based on the effect of reputation on current profits as well as changes in its market value which captures the future profits that reputation brings.

The model is represented as:

$$
\begin{gathered}
\left.\operatorname{Max} \Pi(t)=\int_{0}^{\infty} e^{-\delta t}\{R(G))-C(G)-s * i\right\} d t ; G(0)=G_{o} \\
\text { s.t } \dot{G}=\partial G / \partial t=\varepsilon g(i, f(w))-a G ;
\end{gathered}
$$


where $\partial R / \partial G>0, \partial^{2} R / \partial G^{2}<0$,

$\partial C / \partial G<0, \partial^{2} C / \partial G^{2}>0$

$\partial g / \partial i>0, \quad \partial^{2} g /(\partial i)^{2}<0$.

$R$ is revenue, $C$ is cost of production, $G$ is the firm's environmental reputation, $s * i$ is the firm's expenditure for environmental practices ( $s$ is the cost of pollution abatement and $i$ the pollution it actually abates), $\varepsilon$ is the degree of public exposure, $\delta$ is the firm's discount rate or opportunity cost of time, $w$ is the level of pollution control imposed by regulation, and $a$ is the depreciation rate for reputation.

\section{Analysis}

\section{IV. a. Solution}

In solving this dynamic problem, the current value Hamiltonian becomes:

$H_{c}=R(G)-C(G)-s * i+v_{c}(\varepsilon g(i, f(w))-a G) ; G(0)=G_{o}$

The Hamiltonian is jointly concave in the control, $i$, and state, $G{ }^{8}$ Since these concavity conditions exist, the necessary conditions of the maximum principal (5.1)-(5.3) along with the transversality condition (5.4) are sufficient for an optimal solution to exist.

$i^{*}(t)$ maximizes $H_{c}\left(G(t), i(t), v_{c}\right)$, i.e

$\partial H_{c} / \partial i \leq 0 \Rightarrow-s+v_{c}(\mathrm{t}) \varepsilon \partial g(i(t), f(w)) / \partial i \leq 0$, with equality if $i^{*}(t)>0$

$\partial H_{c} / \partial v_{c}=\dot{G}(t) \Rightarrow \dot{G}(t)=\varepsilon g(i(t), f(w))-a G(t)$

$\partial H_{c} / \partial G=-\dot{v}_{c}(\mathrm{t})+\delta v_{c}(t) \Rightarrow$

$\Rightarrow \dot{v}_{c}(\mathrm{t})=-\left\{R^{\prime}(G(\mathrm{t}))-C^{\prime}(G(\mathrm{t}))\right\}+(\delta+a) v_{c}(\mathrm{t})$

$\lim _{t \rightarrow \infty} \nu_{c}(\mathrm{t}) G(\mathrm{t}) e^{-\delta t}=0$

where $\dot{v}_{c}=\partial v_{c}(\mathrm{t}) / \partial t$

The solution of the canonical equations (5.1)-(5.4) subject to $G(0)=G_{o}$ gives the optimal $i^{*}(t), G^{*}(t)$, and $v c^{*}(t)$ paths. Several behavioral implications can be noted from these conditions.

\footnotetext{
${ }^{8}$ The analysis is conducted under the assumption of strict concavity. The case of a linear relationship between $i$ and $\dot{G}$, will lead to a Most Rapid Approach Path (MRAP) and will be discussed as an extension.
} 
The costate, $v_{c}(t)$, is positive as indicated by condition (5.1) for any interior solution and has a natural interpretation as the shadow value of the firm's environmental reputation. It measures the additional benefit to the firm from increasing the stock of reputation by a small amount.

Condition (5.1), which ensures that the marginal cost of pollution control at every point in time is equal to the marginal benefit that it brings over the remainder of time, is also referred to as the short-term equilibrium condition. Solving it for an interior solution gives the short run supply function of environmental practices.

$$
\begin{aligned}
& i^{*}(t)=i\left(v_{c}(t) ; \varepsilon, w, s\right) ; \\
& \partial i / \partial v_{c}=-\frac{g^{\prime}(i(t))}{v_{c}(t) g^{\prime \prime}(i(t))}>0, \text { such that } i^{*}(t)>0 \\
& \partial i / \partial s=-\frac{-1}{v_{c}(t) \varepsilon g^{\prime \prime}(i(t))}<0, \text { such that } i^{*}(t)>0 \\
& \partial i / \partial w=-\frac{g_{\text {iw }}(i(t), w)}{g^{\prime \prime}(i(t))}>0 \\
& \partial i / \partial \varepsilon=-\frac{g^{\prime}(i(t))}{\varepsilon g^{\prime \prime}(i(t))}>0
\end{aligned}
$$

This function shows the optimal pollution abatement, or prevention, of an environmentally conscious firm at every point in time. An increase in the shadow value of reputation, an increase in regulation, and an increase in public exposure severity all increase environmentally favorable behavior while increases in the cost of pollution abatement and prevention reduce environmental actions.

To expand on the relationship between environmental behavior and the shadow value of reputation, take the time derivative of condition (5.1) and find that pollution abatement and prevention decrease at the rate of change of the shadow value of reputation multiplied by the weighted effect of the environmental actions on the firm's reputation. 


$$
-\dot{v}_{c} \mathcal{E} g_{i}-v_{c} \mathcal{E} g_{i i i} \dot{i}=0 \Rightarrow \dot{i}=-\frac{g_{i}}{g_{i i}} \frac{\dot{v}_{c}}{v_{c}}
$$

Condition (5.2) repeats the equation of motion that must hold at every point in time for the system to find its optimal solution.

Condition (5.3) states that the marginal opportunity cost, $(\delta+a) v_{c}(\mathrm{t})$, of investing in goodwill should be equal to the marginal profit, $R^{\prime}\left(G^{*}(\mathrm{t})\right)-C^{\prime}\left(G^{*}(\mathrm{t})\right)$, from increasing goodwill and the capital goodwill gain, $\dot{v}_{c}(\mathrm{t})$. Rearranging equation (5.3) into equation (8), it is easily seen that oblivion - depreciation $(a)$ - and the discount rate $(\delta)$ have a negative impact on the shadow value of reputation. Given equation (6), the effect of forgetfulness and of the discount rate on environmentally favorable behavior $(i)$ is also negative; an increase in $a$ or $\delta$ will reduce pollution abatement and prevention, $i$. Equation (8) also shows that the greater the effect of reputation on profits, the higher the shadow value of reputation and given equation $(6)$, the greater the investment in reputation through environmentally positive actions.

$$
\nu_{c}(\mathrm{t})=\frac{\left\{R^{\prime}\left(G^{*}(\mathrm{t})\right)-C^{\prime}\left(G^{*}(\mathrm{t})\right)\right\}+\dot{v}_{c}(\mathrm{t})}{\delta+a}
$$

\section{IV. b. Steady State and Phase Diagram Analysis}

The path of $G^{*}(t)$ and $v_{c}(t)$ and, implicitly, $i^{*}(t)$, to a steady state may be further analyzed with the help of a phase diagram which can answer qualitative questions such as those concerning the location and dynamic stability of the intertemporal equilibrium and the dynamic movement of the system from any conceivable initial point. In order to proceed, the modified Hamiltonian dynamic system (MHDS) is constructed by substituting the short run supply functions of environmental practices from equation (6) into equations (5.2) and (5.3). This 
dynamic system is expressed in terms of the stock of reputation and its corresponding shadow value ${ }^{9}$.

$$
\begin{aligned}
& \dot{G}(t)=\varepsilon g\left(i^{*}\left(v_{c}(t)\right), f(w)\right)-a G(t) \\
& \dot{v}_{c}(\mathrm{t})=-\left\{R^{\prime}\left(G^{*}(\mathrm{t})\right)-C^{\prime}\left(G^{*}(\mathrm{t})\right)\right\}+(\delta+a) \nu_{c}(\mathrm{t})
\end{aligned}
$$

The solution to the above system, with boundary conditions delimited by $\mathrm{G}(0)=G_{o}$, and the transversality condition $(5.4)$, determines the optimal path for reputation $G^{*}(t)=S_{S}(t ; \ldots)$ and its corresponding shadow value $v_{c}(t)=v_{c s}(t ; \ldots)$ as functions of the model's parameters. Given the path for the shadow value of reputation, the optimal path for environmental practices $i_{s}^{*}(t)=$ $i_{s}^{*}\left(v_{c s}(t ; \ldots)\right.$ is determined.

In the infinite horizon case, interest is focused on the existence of a steady state where the firm finds itself in a position of equilibrium. Its behavior has been optimized and it has no reason to change its actions. The path of the implicit solutions of $i(t), G(t)$, and $v_{c}(t)$ to a steady state may then be analyzed. The long-run equilibrium or steady state for reputation and its corresponding shadow value are defined as the values $\left(G_{\infty}^{*}, v_{c}{ }_{\infty}^{*}\right)$ for which both $G$ and $v_{c}$ are stationary $\left(\dot{G}=\dot{v}_{c}=0\right)$. To characterize the equilibrium, consider the phase diagram presented in figure 1 . The isocines $l_{l}$ and $l_{2}$ for the MHDS are the loci in the space $\left(G, v_{c}\right)$ for which $G$ and $v_{c}$ do not change, $\dot{G}=\dot{v}_{c}=0$.

$$
\begin{aligned}
& l_{1}\left(G, \nu_{c}\right)=\varepsilon g\left(i^{*}\left(\nu_{c}(t)\right), f(w)\right)-a G(t)=0 \\
& l_{2}\left(G, \nu_{c}\right)=-\left\{R^{\prime}\left(G^{*}(\mathrm{t})\right)-C^{\prime}\left(G^{*}(\mathrm{t})\right)-a \nu_{c}(\mathrm{t})\right\}+\delta \nu_{c}(\mathrm{t})=0
\end{aligned}
$$

\footnotetext{
${ }^{9}$ If we replace equation 7 in equations 2 and 3, we would obtain the MHDS representing the dynamic system of the stock of reputation and of the firm's environmental practices.
} 
From $l_{l}, \frac{d \nu_{c}}{d G}=\frac{g^{\prime}(i) \partial i / \partial \nu_{c}}{-a}<0$ and from $l_{2}, \frac{d \nu_{c}}{d G}=\frac{\delta}{-H^{\prime \prime}(G)}>0$. By the monotonicity of the loci, the long-run equilibrium $S\left(G_{\infty}^{*}, v_{c}{ }^{*}\right)$, which corresponds to the solution of equations (11) and (12), is unique.

At the steady state point $\dot{G}=0$ and $\varepsilon g(i, f(w))=a G$. Since the parameters of the model are constant at the steady state, the firm controls pollution just enough over the level that is found appropriate by consumers and other stakeholders to compensate for reputation loss that comes from memory obsolescence. It is important to note that the consumers' and stakeholders' expectation may not necessarily be equal to the actual level of regulation.

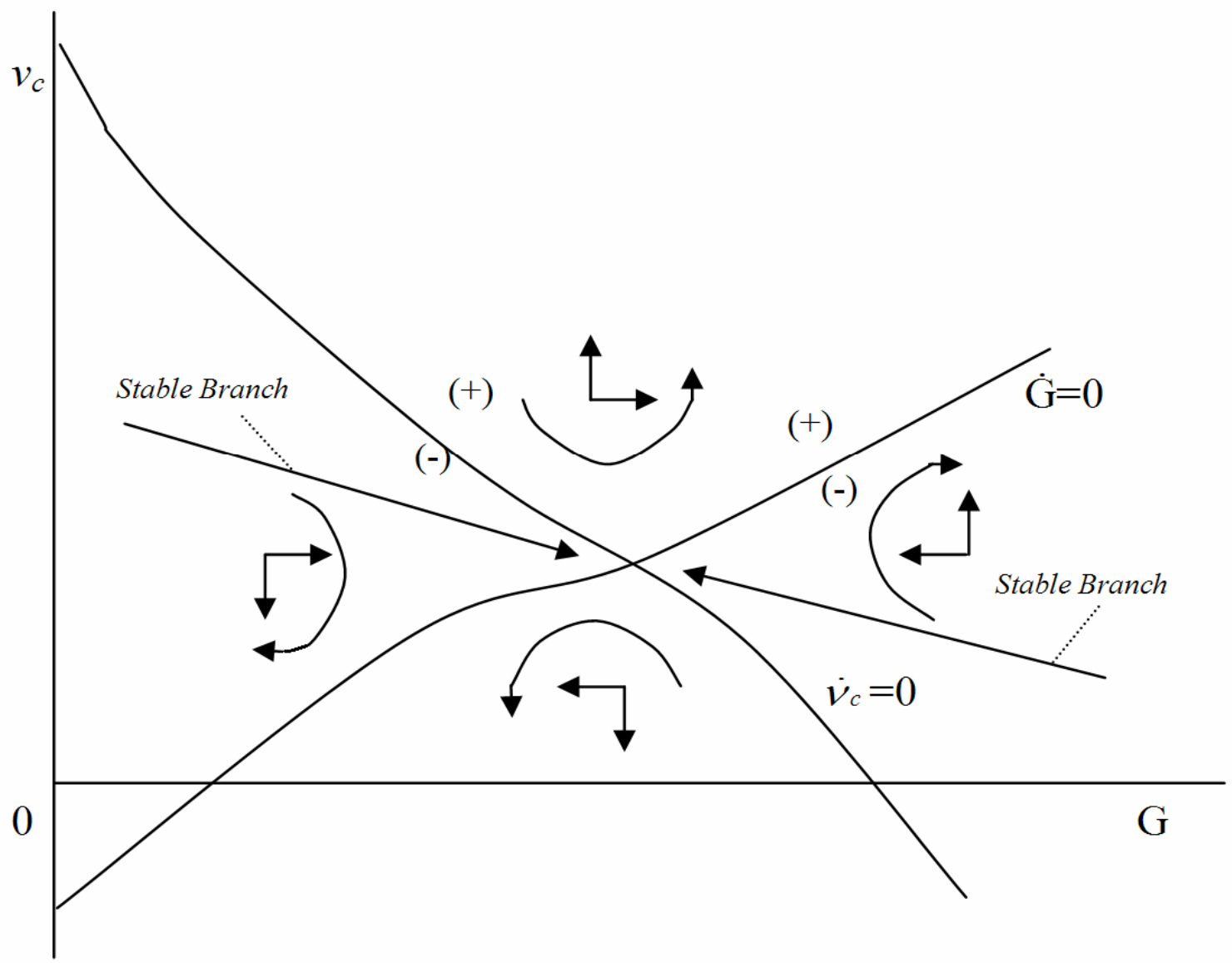

Figure 1. Phase Diagram for an Environmentally Conscious Firm 
To test the stability of the steady state, consider the movement around the steady state point (local stability). The direction of movement is given by partially differentiating the two differential equations in the MHDS. $\partial \dot{G} / \partial v_{c}$ shows the change in $\dot{G}$ when $v_{c}$ changes. $\partial \dot{G} / \partial v_{c}>0$, so as $v_{c}$ increases $\dot{G}$ follows the sign sequence of $(-, 0,+)$. The change in $v_{c}$ as $G$ changes is given by $\partial \dot{\boldsymbol{V}}_{c}(\mathrm{t}) / \partial G$. Note that $\partial \dot{\boldsymbol{v}}_{c}(\mathrm{t}) / \partial G>0$, so as $G$ changes, $v_{c}$ follows the sequence $(-, 0,+)$. These streamlines make the steady state a saddle point.

Long run stability will occur as long as the firm finds itself on the stable branches of the system. For any given initial reputation, the firm must choose an initial shadow value for its environmental reputation such that the ordered pair of initial environmental reputation and shadow value of environmental reputation $\left(G_{o}, v_{c o}\right)$ lies on a stable branch. Otherwise, the model's dynamic forces lead to ever increasing reputation and shadow value (northeast) or to ever decreasing reputation and corresponding lower shadow value (southwest). For the objectives of environmental policy, the former would be desirable and the latter undesirable; however, neither would be sustainable strategies for the firm. Initial reputation $G(0)$ is usually independent of the firm's choices or of any substantial policy the government can utilize. Interesting situations occur when something unexpected happens, for example, if an accident with environmental consequences occurs or a trademark with a specific reputation is bought.

Provided the dynamic movement of the system described by the above phase diagram, condition (5.3) ensures that the shadow value of reputation declines over time for convergence to a steady state to be achieved ${ }^{10}$ (Figure 2). At every passing point of time it declines by the amount of benefit that reputation could have offered if it were already obtained. So the shadow price of reputation declines over time by the effect of reputation on profit that is missed from one

\footnotetext{
${ }^{10}$ The case of initial reputation $\mathrm{G}_{\mathrm{o}}$ being so high that the shadow value of reputation increases while reputation decreases for convergence to a steady state is not discussed because it is uncommon.
} 
instant to the next. Since the shadow value of reputation is highest in initial periods and declines over time, the positive relationship that ties pollution abatement and prevention to the shadow value of repuation means that the same pattern is observed in pollution abatement and pollution prevention. Investment in environmental reputation through environmental practices will be higher in early periods, in order to capture the benefits of the environmentally positive image in future periods.

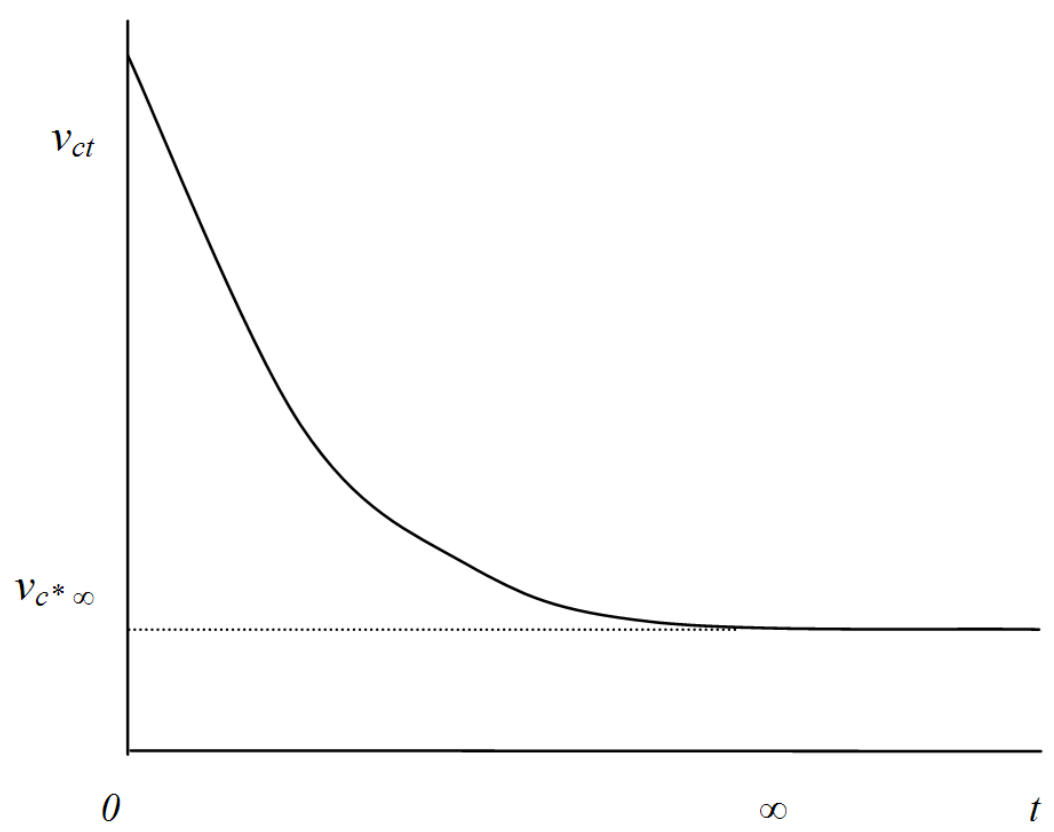

Figure 2. Shadow Value of Environmental Reputation: Convergence to a Steady State.

The model leads to a saddle point equilibrium because an optimization rule needs to be followed. The saddle point equilibrium is attainable but only when the firm places itself on a stable branch by following the profit optimization rules for the long run. The stability properties of the system can be extended to include the concept of the global asymptotic stability that characterizes convergence to equilibrium from any initial state of the system (Brock and Scheinkman, 1976) and ensures that the firm will place itself on a stable branch of the system. 
The long run solution $\left(G_{\infty}^{*}, v_{c}{ }^{*}\right)$ of the MHDS on the stable branch manifold is bounded for $\mathrm{t} \epsilon[0, \infty)$, and the curvature matrix $\mathrm{C}$ is positive definite for a sufficiently small $\delta$.

$$
C=\left[\begin{array}{cc}
-H_{G G} & \frac{\delta}{2} \\
\frac{\delta}{2} & H v_{c} v_{c}
\end{array}\right]=\left[\begin{array}{cc}
-\left(R^{\prime \prime}(G)-C^{\prime \prime}(G)\right) & \frac{\delta}{2} \\
\frac{\delta}{2} & \varepsilon g^{\prime}(i) \frac{\partial i}{\partial v_{c}}
\end{array}\right]
$$

As a result, it follows from the theorem by Brock and Scheinkman (1976) that the equilibrium point $\left(G_{\infty}^{*}, v_{c}{ }^{*}\right)$ is asymptotically stable for all bounded solutions. Consequently, at any conservable initial $G_{o}$, an initial $v_{c o}$ in the steady branches of the system exists which leads the system to equilibrium ${ }^{11}$. The logic behind the model's long run equilibrium stability is that the firm does have control over its profits, and can, by optimizing its behavior, control its actions to the point where it reaches its optimum level of profit.

Public disclosure of environmental behavior can, in a theoretical framework, lead firms to control their pollution over time to reach a state where they control pollution at the level that is expected by consumers and other stakeholders provided that consumers and stakeholders care about the environment enough to have a substantial influence over the firm's profits and behavior. With perfect foresight and rational behavior, the firm will find itself under the conditions that lead to long run stability. When perfect knowledge is not available, a firm still has incentives to become conscious of its environmental behavior but a steady state may not occur. Some firms, influenced by the Porter hypothesis (Porter,1991; Porter and van der Linde, 1995), may expect benefits from stricter pollution control and increase their expenditures on pollution control and prevention, but unless these benefits are proven to be real, their efforts will not necessarily lead to a sustainable strategy of investment.

\footnotetext{
${ }^{11}$ This initial $v_{c}$ is determined by the system.
} 


\section{IV. c. Long run effects of the model's parameters}

The time paths for $i(t), G(t), v_{c}(t)$, and ultimately $\Pi(t)$, and the long run steady state equilibrium depend on the parameters of the problem. Changes in these parameters can have a significant effect on the behavior of the firm and are, therefore, of interest for policy. The effect of parameter changes on the steady state can be analyzed with the help of comparative static analysis, and the effects of parameter changes on the entire optimal path of the firm can be analyzed using comparative dynamics. Both comparative statics and comparative dynamics can provide us with insights which may be useful for policy choices.

\section{IV. c. 1. Comparative Statics}

The comparative static system at the steady state is obtained by totally differentiating the system (10) and (11) which produces the solution for the steady state. The determinant of the system's Jacobian is negative $(|J|<0)$.

$$
|J|=\left|\begin{array}{cc}
-a & \varepsilon g^{\prime}(i) \frac{\partial i}{\partial v_{c}} \\
-\left(R^{\prime \prime}(G)-C^{\prime \prime}(G)\right) & \delta+a
\end{array}\right|<0
$$

To solve for the change of the steady state solutions in relation to the parameters of interest, consider the subsequent comparative static systems.

Government can affect behavior through command and control regulations. For example, government can increase standards for emission control or impose some technological standard. The effect of environmental regulation on the steady state can be found from the following comparative static system:

$$
\mathrm{J}\left[\begin{array}{l}
\frac{\partial \mathrm{G}^{*}(\infty)}{\partial w} \\
\frac{\partial \mathrm{v}_{\mathrm{c}}{ }^{*}(\infty)}{\partial w}
\end{array}\right]=\left[\begin{array}{c}
-\frac{\varepsilon \partial g\left(i^{*}\left(v_{c}(t)\right), f(w)\right)}{\partial w} \\
0
\end{array}\right]
$$


By Cramer's rule $\partial \mathrm{G}(\infty) / \partial w<0$ and $\partial v_{c}(\infty) / \partial w>0$. This means that increases in regulation $(w)$ lead to lower environmental reputation $(\partial \mathrm{G}(\infty) / \partial w<0)$ but higher shadow value of reputation $\left(\partial v_{c}(\infty) / \partial w>0\right)$ and higher pollution control at the steady state.

To examine the effect that the degree of public exposure $(\varepsilon)$ has on the long run equilibrium point, the following comparative static system is used:

$$
\mathrm{J}\left[\begin{array}{c}
\frac{\partial \mathrm{G}^{*}(\infty)}{\partial \varepsilon} \\
\frac{\partial \mathrm{v}_{\mathrm{c}}^{*}(\infty)}{\partial \varepsilon}
\end{array}\right]=\left[\begin{array}{c}
-g\left(i^{*}\left(v_{c}(t)\right), f(w)\right) \\
0
\end{array}\right]
$$

Unless there is no memory loss $(\alpha=0)$, at the long run equilibrium the amount of pollution abated is greater than expected $(i>f(w))$; as a consequence $\partial G(\infty) / \partial \varepsilon>0$ and $\partial v_{c}(\infty) / \partial \varepsilon<0$. Policies that increase public exposure $(\varepsilon)$ lead to higher reputation accumulation over the long run $(\partial G(\infty) / \partial \varepsilon>0)$ through investment in pollution control beyond the amount expected, but to a lower shadow value of reputation at equilibrium $\left(\partial v_{c}(\infty) / \partial \varepsilon<0\right)$ and, subsequently, to lower pollution control and prevention at the steady state.

It is also interesting to examine the effect of reputation depreciation $(\alpha)$ on the long run solution using the following comparative static system:

$$
\mathrm{J}\left[\begin{array}{c}
\frac{\partial G^{*}(\infty)}{\partial a} \\
\frac{\partial v_{c}{ }^{*}(\infty)}{\partial a}
\end{array}\right]=\left[\begin{array}{c}
G(t) \\
-v_{c}(t)
\end{array}\right]
$$

By Cramer's rule $\partial G(\infty) / \partial \alpha<0$ since the shadow value of reputation evaluated at the steady state is positive $\left(v_{c}(\infty)>0\right)$, and $\partial v_{c}(\infty) / \partial \alpha>0$ as long as $a v_{c}<\left|\left(R^{\prime \prime}(G)-C^{\prime \prime}(G)\right) G\right|$. With more forgetful consumers, reputation accumulation over time is lower $(\partial G(\infty) / \partial \alpha<0)$, but the shadow value of reputation at the long run equilibrium is higher $\left(\partial v_{c}(\infty) / \partial \alpha>0\right)$ and in consequence pollution 
control at the long run equilibrium is higher since more environmental actions are needed to compensate for consumer forgetfulness, and vice versa. Consumer forgetfulness as a policy instrument is contingent on the presence of public disclosure but entails a different judgment process. It has separate effects on the firm's behavior and can be used to achieve different goals. Environmental certification creates a more lasting effect on memory whereas periodic evaluations that are publicly exposed can be used to reduce consumers' past memory. Nonetheless, both involve public exposure.

It is important to note that regulatory and informational policies can be used simultaneously in influencing firms to develop environmentally conscious behavior and increase their pollution control.

Finally, it is possible to examine the effect of the discount rate $(\delta)$.

$$
\mathrm{J}\left[\begin{array}{c}
\frac{\partial G^{*}(\infty)}{\partial \delta} \\
\frac{\partial v_{c}^{*}(\infty)}{\partial \delta}
\end{array}\right]=\left[\begin{array}{c}
0 \\
-v_{c}
\end{array}\right]
$$

Thus an increase in the discount rate means that at the steady state the firm has lower reputation accumulation $(\partial \mathrm{G}(\infty) / \partial \delta<0)$ and this reputation has a lower shadow value $\left(\partial v_{c}(\infty) / \partial \delta<0\right)$. Firms that are more interested in the future have larger reputation accumulation and a higher shadow value for it at the equilibrium, which means higher pollution control and prevention.

\section{IV.c. 2. Comparative Dynamics}

Comparative dynamics show how changes in the model's parameters affect the entire optimal profit path of the firm. Substituting the optimal path solutions for $G^{*}(t)=S_{s}(t ; \ldots)$, 
$v_{c}(t)=v_{c s}(t ; \ldots), i_{s}^{*}(t)=i_{s}{ }^{*}\left(v_{c s}(t ; \ldots)\right.$ into the optimal value function $\Pi(t)$ expresses this function in relation to the model's parameters.

$$
\Pi^{*}(w, a, \varepsilon, \delta)=\int_{0}^{\infty} e^{-\delta t}\left\{R\left(G_{\mathrm{s}}(t ; w, a, \mathcal{\varepsilon}, \delta)\right)-C\left(G_{\mathrm{s}}(t ; w, a, \mathcal{\varepsilon}, \delta)\right)-s i_{\mathrm{s}}^{*}\left(\mathrm{vcs}_{\mathrm{cs}}(\mathrm{t} ; w, a, \mathcal{\varepsilon}, \delta)\right\} d t\right.
$$

Changes in the optimal value function induced by changes to the model's parameters are obtained by using the dynamic envelope theorem and Leibniz' rule.

The effect of a change in regulation is negative.

$$
\frac{\partial \Pi^{*}(w, a, \varepsilon, \delta)}{\partial w}=\int_{0}^{\infty} \frac{\partial\left(e^{-\delta t} H^{*}\right)}{\partial w} d t=\int_{0}^{\infty} e^{-\delta t} \nu_{c s}{ }^{*} \frac{\varepsilon \partial g\left(i_{s}^{*}, f(w)\right)}{\partial w} d t<0
$$

An increase in regulation reduces profits by the present value of reputation lost due to the regulation increase.

The effect of a change in public exposure is positive.

$$
\frac{\partial \Pi^{*}(w, a, \varepsilon, \delta)}{\partial \varepsilon}=\int_{0}^{\infty} \frac{\partial\left(e^{-\delta t} H^{*}\right)}{\partial \varepsilon} d t=\int_{0}^{\infty} e^{-\delta t} v_{c s}^{*} g\left(i_{s}^{*}, f(w)\right) d t>0
$$

This means that environmentally conscious firms welcome more public exposure.

The effect of a change in oblivion is negative, as long as $\int_{0}^{\infty} G^{*}(t) d t>0$.

$$
\frac{\partial \Pi^{*}(w, a, \varepsilon, \delta)}{\partial a}=\int_{0}^{\infty} \frac{\partial\left(e^{-\delta t} H^{*}\right)}{\partial a} d t=\int_{0}^{\infty} e^{-\delta t}\left(-v_{c s}^{*} G^{*}(t)\right) d t<0
$$

A reduction in consumer forgetfulness increases profits by an amount equal to the present value of accumulated reputation. This is one of the reasons environmentally conscious firms usually opt for external certification. $\int_{0}^{\infty} G^{*}(t) d t<0$ may occur in cases where $G_{o}$ is extremely low, 
for example when a firm is responsible for an accident that caused high environmental damage. Under such a situation an increase in consumer forgetfulness increases profits.

The effect of a change in the discount rate is negative.

$$
\left.\frac{\partial \Pi^{*}(w, a, \varepsilon, \delta)}{\partial \delta}=\int_{0}^{\infty} \frac{\partial\left(e^{-\delta t} H^{*}\right)}{\partial \delta} d t=-\int_{0}^{\infty} t e^{-\delta t}\{R(.)-C(.))-s i_{s}^{*}\right\} d t .
$$

Since the solutions are bounded for $t \epsilon[0, \infty)$, the net profits $\left.\pi_{s}(t ; w, a, \varepsilon, \delta)=R()-.C().\right)-s i_{s}{ }^{*}$ are also bounded from above by $\bar{\pi}_{s}$.

$$
\frac{\partial \Pi^{*}(w, a, \mathcal{E}, \delta)}{\partial \delta}=-\int_{0}^{\infty} t e^{-\delta t} \pi_{\mathrm{s}} d t \leq-\bar{\pi}_{\mathrm{s}} \int_{0}^{\infty} t e^{-\delta t} d t=\frac{-\bar{\pi}_{\mathrm{s}}}{\delta^{2}}<0
$$

Thus, an increase in the discount rate reduces profits by an amount equal to the present value of profits weighted by the length of time they accrue. As a consequence, firms with long planning horizons as well as firms with low debt to equity ratio are more motivated to undertake voluntary environmental behavior. Trademark firms, firms traded on the stock market, or firms in sectors with high investment needs can be targeted by policymakers for participation in voluntary programs.

\section{IV. d. Most Rapid Approach Path}

The model has been solved under the assumption of strict concavity of the current value Hamiltonian in relation to the control variable - pollution control and prevention - to include the idea of diminishing returns of environmental actions to environmental reputation and profits. The choice of expressing this effect through a concave equation of motion is related to the intuition that environmental actions do not have the same direct and proportional effect on reputation that investment has on capital accumulation. 
The results of the analysis change substantially if the model becomes linear in the control variable of environmental actions under a linear representation of the equation of motion. In this case, the path of the firm becomes a Most Rapid Approach Path (MRAP) to the steady state or the predetermined stock of reputation where the firm invests in pollution control and prevention to the maximum allowable amount at every point in time until it reaches this steady state or a predetermined stock of reputation.

It is possible that a linear representation of the equation of motion would be a better fit under certain circumstances. A proportional effect of environmental actions on reputation may be expected in cases where a certain type of behavior is awarded some universally recognizable label or certification, like an ecolabel, ISO 1400, or Energy Star Program Participant. In these cases investment in environmental actions provide the firm with the desired external certification and reputation is rapid and comes as a lump sum. A most rapid approach path can also explain the behavior of firms that choose to gain from the environmental consciousness of consumers in markets segregated between an environmental and polluting market such as those described by Arora and Gangopadhyay (1995). In a segregated market, a firm can be known either as a polluting or an environmental firm; if it chooses to be an environmental firm it will want to place itself on this side of the market as fast as possible.

Although the above cases could explain an MRAP to a fixed-end point of reputation accumulation $G(T)$, it would be difficult for the effect of environmental actions to be assumed linear in the long run. Even after the firm has achieved a reputation level for joining a market or obtaining some environmental certification, it may still find it in its own self interest to continue 
the investment process even though the effect of its environmental actions on its reputation may have changed form ${ }^{12}$.

\section{Discussion and Policy Considerations}

This study has analyzed the behavior of an environmentally conscious firm, a firm that recognizes and acts upon the fact that its environmental actions have an effect on its profits. It does not constitute a study of overcompliance but rather a study of a firm's reactions to a market that punishes negative environmental behavior while rewarding positive environmental behavior.

The fundamental element of this structure is information availability, and its effect on reputation. The analysis is relevant to both voluntary policies and information disclosure policies since both provide information that can influence a firm's reputation. Voluntary programs and unilateral agreements motivate firms to voluntarily adopt a set of goals, meet specific standards for environmental performance, or adopt cleaner technologies and methods. They can provide participants with positive environmental publicity and reputation and, in the consumers' and other stakeholders' view, separate them from firms that have not shown a proactive attitude in relation to environmental performance. On the other hand, public disclosure policies provide information, positive or negative, about environmental performance of firms to the public and to all possible stakeholders.

Note that these two types of policies are complementary. According to Arora and Cason (1995: p. 274), "there is anecdotal evidence that publication of the TRI data in 1988 'shamed' several top polluting firms to voluntarily reduce toxic releases", and "the $33 / 50$ program was developed in part to take advantage of this voluntary sentiment." Since both these approaches provide information about the environmental performance of firms, both influence firms'

\footnotetext{
${ }^{12}$ And most probably has become concave.
} 
environmental reputation. Arora and Cason (1995: p. 274) also state that it is difficult to distinguish "whether the negative or positive publicity is more important for overcompliance"; but this does not change their main finding "that voluntary programs benefit from greater publicity".

The analysis shows that higher public exposure leads to higher present value of long run profits for an environmentally-conscious firm although it may have a negative effect on short run profits (if a firm's environmental performance is lower than that expected by consumers and other stakeholders). Therefore, disclosing the environmental performance of overcompliant firms can reduce political pressures opposing information disclosure policies. For example, the Proper Color Rating Disclosure Program in Indonesia encourages "good performers to identify themselves" by rewarding superior environmental with public recognition. In addition the program renders such firms with "competitive incentives to help regulators identify poor performers since the latter will be penalized by disclosure". These incentives reduce the "principal-agent problem" that has haunted traditional regulation (Afsah et al., 1996: p.11).

Although public exposure has a positive effect on firms' profits in the long run, oblivion has a negative effect. By encouraging high or low oblivion, policy can advance different objectives. High oblivion reduces short run pollution abatement but leads to higher pollution abatement at the steady state. Indonesia's Proper Color rating program, Canada's Non Compliance List, the United States' TRI, eco-labels under periodic evaluation, and EU's Ecomanagement and Audit Scheme (EMAS) are all examples of programs that allow stakeholders to update their information regularly. Low oblivion, on the other hand, increases short run pollution control, but in the long run, after the steady state is approached, it means lower pollution control. 
Examples of programs and initiatives that allow for a long-lasting effect of environmental reputation include: eco-labels that do not undergo periodic evaluation, the standardized EMS ISO 14000, the Energy Star Program, Responsible Care Initiative of the Chemicals Manufacturing Association, and environmental awards. It should be noted that with some permanent labels, like the Energy Star Label for energy efficient buildings, investment in environmental technology is necessary for certification. These types of programs are usually related to a proportional effect of environmental actions on reputation. Consequently, in programs promoting low oblivion a Most Rapid Approach Path can be expected which may be a policy objective on its own when there is an interest in inducing firms to undertake certain investments and management changes without delays.

It is evident from the analysis that even though influencing oblivion and providing public information are both information tools that complement each other in information based policies, they lead to different results and can be used to achieve different goals.

Finally, there have been discussions in the literature about the effectiveness of information policies in relation to traditional regulation policies. This study cannot provide direct input about their effectiveness. Nonetheless, it makes clear that reputation reactions are based on regulation since regulation influences the market expectations for the environmental performance and behavior of firms. It also suggests that the effects of information policies cannot easily be distinguished from the effects of regulation. Nonetheless, it shows that information does have a role to play as a policy instrument by creating additional pressure for environmental behavior. Even in Indonesia where regulation is not easily enforceable, regulation provides the basis for evaluating environmental performance under the Proper Color Rating Disclosure Program (Afsah et al., 1996). The analysis presented here demonstrates that higher regulation leads to 
higher pollution control both in the short run and at the steady state. Increases in public exposure also lead to higher pollution control and prevention in the short run. In addition, they lead to higher reputation at the steady state as public exposure creates incentives for investing in overcompliance. Therefore, the analysis shows that combining both approaches leads to superior policy choices and results since policy-makers should be interested in both higher investment in overcompliance and higher pollution control and prevention.

\section{Conclusion}

This study analyzes a firm's environmental practices as an internal, firm-initiated decision based upon market signals. This behavior is captured by a dynamic profit optimization model where voluntary environmental actions are undertaken in an effort to influence environmental reputation and profits. The link between environmental behavior and profitability is reputation that is influenced by the firm's environmental behavior and affects the firm's profits. In an era where environmental policy makers take an interest in voluntary environmental action when designing programs, it is necessary to understand the incentives for voluntary compliance and overcompliance, and the reactions that different policy tools may induce.

This model of an environmentally conscious firm was solved for the optimal paths of a firm's environmental actions to provide insights into the firm's behavior over time. The study of the impact of the model's variables on the firm's behavior and profits produced further insights into firms' motivations for voluntary environmental behavior and their reactions to environmental policy tools.

The reactions of consumers and other stakeholders to a firm's environmental behavior are based on their expectations and on information in relation to the firm's environmental actions; this creates opportunities for effective environmental policy. The marginal value of the firm's 
environmental reputation is always positive when the firm undertakes pollution abatement and prevention. The short run supply of environmental practices bears a positive relationship to the shadow value of reputation, to regulation, and to public exposure. The shadow value of reputation, and thus the firm's environmental actions, decrease over time and are positively related to the influence of reputation on profits, to stakeholders' memory, and to the importance that the firm exerts on future profits.

In the long run, a unique steady state is produced which is stable in the economic sense of equilibrium coming from an optimization process. Since the firm has control over its profits, assuming perfect foresight and rationality, it can reach equilibrium for any conceivable initial reputation it may hold. At the steady state the firm controls pollution above the level that is expected by stakeholders to compensate for memory oblivion. Pollution abatement at the steady state increases with regulation, consumer forgetfulness, and the importance that the firm places on future profits and decreases with public exposure. On the other hand, reputation increases with public exposure and the importance that the firm places on future profits and decreases with regulation and consumer forgetfulness.

Under the incentive of higher reputation leading firms to participate in voluntary programs and invest in overcompliance, it is necessary for policy-makers to balance their goals with the methods they use. When considering the attractiveness of voluntary policies for firms and on which firms to focus, policy-makers should keep in mind that in the long run higher stakeholder oblivion rates and higher regulation reduce overall firm profits, in contrast to public exposure and lower firm discount rates. Finally it is important to note that regulatory and informational policies can not only be used simultaneously to influence firms in developing 
environmentally conscious behavior but can also produce better short run and long run policy results when combined.

This study examines the behavior of an environmentally conscious firm and is able to extract some implications for environmental policies from this exercise. However, it does not deal with optimal levels of pollution control from a social perspective or with welfare implications. As a society, we may end up with too little or too much pollution control. The study is also limited in its findings to the extent that it takes into account only reputational considerations and ignores other motivations for voluntary pollution abatement and overcompliance which may have important implications.

Future research could explore the implications of voluntary environmental behavior when firms can choose between innovation and pollution control, especially since many of the voluntary programs that are in existence largely promote pollution reduction through pollution prevention and technological or managerial innovation. Firm level interactions, as well as interactions between firms and the industry, may also provide further insight into how stakeholder expectations change over time under a structure of reputation and information providing incentives for voluntary environmental behavior. 


\section{References}

Afsah, S., B. Laplante, and D. Wheeler. 1996. Controlling Industrial Pollution: A New Paradigm. Policy Research Working Paper 1672. Washington DC: Development Research Group, The World Bank.

Arora, S. and T. Cason. 1995. An Experiment in Voluntary Environmental Regulation: Participation in EPA's 33/50 Program. Journal of Environmental Economics and Management 28:271-286.

. 1996. Why Do Firms Volunteer to Exceed Environmental Regulations?

Understanding Participation in the EPA's 33/50 Program. Land Economics 72:413-432.

Arora, S. and S. Gangopadhyay. 1995. Towards a Theoretical Model of Voluntary Overcompliance. Journal of Economic Behavior and Organization 28:289-309.

Bandyopadhyay S. and J.K. Horowitz. 2001. Overcompliance with the Clean Water Act? Proceedings of the Workshop Beyond Compliance: What Motivates Environmental Behavior? The National Center for Environmental Economics and National Center for Environmental Research, U.S. Environmental Protection Agency, June 4, 2001, Washington DC.

Barrett. S. 1991. Environmental Regulation for Competitive Advantage. Business Strategy Review 2:1-15.

Brock, W.A. and J. Scheinkman. 1976. The Global Asymptotic Stability of Optimal Control Systems with Applications to the Theory of Economic Growth. Journal of Economic Growth Theory 12:164-190. 
Carraro, C. and F. Lévêque. 1999. Voluntary Approaches in Environmental Policy. Fondazione Eni Enrico Mattei Series on Economics, Energy, and the Environment. Dordrecht, The Netherlands: Kluwer Academic Publishers.

Cavaliere, R. 2000. Overcompliance and Voluntary Agreements. Environmental and Resource Economics 17(2):59-66.

Dasgupta, S., B. Laplante, and N. Mamingi. 1998. Capital Market Responses to Environmental Performance in Developing Countries. Policy Research Working Paper 1909. Washington DC: Development Research Group, The World Bank.

Dehez, P. and A. Jaquemine. 1975. Note on Advertising Policy Under Uncertainty and Dynamic Conditions. Journal of Industrial Economics 24(1):73-78.

Dowell, G., S. Hart, and B. Yeung. 2000. Do Corporate Global Environmental Standards Create or Destroy Market Value? Management Science 46(8):1059-1074.

Foulon, J., P. Lanoie, and B. Laplante. 2003. Incentives for Pollution Control: Regulation or Information? Journal of Environmental Economics and Management 44:169-187.

Hamilton, J.T. 1995. Pollution as News: Media and Stock Market Reactions to the Toxics Release Inventory Data. Journal of Environmental Economics and Management 28:98113.

Harrison, K. and W. Antweiter. 2003. Incentives for Pollution Abatement: Regulation, Regulatory Threats, and Non-Governmental Pressures. Journal of Policy Analysis and Management 22(3):361-382.

Henriques, I. and P. Sadorsky. 1996. The Determinants of an Environmentally Responsive Firm: An Empirical Approach. Journal of Environmental Economics and Management 30:381395. 
Hoffman, A.J. 1997. From Heresy to Dogma: An Institutional History of Corporate Environmentalism. San Francisco: The New Lexington Press.

Innest, R. and J.J. Bial. 2002. Inducing Innovation in the Environmental Technology of Oligopolistic Firms. The Journal of Industrial Economics 3:265-287.

Jacquemin, A.P. 1973. Optimal Control and Advertising Policy. Metro-economica 25(May):200209.

Karamanos, P. 2000. Voluntary Environmental Agreements for the Reduction of Greenhouse Gas Emissions: Incentives and Characteristics of Electricity Utility Participants in the Climate change Program. Working Paper. Durham, NC: Sanford Institute of Public Policy Duke University.

Khanna, M. 2001. Non-Mandatory Approaches to Environmental protection. Journal of Economic Surveys 15(3):291-324

Khanna, M. and W. Anton. 2001. Business-Led Environmental Management: Regulatory and Market-Based Incentives. Proceedings of the Workshop Beyond Compliance: What Motivates Environmental Behavior? The National Center for Environmental Economics and National Center for Environmental Research, U.S. Environmental Protection Agency, June 4, 2001, Washington DC.

Khanna, M. and L. Damon. 1999. EPA's Voluntary 33/50 Program: Impact on Toxic Releases and Economic Performance of Firms. Journal of Environmental Economics and Management 37(1):1-25.

Khanna, M., W.R.H. Quimio, and D. Bojilova. 1998. Toxics Release Information: a Policy Tool for Environmental Protection. Journal of Environmental Economics and Management 36(3):243-266. 
King, A A. and M.J. Lenox. 2004. The ISO 14001 Management Standard: Exploring the Drivers of Certification. Proceedings of the Workshop Corporate Environmental Behavior and the Effectiveness of Government Interventions. The National Center for Environmental Economics and National Center for Environmental Research, U.S. Environmental Protection Agency, April 26-27, 2004, Washington DC. . 2001. Does it Really Pay to Be Green? Journal of Industrial Ecology 5(1):105-116. . 2000. Industry Self-regulation without Sanctions: The Chemical Industry's Responsible Care Program. Academy of Management Journal 43(4):698-716.

Konar, S. and M.A. Cohen. 2001. Does the Market Value Environmental Performance? The Review of Economics and Statistics 83(2):281-289.

1997. Information as Regulation: The Effect of Community Right to Know Laws on Toxic Emissions. Journal of Environmental Economics and Management 32:109-124.

Labatt, S. 1997. External Influences on Environmental Decision Making: A Case Study of Packaging Waste Reduction. The Professional Geographer 49:105-116.

Labatt, S. and V.W. Maclaren. 1998. Voluntary Corporate Environmental Incentives: A Typology and Preliminary Investigation. Environment and Planning C: Government and Policy 16:195-202.

Lanoie, P., B. Laplante, and M. Roy. 1997. Can Capital Markets Create Incentives for Pollution Control? Policy Research Working Paper 1753. Washington DC: Environment, Infrastructure and Agriculture Division, The World Bank.

Mazurek, J. 1999. Voluntary Agreements in the United States. An Initial Survey. Concerned Action on Voluntary Approaches (CAVA). Working Paper no 98/11/1/. January. Paris, France: Centre d'Economy Industrielle (CERNA). 
Maxwell, J., T. Lyon, and S. Hacket. 1998. Self-Regulation and Social Welfare: The Political Economy of Corporate Environmentalism. Milan, Italy: Fondazione Eni Enrico Mattei (FEEM).

McClelland, J. and J. Horowitz. 1999. The Costs of Water Pollution Regulation in the Pulp and Paper Industry. Land Economics 75(2):220-232.

Nadeau, L., J. Cantin, and R. Well. 2004. Participation in Voluntary Programs, Corporate Reputation, and Intangible Value: Estimating the Value of Participating in EPA's ENERGYSTAR Program. Proceedings of the Workshop Corporate Environmental Behavior and the Effectiveness of Government Interventions. The National Center for Environmental Economics and National Center for Environmental Research, U.S. Environmental Protection Agency, April 26-27, 2004, Washington DC.

National Center for Environmental Economics. 2001. The United States Experience with Economic Incentives for Protecting the Environment. Environmental and Economic Report EPA-240-R-01-001. Washington, DC: Office of Policy, Economics, and Innovation, U.S. Environmental Protection Agency.

Porter, M.E. 1991. America's Green Strategy. Scientific America 264:168.

Porter, M.E. and C. van der Linde. 1995. Toward a New Conception of the Environment Competitiveness Relationship. Journal of Economic Perspectives 9(4):97-118.

Reed, D.J. 2001. Pursuing the Elusive Business Case for Sustainable development. Washington D.C.: World Resources Institute, Sustainable Enterprise Series.

Reinhardt, F. 1999. Market Failure and the Environmental Policies of Firms. Journal of Industrial Ecology 3(1):9-22. 
Salop, S. and D. Scheffman. 1983. Raising Rivals' Costs. American Economic Review, 73:267271.

Schmidheiny S. 1992. Changing Course. Cambridge, MA: MIT Press.

Sethi, S.P. and G.L. Thompson. 1981. Optimal Control Theory. Boston: Martinus Nijhoff Publishing.

Snir, E.M. 2001. Liability as a Catalyst for Product Stewardship. Production and Operations Management 10(2):190-206.

Vidaras, J. and A. Alberini. 2000. The Appeal of Voluntary Environmental Programs: Which Firms Participate and Why?" Contemporary Economic Policy 18(4):449-461.

Wells, R. 2000. Corporate Environmental Governance: Benchmarks toward World Class Systems. Research Report R-1266-00-RR. May. New York: The Conference Board. 


\title{
CHAPTER 3: ESSAY 2 \\ Price and Volatility Transmission between Primary and Scrap Metal Markets
}

\begin{abstract}
The relationship between primary and scrap prices has been hypothesized for the most part as unidirectional, characterized by spillovers from primary to scrap prices. The purpose of this study is to evaluate empirically the dynamic interactions between primary and scrap metal prices through multivariate time series methods. In addition, the study expands the investigation at the level of volatility transmission which has not been previously examined. The metal prices utilized are for copper, lead, and zinc for the period 1984-2001. The paper demonstrates differing long run and short run links. Scrap prices do not improve the long run interpretation of primary prices, but information flows from the scrap to the primary markets exist in the short run. Additionally, the copper and lead markets exhibit bidirectional information flows in terms of volatility transmission.
\end{abstract}




\section{Introduction}

Recycled materials act both as inputs into the production of and as substitutes for refined primary materials. As a consequence, demand and supply fluctuations in the recycled material markets both influence and are influenced by the primary material markets. Intermarket adjustments to market and expectation changes lead to spillover effects. These influences are evident in terms of relationships among the prices which capture market information (market movements and expectations) available at every point in time. Therefore, price relationships express information spillovers that occur between primary and scrap markets.

This study evaluates how primary and scrap metal markets interact through an examination of price relationships. In the seventies and eighties many studies examined links between primary and scrap metal fundamentals, including prices, through structural modeling in which the most popular specification of the relationship between scrap and primary prices was that primary prices determine scrap prices. This paper tests this assertion using time series methods to evaluate the direction of influence between primary and scrap prices. In doing so, the paper revives interest in the links between primary and scrap markets and is the first attempt to look at this issue without structural assumptions.

The analysis concentrates on three non-ferrous metal markets: copper, lead and zinc. For each market the dynamic interactions between primary and scrap metal prices are estimated using multivariate time series methods which bypass structural modeling. Price links are discussed in both the long run and the short run. While long term variations are driven by economic equilibrium (steady state) relationships, short term dynamics are affected by random disturbances and market constraints. Understanding both short and long run relationships is important because short run relationships, while transitory, may be persistent. In addition, the 
study expands the analysis of primary and scrap price relationships by describing volatility spillovovers.

The study of volatility is especially important for scrap materials for which there are no futures markets to offset, even partially, the effects of volatility through hedging. Volatility approximates how much prices may vary in the future (Weaver and Natcher, 2000). Increased volatility in a market implies higher uncertainty for participants not only in this market but also in interrelated markets due to expected spillover effects. Consequently, volatility is often interpreted as a proxy for information flow over time and across markets (Chan et al., 1991). In addition, Engle et al. (1990) relate volatility movements to the time required for assimilating new information. Thus, to better understand the information transmission mechanism between primary and scrap markets, this study evaluates both price and volatility interdependencies and addresses questions of how fast information is assimilated, in which direction information flows, and by which process information is transmitted (i.e. through prices themselves or through the variance of these prices).

The study shows that the long run relationship between primary and scrap prices is led for the most part by primary prices while scrap prices follow, as expected, based on the demandpull theory ${ }^{1}$. The short run relationships differ: primary lead price changes influence scrap lead price changes, primary zinc price changes follow scrap zinc price changes, whereas in the case of copper, spillovers are bidirectional. The study also indicates that information transmission occurs though volatility spillovers in the cases of copper and lead. In the copper market, volatility transmission from the scrap to the primary market is higher than the volatility transmission from the primary to the scrap market. These volatility results suggest that even if information flow is unidirectional in terms of price, information transmission between primary and scrap markets is

\footnotetext{
${ }^{1}$ In the case of copper, scrap prices have an important role in the long run as well.
} 
bidirectional when the analysis considers price spillovers not only in the first moment (price levels) but also in the second moment (price volatility).

These findings are important for participants in both the primary and scrap sectors of the metal industry. Recycled material markets are so closely linked to their primary markets through complementary and competing relationships that any investigation of these markets must be in some way conducted in the context of the primary market. In addition, recycling has been playing an increasingly important role in many primary markets because of technological advances and in response to concerns about resource depletion and sustainability. At present, more than 50 percent of the metal industry's apparent supply comes from recycling. Consequently, the behavior of recycled material markets, including price volatility, should affect primary markets.

By establishing empirical relationships for the spillovers between primary and scrap prices for copper, lead and zinc, the analysis provides market participants with valuable insight into the interactions of the primary and scrap metal sectors which can be used to improve forecasting and planning. The study also extends the metal prices forecasting capabilities especially needed for the highly unpredictable scrap markets.

\section{Background}

Interactions between primary and scrap markets have been modeled largely using a structural approach. Fisher and Owen (1981) expressed explicit structural relationships for scrap and primary aluminium and indicated that primary prices influence scrap prices. Stollery (1983) modeled the demand and supply relationships between scrap, primary input, and primary output for copper and steel. His empirical model of copper showed that the scrap price varies in direct proportion to the primary London Metal Exchange (LME) price. The copper market has also 
been modeled under a disequilibrium framework by Labys (1980) and Labys and Kaboudan (1980). Under their formulation, the direction of influence passes from the primary (LME) to the scrap price. Taylor (1979) modeled the copper industry in the short run and found that scrap prices are not only affected by, but also influence, primary prices. Hashimoto (1983) followed the tradition of structural analysis in simulating steel production from small scale mills. He argued for simultaneous movements of primary and scrap steel prices due to the industry's inherent inelasticities and sensitivity to the business cycle.

Most of these studies assumed that primary price changes determine scrap price changes. This assumption is in accord with the demand-pull theory in which macroeconomic factors affect demand for final goods which, in turn, changes the derived demands for production inputs. Therefore, information spills over from final good prices to input prices.

Metal end uses are heavily concentrated in the durables and engineering sectors which produce goods in high demand during economic expansions but which stagnate in recessions. As a consequence, instability in metal markets is demand-driven; information passes down from final markets though intermediate metal markets to input markets. Tilton and Vogely (1981) devoted a whole issue of Materials and Society to "Market Instability in the Metal Industries" where instability was identified as primarily a short run phenomenon caused by inelastic supply and demand, high-income elasticity of metals, and frequent demand fluctuations from industrial activity. Labys et al. (1998) note that metal price cycles exist because supply is relatively price inelastic in the short run whereas demand responds quickly to changes in industrial activity over the business cycle. Two issues are noted: (1) since the metal supply and demand are characterized by short run inelasticities, demand changes and spillover effects are largely indicated by price rather than quantity changes; and (2) the short run horizon is important for 
metal markets; therefore short run information spillovers identified through price and volatility transmissions should also be considered.

Scrap is an input to refined metal production. Therefore, modeling price spillovers from the primary to the scrap market is approapriate based on the demand-pull theory. However, scrap can also substitute for, or complement, refined primary metal in producing metal goods. In addition, participants in metal markets can act in both the primary and scrap sectors, and information may be shared in the two markets (Goodwin et al., 1990). Information that enters the metal market simultaneously alters expectations across both primary and scrap markets. Reactions to such information provides further information that can spill over between these markets. Feedback effects and differences in the assimilation of market information between primary and scrap market sectors could mean that scrap prices influence primary prices, at least in the short term.

Although price spillovers may be directed only from the primary market to the scrap market in some market structures, it is not obvious a priori that this assumption holds. Although one may accept that demand pull theory explains the pricing mechanism in metal markets, useful information may still be lost by assuming that primary prices are exogenous. Additionally, interactions between primary and scrap prices differ between the short and long run. As an example note that Taylor's (1979) analysis of the copper market in the short term was one of the few studies to identify price spillovers directed from the scrap to the primary market.

A notable exception to the structural analysis of primary to scrap market links can be found in the study of the LME copper price behaviour performed by Labys et al. (1971) through spectral methods. As part of this study, Labys et al. investigated the relationships between the primary London Metal Exchange (LME) price and scrap copper prices - inspired by references 
for LME leadership over scrap prices (Metals Today, 1965; Brown and Butler, 1968) - and found that LME prices lead three out of four scrap copper price series.

The present study empirically evaluates information flows between primary and scrap markets through a multivariate price and volatility model. Price and volatility spillovers have been previously examined for energy and agricultural markets. Lanza et al. (2005); Girma and Paulson (1999); Adrangi et al. (2001); Gjolberg and Johnsen (1999); Serletis (1994); and Asche et al., (2003) examined the links between crude oil and refined product prices. Ewing et al. (2002) examined volatility transmission between oil and natural gas markets. Volatility spillover effects in retail meat markets were studied by Rezitis (2003). Finally, the literature in price transmission between farm and retail prices has focused on transmission asymmetries for which Meyer and Cramon-Taubadel (2004) provide a summary. Multivariate price and volatility models have been the most popular method used for examining information spillovers in the above studies.

\section{Methodology}

The methodology entails testing price spillovers though multivariate Vector Error Correction (VECM) Models and volatility transmission through Multivariate Generalized Autoregressive Conditional Heteroskedasticity (MGARCH) Models. Both the VECM and GARCH Models are dependent on the Vector Autoregression (VAR) approach which allows regularities in the data to be studied without imposing as many prior restrictions as structural models do (Greene, 2000). The VAR reduced form models express every endogenous variable in the system as a function of the lagged values of all the endogenous variables. Such models are commonly used for examining links of interrelated time series. To specify the form of the VAR, however, it is necessary to check for the integration and cointegration characteristics of the 
primary and scrap price series. For example, stationary data are modeled in levels. Nonstationarity implies that the VAR should be specified in first differences. When cointegration is present in addition to non-stationarity, the VAR is transformed to a VECM which reveals and distinguishes long run relations (cointegration) between primary and scrap prices from the noise of short run fluctuations (changes). After the VECM models are specified, price interrelations are studied in the long and short run. Additionally the errors of the VECM formulations are used to construct the MGARCH models which provide the basis for examining volatility spillovers.

\section{III. a.Vector Autoregression}

The form of the VAR for primary and scrap prices is:

$$
P_{t}=A_{1} P_{t-1}+\ldots+A_{p} P_{t-p}+\varepsilon_{t} \quad \varepsilon_{t} I_{t-1} \sim N\left(0, H_{t}\right)
$$

where $P_{t}$ is a $\mathrm{k} \times 1$ vector of monthly primary $(P p)$ and secondary prices $(P s)$ and $\varepsilon_{t}$ is the $\mathrm{k} \times 1$ vector of random errors which includes the innovation for each market at time $t$ with its corresponding $\mathrm{k} \times \mathrm{k}$ conditional variance covariance matrix $H_{t}$. The $\alpha_{i j}$ elements of the $\mathrm{k} \times \mathrm{k}$ matrix $A$ represent the degree of price transmission from each market $i$ to market $j$. This model provides the conditional expected price equations given the market information available at time t-1 $\left(I_{t-1}\right)$. The model specification is determined by the integration properties of the primary and scrap prices. Based on the random errors of the price equations, the conditional volatility of the primary and scrap prices is then modeled.

\section{III. b. Price Links Modeling}

The specification of the VAR models entails the following steps. First, the primary and scrap price series are tested for unit roots with the non-parametric P-P unit root test developed by Phillips and Perron (1988). The Phillips and Perron unit root test is preferred to the augmented 
Dickey and Fuller (1981) test because it is robust with respect to the presence of serial correlation and heteroskedasticity.

The second step deals with the presence of a long run relationship between primary and scrap prices. A long-run equilibrium between primary and scrap prices is said to exist if the series are found to be cointegrated ${ }^{2}$. Engle and Granger (1987) first pointed out that a linear combination of two or more non-stationary (with a unit root) series may be stationary. If such a stationary, or $\mathrm{I}(0)$, linear combination exists, the non-stationary time series are said to be cointegrated. The stationary linear combination is called the cointegrating equation and may be interpreted as a long-run equilibrium relationship between the variables. The Johansen (1991, 1995) cointegration tests based on a VAR approach are used. This step allows identification of the proper specification of the price mean models which includes both the long run equilibrium relationship between primary and scrap prices and their short run adjustments.

Johansen's method tests the restrictions imposed by co-integration on the unrestricted VAR model in equation (1). To test for the cointegrating restrictions between the variables, the VAR is transformed using the following Vector Error Correction (VECM) specification:

$$
\Delta P_{t}=\Pi P_{t-1}+\sum_{i=1}^{p-1} \Gamma_{i} \Delta P_{t-i}+\varepsilon_{t}
$$

where $\Pi=\sum_{i=1}^{p} A_{i}-I_{i}, \quad \Gamma_{i}=-\sum_{j=i+1}^{p} A_{j}$

Granger's representation theorem (Johansen, 1991; Engle and Granger, 1987) asserts that if the coefficient matrix $\Pi$ has reduced rank $\mathrm{r}<\mathrm{k}$, then there exist $\mathrm{k} \times \mathrm{r}$ matrices $\alpha$ and $\beta$ each with rank r such that $\Pi=\alpha \beta^{\prime}$ and $\beta^{\prime} P_{t}$ is stationary. The variable, $r$, is the number of cointegrating

\footnotetext{
${ }^{2}$ In order to test for such a relationship, it must be established that the primary and scrap prices are integrated of the same order.
} 
relations (the cointegrating rank), each column of $\beta$ is the cointegrating vector, and elements of $\alpha$ are known as the adjustment parameters to the cointegrating restrictions.

The VECM models produced restrict the long-run behavior of the endogenous variables to converge to their cointegrating relationships while allowing a wide range of short run dynamics. Since the VECM models include both short run and long run dynamics, they can be used to separate long run from short run spillovers between primary and scrap prices. To identify the long run price leader, weak exogeneity tests are performed. The vector $\alpha$ contains the information about weak exogeneity (Johansen and Juselius, 1990). If one of the elements in $\alpha$ is zero, there will be no long run causation towards this variable within the system; this variable is weakly exogenous, i.e. it drives the system in the long run. This variable is strongly exogenous if moreover, it is not affected by the short run dynamics of other variables in the system. Granger causality tests (Granger, 1969) indicate the direction of influence in the short run between primary and scrap prices. If the lag structure of the short run changes of the $i$ price series adds to the explanatory power of the short run changes of the $j$ price series, then it "Granger causes" this series in the short term.

\section{III. c. Volatility Links Modeling}

Interrelations between primary and secondary markets are also inferred by analyzing the conditional variance-covariance matrix $H_{t}$. The errors of the VECM price models $\varepsilon_{t} \mid I_{t-1} \sim N\left(0, H_{t}\right)$ are used to represent the residual conditional volatility in a Multivariate Generalized Autoregressive Conditional Heteroskedasticity (MGARCH) framework so that volatility transmission may be studied ${ }^{3}$. The most obvious application of MGARCH models is the study of

\footnotetext{
${ }^{3}$ Although the conditional mean (VECM) parameters generally enter the conditional variance specification through the residuals, the GARCH parameters do not affect the conditional mean (Bauwens et al., 2003). In this way, use of a two-stage procedure allows, with only a small loss in efficiency, consistent estimation of the price level onnections
} 
the relationships between the volatilities of multiple markets (Kearney and Patton, 2000; Karolyi, 1995). The MGARCH can help explain whether the volatility of one market is leading the volatility of other markets, whether the volatility of a price is transmitted to another price directly (through its conditional variance) or indirectly (through its conditional covariances), or whether a shock within a market increases volatility within another market, and if so, by how much.

Under the MGARCH representation each element of the conditional variance-covariance matrix $H_{t}$ is a function of the lagged squared innovations, the past cross products of innovations, and the lagged values of the elements of $H_{t}$. The MGARCH parameterization used here is the BEKK model introduced by Engle and Kroner (1995) which incorporates quadratic forms to ensure the positive semi-definiteness of the variance-covariance matrix. The BEKK parametrization for the $\mathrm{MGARCH}(1,1, \mathrm{k})$ is represented as:

$$
H_{t}=C C^{\prime}+B^{\prime} H_{t-1} B+D^{\prime} \varepsilon_{t-1} \varepsilon_{t-1} D
$$

Where $C$ is an $\mathrm{k} \times \mathrm{k}$ lower triangular matrix with parameters expressing the constants, $B$ is a $\mathrm{k} \times \mathrm{k}$ square matrix that includes the elements $b_{i j}$ which measure the degree of transmission of past conditional variance from market $i$ to market $j$, and $D$ is also a $\mathrm{k} \times \mathrm{k}$ square matrix that includes the elements $d_{i j}$, which capture the effect of shocks or unexpected events in market $i$ on market $j$. This specification requires the estimation of a limited number of parameters while simultaneously allowing sufficient generality by representing direct and indirect volatility transmission between the primary and scrap prices (Karolyi, 1995).

For the bivariate case the $\operatorname{GARCH}(1,1)$ is:

from the VECM of the market, and afterwards represents the volatility connections in an M-Garch, using the residuals produced from the VECM models. 


$$
\begin{aligned}
{\left[\begin{array}{ll}
h_{11, t} & h_{21, t} \\
h_{21, t} & h_{22, t}
\end{array}\right]=} & {\left[\begin{array}{ll}
c_{11} & o \\
c_{21} & c_{22}
\end{array}\right]\left[\begin{array}{ll}
c_{11} & o \\
c_{21} & c_{22}
\end{array}\right]^{\prime}+\left[\begin{array}{ll}
b_{11} & b_{12} \\
b_{21} & b_{22}
\end{array}\right]^{\prime}\left[\begin{array}{cc}
\varepsilon_{1, t-1}^{2} & \varepsilon_{1, t-1} \varepsilon_{2, t-1} \\
\varepsilon_{2, t-1} e_{1, t-1} & \varepsilon_{2, t-1}^{2}
\end{array}\right]\left[\begin{array}{ll}
b_{11} & b_{12} \\
b_{21} & b_{22}
\end{array}\right] } \\
& +\left[\begin{array}{ll}
d_{11} & d_{12} \\
d_{21} & d_{22}
\end{array}\right]^{\prime}\left[\begin{array}{ll}
h_{11, t-1} & h_{21, t-1} \\
h_{21, t-1} & h_{22, t-1}
\end{array}\right]\left[\begin{array}{ll}
d_{11} & d_{12} \\
d_{21} & d_{22}
\end{array}\right]
\end{aligned}
$$

The parameters in the matrices $C, B$, and $D$ cannot be explained independently; the interest lies within the functions of the parameters which form the intercept terms and the coefficients of the lagged variances/covariances and innovations/coinnovations (Kearney and Patton, 2000). The conditional variance for each equation in the bivariate GARCH $(1,1)$ is expanded in equations (5) and (6) to represent these coefficients and show how volatility and shocks are transmitted between primary and scrap prices and over time.

$$
\begin{aligned}
& h_{11, t}=c_{11}^{2}+b_{11}^{2} \varepsilon_{1, t-1}^{2}+b_{11} b_{21} \varepsilon_{1, t-1} e_{2, t-1}+b_{21}^{2} \varepsilon_{2, t-1}^{2}+d_{11}^{2} h_{11, t-1}+d_{11} d_{21} h_{21, t-1}+d_{21}^{2} h_{22, t-1} \\
& h_{22, t}=c_{21}^{2}+c_{22}^{2}+b_{12}^{2} \varepsilon_{1, t-1}^{2}+b_{22} b_{12} \varepsilon_{1, t-1} \varepsilon_{2, t-1}+b_{22}^{2} \varepsilon_{2, t-1}^{2}+d_{12}^{2} h_{11, t-1}+d_{22} d_{12} h_{21, t-1}+d_{22}^{2} h_{22, t-1}
\end{aligned}
$$

\section{Empirical Analysis}

The description of primary and scrap prices is followed by unit root testing and cointegration analysis. Cointegration analysis includes the estimation of the long run equilibrium relationship that links primary and scrap prices as well as the computation of the adjustment rates of short run primary and scrap price towards their long run equilibrium. The VECM models are constructed from the cointegration results and used to examine the direction of price transmission in the short and long run. The VECM models also constitute the basis for describing weak and strong exogeneity which convey information on whether scrap prices lead primary prices or whether primary prices lead scrap prices in the short and long run. Finally, MGARCH 
models computed from the errors of the VECM representations assess the direction and speed of volatility transmission. ${ }^{4}$

\section{IV. a. Data}

Three metal markets are analysed: copper, lead, and zinc. Lead is the most recycled metal; 71 percent of apparent supply in the lead market is provided by recycled materials. One of the least recycled metals is zinc at 26 percent (USGS, 2002). Therefore, this study includes metals with high (lead), medium (copper), and low (zinc) recycling rates. Table 1 gives recycling rates by metal for selected years.

Table 1. Recycling Rates and Old to New Scrap Ratios by Metal

\begin{tabular}{lccc}
\hline & 1998 & 2000 & 2002 \\
\hline Copper & 35.7 & 32.1 & 30.4 \\
Recycled \% & $33 / 67$ & $27 / 73$ & $20 / 80$ \\
Old/New Ratio & & & \\
\hline Lead & 63.1 & 62.6 & 71.4 \\
Recycled \% & $95.5 / 4.5$ & $96.5 / 3.5$ & $97 / 3$ \\
Old/New Ratio & & & 25.6 \\
Zinc & 27.5 & 26.9 & $13 / 87$ \\
Recycled \% & $21 / 79$ & $16 / 84$ & \\
Old/New Ratio &
\end{tabular}

Computed from Salient US Recycling Statistics for Selected Metals (USGS, 2003)

The data employed consist of United States average monthly primary and scrap metal prices. The time periods examined are 1984-2001 for copper, 1984-2000 for lead and 1984-1996 for zinc. Primary prices are prices for refined metal which can be produced from either primary ore/concentrate or scrap metal. The primary prices used are the producer price of delivered copper cathode (PPC), the New York delivery prices of the primary producers' pig lead (PPL), and the domestic and foreign producer prices for primary zinc slab delivered in the United States

\footnotetext{
${ }^{4}$ Computations for specifying and analysing the VECM models were performed in Eviews (version 5.1). MGARCH models were computed in Matlab (version 6.5) using code from the UCSD GARCH toolbox for Matlab developed by K.K. Sheppard.
} 
$(\mathrm{PPZ})^{5}$. The focus of this paper is on the United States market. Consequently, United States producer prices are utilized even though LME prices are used internationally as reference prices. Edwards and Robbins (1979) indicate that, after the middle of 1970, producer prices reflect the metal exchange spot prices closely. Figuerola-Ferretti and Gilbert (2001) also show that current producer price volatility in non-ferrous metals is not much smaller than that of market exchange prices.

Commercial scrap metal can be divided into new and old scrap. New scrap, such as cuttings and turnings, is generated during processing and fabrication of metal products and is usually denoted as No. 1 scrap. It is desirable for its higher quality and for its consistency in terms of content and supply. Old scrap (usually No. 2 scrap) is metal incorporated in postconsumer products, obsolete manufactured products, or spent materials. The relative utilization of old and new scrap in each market for sample years is shown in table 1 above. Both new and old scrap prices are used in the study. New scrap prices included are the price for brass mills No.1 copper scrap (PS1C) and the price of new zinc clippings (PSZ). Old scrap prices in the study are the price for refiners' No. 2 copper scrap (PS2C) and the smelters' buying price for heavy soft scrap lead (PSL).

As the graphs in figure 1 show, primary prices are correlated with scrap prices. However, primary and scrap prices are not always in correspondence and substantial short term volatility exists. Table 2 indicates that the degree of variation is higher for scrap prices in terms of both volatility and coefficients of variation. This result agrees with the findings of Edgren and

\footnotetext{
${ }^{5}$ PPC was obtained from the United States Geological Survey specialist D.L Edelstein, PPL is published in the Commodity Research Bureau Commodity Yearbook, and PPZ is available in the Metal Statistics publication of the American Metal Market. The length of each time series is determined by data availability and compatibility.

${ }^{6}$ The Metal Statistics publication of the American Metal Market is the source for PSL and PSZ. PS1C and PS2C data were obtained from United States Geological Survey specialist D.L. Edelstein. The length of each time series is determined by data availability and compatibility.
} 

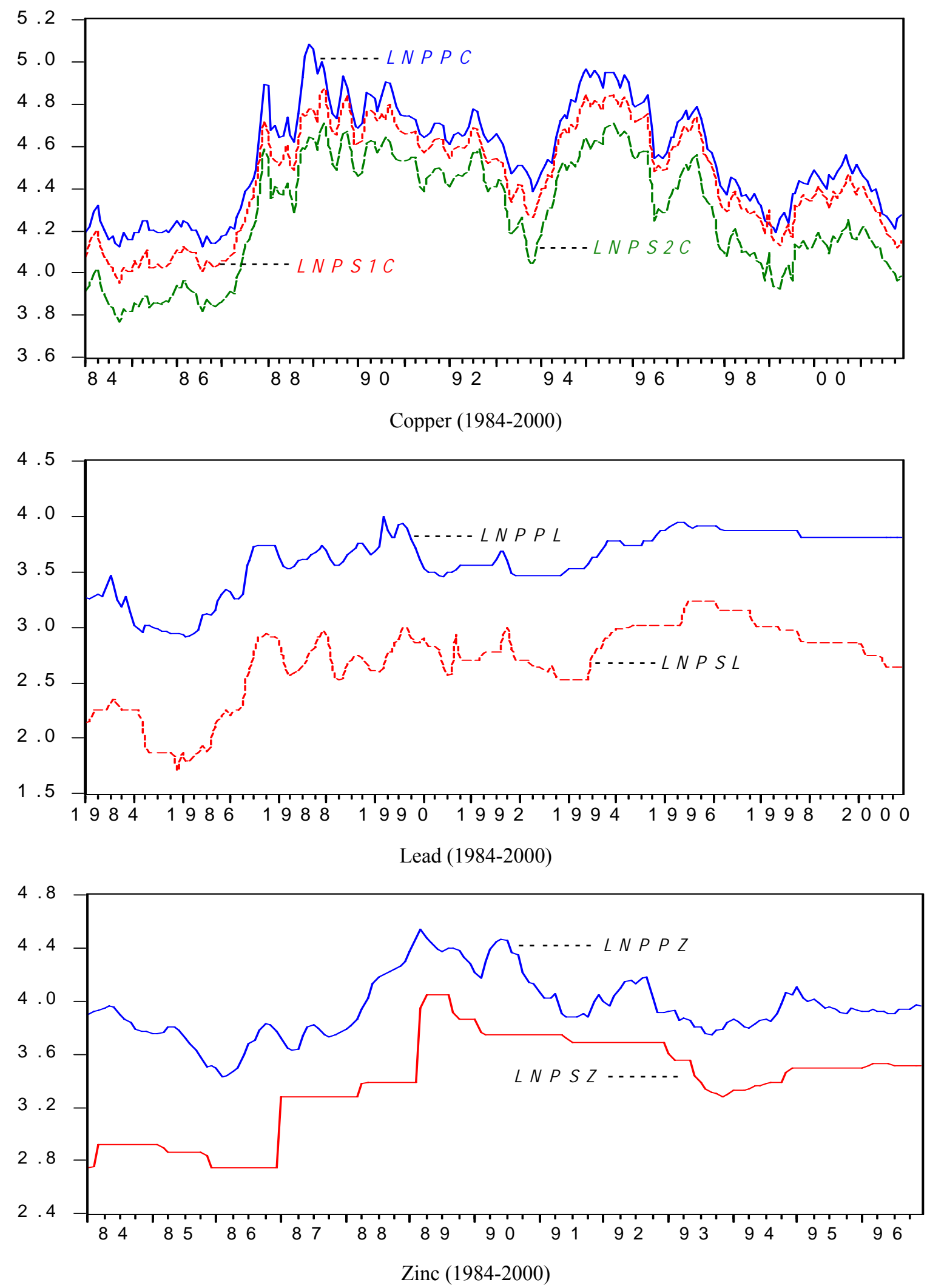

Figure 1. Primary and Scrap Price Series by Metal 
Table 2. Characteristics of Primary and Scrap Prices by Metal

\begin{tabular}{|c|c|c|c|c|c|c|c|}
\hline \multirow[t]{3}{*}{ Characteristic } & \multicolumn{7}{|c|}{ Price Series } \\
\hline & \multicolumn{3}{|c|}{ Copper } & \multicolumn{2}{|c|}{ Lead } & \multicolumn{2}{|c|}{ Zinc } \\
\hline & PPC & PS1C & $\mathrm{PS} 2 \mathrm{C}$ & PPL & PSL & PPZ & PSZ \\
\hline Mean & 4.545 & 4.443 & 4.271 & 3.602 & 2.690 & 3.952 & 3.384 \\
\hline Standard Deviation & 0.255 & 0.257 & 0.271 & 0.277 & 0.360 & 0.237 & 0.356 \\
\hline Coef. of Variation & 0.056 & 0.058 & 0.064 & 0.077 & 0.134 & 0.060 & 0.105 \\
\hline Skewness & 0.033 & -0.196 & -0.156 & -0.969 & -0.914 & 0.425 & -0.402 \\
\hline Kurtosis & 1.838 & 1.793 & 1.697 & 3.078 & 3.220 & 2.949 & 2.271 \\
\hline Jarque-Bera (J-B) & 12.187 & 14.499 & 16.164 & 31.960 & 28.816 & 4.702 & 7.662 \\
\hline Probability (J-B) & 0.002 & 0.001 & 0.0003 & 0.000 & 0.000 & 0.095 & 0.022 \\
\hline
\end{tabular}

Moreland (1990), Slade (1980), and Van Beukering and Bouman (2001) that price volatility is higher in recycled relative to primary material markets. However, this finding is constrained to a long run measure of volatility.

\section{IV. b. Integration and Cointegration}

The Phillips and Perron (1988) (P-P) unit root tests are appropriate tests for unit roots for the price series considered. The results are reported in Table 3. The hypothesis of a unit root in each price series cannot be rejected at the 5 percent significance level, indicating that primary and scrap prices are non-stationary. The next step is to check whether the price series are integrated of order one [I(1)]: rejection of a unit root in the first differences of the prices suffices. Table 3 shows that nonstationarity is rejected for first differences, suggesting that all variables are $\mathrm{I}(1)$.

Nonstationarity means that the prices will be represented in first differences. Time series characteristics of price changes are presented in table 4 . Table 5 presents the Ljung-Box Qstatistics for the squared residuals of the univariate first difference price models and Engle's Lagrange multiplier (LM) test for autoregressive conditional heteroskedasticity (ARCH) in the residuals (Engle 1982). The test results suggest that the primary and scrap price change residuals 
Table 3. Phillips Perron Unit-Root Tests by Metal

\begin{tabular}{|c|c|c|c|c|c|c|}
\hline \multirow[b]{2}{*}{ Series } & \multicolumn{2}{|c|}{ Level } & \multicolumn{2}{|c|}{ First Difference } & \multicolumn{2}{|c|}{ Critical Value } \\
\hline & P-P Value & Probability* & P-P Value & Probability* & $1 \%$ & $5 \%$ \\
\hline \multicolumn{7}{|l|}{ Copper } \\
\hline PPC & -1.937 & 0.3149 & -10.871 & 0.000 & -3.462 & -2.876 \\
\hline PS1C & -1.777 & 0.3914 & -12.459 & 0.000 & -3.462 & -2.876 \\
\hline PS2C & -1.813 & 0.3734 & -12.605 & 0.000 & -3.462 & -2.876 \\
\hline \multicolumn{7}{|l|}{ Lead } \\
\hline PPL & -1.688 & 0.436 & -10.180 & 0.000 & -3.462 & -2.876 \\
\hline PSL & -1.961 & 0.304 & -11.736 & 0.000 & -3.462 & -2.876 \\
\hline \multicolumn{7}{|l|}{ Zinc } \\
\hline PPZ & -1.864 & 0.349 & -7.673 & 0.000 & -3.473 & -2.880 \\
\hline PSZ & -1.899 & 0.332 & 11.039 & 0.000 & -3.473 & -2.880 \\
\hline
\end{tabular}

*MacKinnon (1996) one-sided p-values for rejection of hypothesis of a unit root Constant included at the test regression; the test results were insensitive to the addition of a trend in the test regression.

Table 4. Characteristics of Primary and Scrap Price Changes by Metal

\begin{tabular}{|c|c|c|c|c|c|c|c|}
\hline \multirow[t]{3}{*}{ Characteristic } & \multicolumn{7}{|c|}{ Price Series } \\
\hline & \multicolumn{3}{|c|}{ Copper } & \multicolumn{2}{|c|}{ Lead } & \multicolumn{2}{|c|}{ Zinc } \\
\hline & $\triangle \mathrm{PPC}$ & $\triangle \mathrm{PS} 1 \mathrm{C}$ & $\triangle \mathrm{PS} 2 \mathrm{C}$ & $\triangle \mathrm{PPL}$ & $\triangle \mathrm{PSL}$ & $\triangle \mathrm{PPZ}$ & $\triangle \mathrm{PSZ}$ \\
\hline Mean & 0.000 & 0.000 & 0.000 & 0.003 & 0.002 & 0.001 & 0.003 \\
\hline Standard Deviation & 0.057 & 0.055 & 0.061 & 0.049 & 0.070 & 0.049 & 0.067 \\
\hline Coef. of Variation & 213.362 & 304.434 & 246.165 & 17.925 & 28.742 & 38.824 & 22.171 \\
\hline Skewness & 0.331 & 0.107 & -0.041 & 1.052 & 0.458 & -0.211 & 5.951 \\
\hline Kurtosis & 4.849 & 3.687 & 4.265 & 10.931 & 8.629 & 3.714 & 52.320 \\
\hline Jarque-Bera (J-B) & 34.724 & 4.661 & 14.458 & 572.264 & 276.497 & 5.137 & 19198.490 \\
\hline Probability (J-B) & 0.000 & 0.097 & 0.001 & 0.000 & 0.000 & 0.077 & 0.000 \\
\hline
\end{tabular}

Table 5. Autoregressive Conditional Heteroskedasticity Tests by Metal

\begin{tabular}{|c|c|c|c|c|c|c|c|}
\hline \multicolumn{8}{|c|}{$\varepsilon_{\mathrm{t}}=\Delta \mathrm{P}_{\mathrm{t}}-\Sigma \mathrm{a}_{\mathrm{i}} \Delta \mathrm{P}_{\mathrm{t}-1}$} \\
\hline & \multicolumn{3}{|c|}{ Copper } & \multicolumn{2}{|c|}{ Lead } & \multicolumn{2}{|c|}{ Zinc } \\
\hline & $\triangle \mathrm{PPC}$ & $\triangle \mathrm{PS} 1 \mathrm{C}$ & $\triangle \mathrm{PS} 2 \mathrm{C}$ & $\triangle \mathrm{PPL}$ & $\triangle \mathrm{PSL}$ & $\Delta \mathrm{PPZ}$ & $\triangle \mathrm{PSZ}$ \\
\hline $\mathrm{Q}^{2}(10)$ & 48.893 & 19.074 & 23.005 & 22.244 & 17.972 & 14.939 & 0.487 \\
\hline Probability & 0 & 0.025 & 0.003 & 0.008 & 0.035 & 0.093 & 1 \\
\hline ARCH LM & 5.793 & 1.988 & 5.264 & 15.405 & 15.083 & 0.634 & 0.015 \\
\hline Probability & 0.016 & 0.159 & 0.022 & 0 & 0 & 0.426 & 0.902 \\
\hline
\end{tabular}


for the copper and lead markets are characterized by autoregressive conditional heteroskedasticity. It is evident that there is no autoregressive conditional heteroskedasticity in the residuals of zinc price changes.

Since both primary and scrap prices are integrated of the same order, i.e. I(1), in each market it is possible that they are cointegrated. Cointegration tests indicated the long run equilibrium relationships between primary and scrap prices. The results of the Johansen (1991, 1995) cointegration tests are presented in table 6. Cointegration between primary and scrap prices is indicated and one cointegration relationship is found to link primary to scrap prices in each market. Two common stochastic trends are present in the copper system and one each in the lead and zinc systems. Cointegration implies that even though short run dynamics may be in disequilibrium, primary and scrap prices are intrinsically linked and cannot wander arbitrarily far away from each other.

Table 6. Johansen Cointegration Tests by Metal

\begin{tabular}{|c|c|c|c|c|c|c|c|c|}
\hline \multirow[t]{2}{*}{ Prices } & \multirow[t]{2}{*}{ No. C.E.s } & \multirow[t]{2}{*}{ Ho: $r=p$} & \multicolumn{3}{|c|}{ Maximum Eigenvalue Test } & \multicolumn{3}{|c|}{ Trace Test } \\
\hline & & & Statistic & 5\% Crit.Val. & Prob.** & Statistic & 5\% Crit.Val. & Prob.** \\
\hline Copper & \multirow{3}{*}{1} & $\mathrm{p}=0$ & $27.377^{*}$ & 22.300 & 0.009 & $42.646^{*}$ & 35.193 & 0.007 \\
\hline \multirow[t]{2}{*}{ PPC, PS1C,PS2C } & & $\mathrm{p} \leq 1$ & 11.989 & 15.892 & 0.187 & 15.269 & 20.262 & 0.211 \\
\hline & & $\mathrm{p} \leq 2$ & 3.280 & 9.165 & 0.530 & 3.280 & 9.165 & 0.530 \\
\hline Lead & \multirow{2}{*}{1} & $\mathrm{p}=0$ & $16.427^{*}$ & 15.892 & 0.041 & $20.449 *$ & 20.262 & 0.047 \\
\hline PPL, PSL & & $\mathrm{p} \leq 1$ & 4.022 & 9.165 & 0.409 & 4.022 & 9.165 & 0.409 \\
\hline Zinc & \multirow{2}{*}{1} & $\mathrm{p}=0$ & $17.845^{*}$ & 15.892 & 0.024 & $20.460 *$ & 20.262 & 0.047 \\
\hline PPZ, PSZ & & $\mathrm{p} \leq 1$ & 2.616 & 9.165 & 0.655 & 2.616 & 9.165 & 0.655 \\
\hline
\end{tabular}

*denotes rejection of the hypothesis at the 0.05 level

**MacKinnon-Haug-Michelis (1999) p-values 
Normalizing with respect to the coefficient of the primary price produces the long run price relationship between primary and scrap metal in each market. These are expressed by equations (7) - (9). The long run relationship of old copper scrap prices to primary and new scrap prices is relatively weak. However, bivariate cointegration tests ${ }^{7}$ establish that old copper prices do hold a long run relationship both to primary and old scrap prices.

$$
\begin{gathered}
\beta_{\mathrm{c}}: P P C-0.416-0.526 P S 1 C+0.42 P S 2 C \\
{[-2.41]^{* *}[-1.73]^{*}} \\
\beta_{1}: P P L-1.452-0.798 P S L \\
{[-7.81]^{* * *}[-11.64]^{* * *}} \\
\beta_{\mathrm{z}}: P P Z-1.775-0.636 P S Z \\
{[-4.88]^{* * *}[-5.94]^{* * *}}
\end{gathered}
$$

As shown in table 7 , the adjustment speed of primary and scrap prices to their long run equilibrium differs among the three markets. In the lead and zinc markets the parameter associated with the scrap price ( 0.167 and 0.123 , respectively) is substantially larger than the one related to primary prices (-0.012 and -0.035 , respectively). This suggests that lead and zinc scrap prices react much more intensely to unanticipated shocks than do their respective primary prices. In addition, most of the shift towards the long run relationship between primary and scrap prices is borne by adjustments in the scrap market; this is denoted by the fact that only scrap prices have statistically significant adjustment rates. This is not true in the case of copper where the speed of adjustment is relatively symmetric for primary and scrap prices.

The magnitude of the adjustment parameters is not high ${ }^{8}$. This implies a moderate speed of price adjustments towards the equilibrium relationship between primary and scrap prices after unexpected shocks. It also suggests that short run conditions can be persistent and denotes the importance of understanding the short-term interactions between primary and scrap prices.

\footnotetext{
${ }^{7}$ Not presented in the paper, but available upon request.

${ }^{8}$ The speed of adjustment can range from zero to one.
} 
Table 7. Speed of Adjustment for Primary and Scrap Prices

to their Long-run Equilibrium by Metal

\begin{tabular}{cccc}
\hline System (i) & Variable $(\mathrm{j})$ & $\alpha_{\mathrm{i}, \mathrm{j}}$ & $\mathrm{t}$ value \\
\hline \multirow{2}{*}{ Copper } & $\Delta(\mathrm{PPC})$ & -0.149 & {$[-1.548]$} \\
& $\Delta(\mathrm{PS} 1 \mathrm{C})$ & 0.171 & {$[1.863]^{*}$} \\
& $\Delta(\mathrm{PS} 2 \mathrm{C})$ & 0.168 & {$[1.673]^{*}$} \\
\multirow{2}{*}{ Lead } & $\Delta(\mathrm{PPL})$ & -0.012 & {$[-0.361]$} \\
& $\Delta(\mathrm{PSL})$ & 0.167 & {$[3.857]^{* * *}$} \\
& & & {$[-1.647]$} \\
\multirow{2}{*}{ Zinc } & $\Delta(\mathrm{PPZ})$ & -0.035 & {$[3.879]^{* * *}$} \\
\hline
\end{tabular}

t-statistics in brackets. Asterisks indicate significance at ${ }^{*--0.10,}{ }^{* *}{ }_{--} 0.05,{ }^{* * *}{ }_{--} 0.01$ level.

\section{IV. c. Price Transmission}

The estimated VECM models describe short run price movements while restricting the long run price movements so that primary and scrap prices in each market converge to their respective cointegrating relationship shown in equations (7) - (9) above. The results in table 8 show that the error correction term (cointegrating relationship between primary and scrap prices) can always be used to explain the next period's scrap price change in every market. In the cases of zinc and copper the error correction term, though insignificant at the 10 percent significance level, is significant if a significance level of 15 percent is accepted.

Table 8 shows that statistically significant short run information spillovers come from prices lagged by only one month, indicating fast assimilation of short run information. Short run primary copper price changes influence scrap price changes with a lag of one month. Price changes of new scrap copper have a significant effect on the next period's primary price changes as well as on old copper prices. In the lead market, short run information passes from the primary to the scrap market; in the case of zinc, information spillovers are directed from scrap prices to primary prices. 
Table 8. VECM Models by Metal

\begin{tabular}{|c|c|c|c|c|c|c|c|c|c|}
\hline \multicolumn{4}{|c|}{ Copper } & \multicolumn{3}{|c|}{ Lead } & \multicolumn{3}{|c|}{ Zinc } \\
\hline & $\Delta(\mathrm{PPC})$ & $\Delta(\mathrm{PS} 1 \mathrm{C})$ & $\Delta(\mathrm{PS} 2 \mathrm{C})$ & & $\Delta(\mathrm{PPL})$ & $\Delta(\mathrm{PSL})$ & & $\Delta(\mathrm{PPZ})$ & $\Delta(\mathrm{PSZ})$ \\
\hline \multirow[t]{2}{*}{$\beta_{\mathrm{c}}$} & -0.148996 & 0.17077 & 0.167733 & $\beta_{1}$ & -0.012 & 0.167 & $\beta_{\mathrm{z}}$ & -0.035 & 0.123 \\
\hline & {$[-1.548]$} & {$[1.863]^{*}$} & {$[1.673]^{*}$} & & {$[-0.361]$} & {$[3.857]^{* * *}$} & & {$[-1.647]$} & {$[3.879]^{* * *}$} \\
\hline \multirow[t]{2}{*}{ lag1 $\Delta(\mathrm{PPC})$} & 0.214 & 0.397 & 0.419 & lag1 $\Delta(\mathrm{PPL})$ & 0.312 & 0.379 & lag1 $\Delta(\mathrm{PPZ})$ & 0.491 & 0.08 \\
\hline & {$[1.736]^{*}$} & {$[3.380]^{* * *}$} & {$[3.258]^{* * *}$} & & {$[4.040]^{* * *}$} & {$[3.701]^{* * *}$} & & {$[6.681]^{* * *}$} & {$[0.726]$} \\
\hline \multirow[t]{2}{*}{ lag1 $\Delta(\mathrm{PS} 1 \mathrm{C})$} & 0.332 & -0.202 & 0.385 & lag1 $\Delta(\mathrm{PSL})$ & 0.011 & 0.102 & lag1 $\Delta(\mathrm{PSZ})$ & -0.109 & 0.089 \\
\hline & {$[1.795]^{*}$} & {$[-1.147]$} & {$[1.999]^{* *}$} & & {$[0.222]$} & {$[1.527]$} & & {$[-2.153]^{* *}$} & {$[1.165]$} \\
\hline \multirow[t]{2}{*}{$\operatorname{lag} 1 \Delta(\mathrm{PS} 2 \mathrm{C})$} & -0.144 & 0.103 & -0.406 & & & & & & \\
\hline & {$[-0.841]$} & {$[0.633]$} & {$[-2.277]^{* *}$} & & & & & & \\
\hline \multirow[t]{2}{*}{ lag2 $\Delta(\mathrm{PPC})$} & -0.082 & -0.112 & -0.193 & & & & & & \\
\hline & {$[-0.705]$} & {$[-1.005]$} & {$[-1.587]$} & & & & & & \\
\hline \multirow[t]{2}{*}{ lag2 $\Delta(\mathrm{PS} 1 \mathrm{C})$} & 0.031 & -0.233 & 0.085 & & & & & & \\
\hline & {$[0.166]$} & {$[-1.324]$} & [ 0.442] & & & & & & \\
\hline \multirow[t]{2}{*}{ lag2 $\Delta(\mathrm{PS} 2 \mathrm{C})$} & -0.105 & 0.112 & -0.157 & & & & & & \\
\hline & {$[-0.620]$} & [ 0.693$]$ & {$[-0.889]$} & & & & & & \\
\hline Adj. $R^{2}$ & 0.134 & 0.164 & 0.183 & Adj. $R^{2}$ & 0.084 & 0.209 & Adj. $R^{2}$ & 0.230 & 0.105 \\
\hline AIC & -2.969 & -3.067 & -2.888 & AIC & -3.256 & -2.692 & AIC & -3.411 & -2.601 \\
\hline $\mathrm{SC}$ & -2.859 & -2.957 & -2.778 & $\mathrm{SC}$ & -3.208 & -2.643 & $\mathrm{SC}$ & -3.352 & -2.542 \\
\hline \multicolumn{4}{|c|}{$\mathrm{Q}(10) 88.469$ [0.09] } & \multicolumn{3}{|c|}{$\mathrm{Q}(10) 33.038[0.61]$} & \multicolumn{3}{|c|}{$\mathrm{Q}(10) \quad 18.267$ [0.99] } \\
\hline \multicolumn{4}{|c|}{$\mathrm{LM}(1) 11.236[0.25]$} & \multicolumn{3}{|c|}{$\operatorname{LM}(1) 4.097$ [0.39] } & \multicolumn{3}{|c|}{$\operatorname{LM}(1) \quad 0.872[0.93]$} \\
\hline \multicolumn{4}{|c|}{$\mathrm{LM}(4) 1.447$ [0.99] } & \multicolumn{3}{|c|}{$\operatorname{LM}(4) 5.243[0.26]$} & \multicolumn{3}{|c|}{$\mathrm{LM}(4) 3.240[0.51]$} \\
\hline
\end{tabular}

$\mathrm{t}$-statistics in in brackets. Asterisks indicate significance at $*_{--} 0.10, *_{--0.05} *_{*} *_{--0.01}$ level.

Interestingly, new scrap copper, lead scrap, and zinc scrap prices do not pass information in their own markets over time. This finding seems to support the modeling approach of Stollery (1983), Fisher and Owen (1981), and Labys (1980) which describes scrap prices as a function of primary prices alone. However, as can be seen in table 8 the analysis does not find this relationship to hold for old copper scrap prices; old copper scrap prices pass information in their 
own market over time. The contradiction of this finding to the above studies is even more pronounced due to the fact that Stollery (1983) and Labys (1980) were describing the behavior of old copper scrap. In addition, the cointegration term that affects scrap prices in every market includes past information from the scrap prices.

The VECM models allow examination of both the long and the short run relationships between primary and scrap prices. Weak exogeneity tests that allow inferences about long run price leadership are presented in table 9. It is clear that in the lead market primary prices are weakly exogenous and scrap prices react to changes in the primary prices. The evidence for weak exogeneity of primary price is not as strong in the copper and zinc markets. However, it can be concluded that zinc primary prices lead the market in the long run. In contrast, though primary copper prices are weakly exogenous at a confidence level of 14 percent, they do not lead the market since old scrap prices are found to be weakly exogenous as well at a confidence level of 12 percent. Thus, new scrap prices react to changes in both primary and old scrap prices.

Table 9. Weak Exogeneity Tests by Metal

\begin{tabular}{ccccc}
\hline System & Variable & Exogeneity Test & LR Stat. & Probability \\
\hline \multirow{3}{*}{ Copper } & PPC & $\alpha_{\mathrm{ppc}}=0$ & 2.173 & 0.140 \\
& PS1C & $\alpha_{\mathrm{ps} 1 \mathrm{c}}=0$ & 3.145 & 0.076 \\
& PS2C & $\alpha_{\mathrm{ps} 2 \mathrm{c}}=0$ & 2.383 & 0.123 \\
\multirow{3}{*}{ Lead } & PPL & $\alpha_{\mathrm{ppl}}=0$ & 0.101 & 0.751 \\
& PSL & $\alpha_{\mathrm{psl}}=0$ & 11.012 & 0.001 \\
& Zinc & $\alpha_{\mathrm{ppz}}=0$ & 2.357 & 0.125 \\
& PPZ & $\alpha_{\mathrm{psz}}=0$ & 17.845 & 0.024 \\
\hline
\end{tabular}

From the weak exogeneity tests it is inferred that scrap prices cannot be used to forecast primary prices in the long run. For this to be the case in the short run as well, the primary prices must also be strongly exogenous and, hence, not be affected by the short run movements in the 
scrap prices. Table 10 shows that primary prices are strongly exogenous in the case of lead, since in addition to long run primary price leadership, short run changes in scrap prices do not "Granger cause" short run changes in primary prices. In the case of zinc, primary prices are "Granger caused" by scrap zinc prices. In addition, short run changes in primary prices cannot be used in forecasting short run changes in scrap zinc prices. Therefore in the short run scrap zinc prices lead primary zinc prices. In the case of copper, the Granger causality results show that even though there is information spillover in the short run from the new scrap market to the primary market, the prediction of short run changes in primary copper prices is not improved by adding lags of short run scrap price changes. Additionally, the results indicate that primary prices "Granger cause" new scrap prices in the short run. However, they do not "Granger cause" old scrap price changes; the prediction of old scrap prices is improved by including new scrap price information.

Table 10. Granger Causality Tests by Metal

\begin{tabular}{|c|c|c|c|c|}
\hline System & Ho & Chi-sq & df & Probability \\
\hline \multirow{7}{*}{ Copper } & $\Delta(\mathrm{PS} 1 \mathrm{C}) \neq \rightarrow \Delta(\mathrm{PPC})$ & 3.613 & 2 & 0.164 \\
\hline & $\Delta(\mathrm{PS} 2 \mathrm{C}) \neq \rightarrow \Delta(\mathrm{PPC})$ & 0.798 & 2 & 0.671 \\
\hline & $\Delta(\mathrm{PS} 1 \mathrm{C}), \Delta(\mathrm{PS} 2 \mathrm{C}) \neq \rightarrow \Delta(\mathrm{PPC})$ & 5.901 & 4 & 0.207 \\
\hline & $\Delta(\mathrm{PPC}) \neq \rightarrow \Delta(\mathrm{PS} 1 \mathrm{C})$ & 17.467 & 2 & 0.000 \\
\hline & $\Delta(\mathrm{PPC}) \neq \rightarrow \Delta(\mathrm{PS} 2 \mathrm{C})$ & 0.627 & 2 & 0.731 \\
\hline & $\Delta(\mathrm{PS} 1 \mathrm{C}) \neq \rightarrow \Delta(\mathrm{PS} 2 \mathrm{C})$ & 19.826 & 2 & 0.000 \\
\hline & $\Delta(\mathrm{PS} 2 \mathrm{C}) \neq \rightarrow \Delta(\mathrm{PS} 1 \mathrm{C})$ & 4.165 & 2 & 0.125 \\
\hline \multirow{2}{*}{ Lead } & $\Delta(\mathrm{PSL}) \neq \rightarrow \Delta(\mathrm{PPL})$ & 0.049 & 1 & 0.825 \\
\hline & $\Delta(\mathrm{PPL}) \neq \rightarrow \Delta(\mathrm{PSL})$ & 13.700 & 1 & 0.000 \\
\hline \multirow{2}{*}{ Zinc } & $\Delta(\mathrm{PSZ}) \neq \rightarrow \Delta(\mathrm{PPZ})$ & 4.635 & 1 & 0.031 \\
\hline & $\Delta(\mathrm{PPZ}) \neq \rightarrow \Delta(\mathrm{PSZ})$ & 0.527 & 1 & 0.468 \\
\hline
\end{tabular}

$\neq \rightarrow$ denotes does not Granger cause. The test procedure is based on the VECM estimated models 


\section{IV. d. Volatility Transmission}

Autoregressive conditional residual heteroskedasticity was established in table 5 only for copper and lead. Volatility transmission over time and between primary and scrap prices is captured though the MGARCH volatility representation produced by the residuals of the VECM models. Since there is no autoregressive conditional heteroskedasticity in the residuals of zinc prices, information spillover within and between the primary and scrap markets is captured only in terms of price levels and not through volatility spillovers. All the parameters of the bivariate GARCH model for zinc were insignificant with the exception of the constant which would correspond to its unconditional volatility. ${ }^{9}$

The MGARCH model results for copper and lead are presented in table 11. The presence of autoregressive conditional heteroskedasticity in lead and copper prices is confirmed by the significance of the estimated parameters. The estimated coefficients quantify the effects of the lagged own and cross innovations (ARCH elements indicating the effect of past shocks) and the lagged own and cross volatility persistence (GARCH elements indicating the effect of past volatility) on the conditional volatility of primary and scrap prices. In the case of copper, 78 percent (14 out of 18) of the estimated ARCH coefficients and 61 percent (11 out of 18) of the estimated GARCH coefficients were statistically significant. In the case of lead, 33 percent (2 out of 6 ) of the estimated ARCH coefficients and 100 percent (6 out of 6 ) of the estimated GARCH coefficients were statistically significant.

Strong own ARCH effects are present mostly in the primary markets. Own lagged volatility effects are significant in explaining both primary and scrap price volatility. The only exception is old copper scrap prices, where own instability information comes from past own innovation influences and not from lagged volatility effects.

\footnotetext{
${ }^{9}$ The results are not presented because they do not provide any further information.
} 
Table 11. Multivariate GARCH Models By Metal

\begin{tabular}{|c|c|c|c|c|c|c|}
\hline \multicolumn{4}{|c|}{ Copper } & \multicolumn{3}{|c|}{ Lead } \\
\hline & $\mathrm{h}_{\mathrm{PP}, \mathrm{t}}$ & $\mathrm{h}_{\mathrm{S} 1 \mathrm{~S} 1, \mathrm{t}}$ & $\mathrm{h}_{\mathrm{S} 2 \mathrm{~S} 2, \mathrm{t}}$ & & $\mathrm{h}_{\mathrm{PP}, \mathrm{t}}$ & hss, $t$ \\
\hline \multirow[t]{2}{*}{$\mathrm{c}$} & 0 & 0.001 & 0.001 & $\mathrm{c}$ & 0 & 0 \\
\hline & $(1.151)$ & $(2.999)^{* * *}$ & $(2.048)^{* *}$ & & $(0.757)$ & $(1.530)^{*}$ \\
\hline \multirow[t]{2}{*}{$\varepsilon_{\mathrm{P}, \mathrm{t}-1}^{2}$} & 0.118 & 0.136 & 0.19 & $\varepsilon_{\mathrm{P}, \mathrm{t}-1}^{2}$ & 0.187 & 0.011 \\
\hline & $(1.665)^{* *}$ & $(1.644)^{* *}$ & $(1.395)^{*}$ & & $(2.786)^{* * *}$ & $(0.42)$ \\
\hline \multirow[t]{2}{*}{$\varepsilon_{\mathrm{P}, \mathrm{t}-1} \varepsilon_{\mathrm{S} 1}, \mathrm{t}-1$} & -0.462 & 0.15 & 0.27 & $\varepsilon_{\mathrm{P}, \mathrm{t}-1} \varepsilon_{\mathrm{S}, \mathrm{t}-1}$ & -0.036 & 0.022 \\
\hline & $(-2.004)^{* *}$ & $(0.961)$ & $(1.733)^{* *}$ & & $(-1.418)^{*}$ & $(0.909)$ \\
\hline \multirow[t]{2}{*}{$\varepsilon_{\mathrm{S} 1, \mathrm{t}-1}^{2}$} & 0.452 & 0.041 & 0.096 & $\varepsilon_{S}^{2}, t-1$ & 0.002 & 0.011 \\
\hline & $(1.958)^{* *}$ & $(0.507)$ & $(0.961)$ & & $(0.679)$ & $(0.995)$ \\
\hline \multirow[t]{2}{*}{$\varepsilon_{\mathrm{S} 2, \mathrm{t}-1}^{2}$} & 0.248 & 0.258 & 0.498 & & - & - \\
\hline & $(2.641)^{* * *}$ & $(1.720)^{* *}$ & $(4.174)^{* * *}$ & & & \\
\hline \multirow[t]{2}{*}{$\varepsilon_{\mathrm{P}, \mathrm{t}-1} \varepsilon_{\mathrm{S} 2}, \mathrm{t}-1$} & 0.342 & -0.375 & -0.615 & & - & - \\
\hline & $(2.927)^{* * *}$ & $(-1.988)^{* *}$ & $(-2.263)^{* *}$ & & & \\
\hline \multirow[t]{2}{*}{$\varepsilon_{\mathrm{S} 1}, \mathrm{t}-1 \varepsilon_{\mathrm{S} 2}, \mathrm{t}-1$} & -0.669 & -0.207 & -0.438 & & - & - \\
\hline & $(-2.487)^{* * *}$ & $(-0.815)$ & $(-1.747)^{* *}$ & & & \\
\hline \multirow[t]{2}{*}{$\mathrm{h}_{\mathrm{PP}, \mathrm{t}-1}$} & 0.593 & 0.004 & 0.069 & $\mathrm{~h}_{\mathrm{PP}, \mathrm{t}-1}$ & 0.812 & 0.024 \\
\hline & $(2.8409)^{* * *}$ & $(0.397)$ & $(1.619)^{*}$ & & $(38.796)^{* * *}$ & $(1.741)^{* *}$ \\
\hline \multirow[t]{2}{*}{$\mathrm{h}_{\mathrm{S} 1 \mathrm{P}, \mathrm{t}-1}$} & 1.81 & 0.189 & 0.379 & $\mathrm{~h}_{\mathrm{SP}, \mathrm{t}-1}$ & 0.106 & -0.308 \\
\hline & $(13.689)^{* * *}$ & $(0.792)$ & $(2.619)^{* * *}$ & & $(4.576)^{* * *}$ & $(-3.331)^{* * *}$ \\
\hline \multirow[t]{2}{*}{$\mathrm{h}_{\mathrm{S} 1 \mathrm{~S} 1, \mathrm{t}-1}$} & 1.38 & 2.292 & 0.521 & $\mathrm{~h}_{\mathrm{SS} \mathrm{t}-1}$ & 0.003 & 0.98 \\
\hline & $(2.503)^{* * *}$ & $(27.018)^{* * *}$ & $(3.305)^{* * *}$ & & $(2.214)^{* *}$ & $(28.796)^{* * *}$ \\
\hline \multirow[t]{2}{*}{$\mathrm{h}_{\mathrm{S} 2 \mathrm{~S} 2, \mathrm{t}-1}$} & 1.014 & 0.605 & 0 & & - & - \\
\hline & $(4.242)^{* * *}$ & $(10.126)^{* * *}$ & $(0.047)$ & & & \\
\hline \multirow[t]{2}{*}{$\mathrm{h}_{\mathrm{S} 2 \mathrm{P}, \mathrm{t}-1}$} & -1.552 & -0.097 & -0.004 & & - & - \\
\hline & $(-9.586)^{* * *}$ & $(-0.769)$ & $(-0.092)$ & & & \\
\hline \multirow[t]{2}{*}{$\mathrm{h}_{\mathrm{S} 2 \mathrm{~S} 1, \mathrm{t}-1}$} & -2.366 & -2.354 & -0.012 & & - & - \\
\hline & $(-3.187)^{* * *}$ & $(-16.314)^{* * *}$ & $(-0.092)$ & & & \\
\hline $\begin{array}{l}\text { Volatility } \\
\text { Persistence }\end{array}$ & 0.908 & 0.643 & 0.955 & $\begin{array}{l}\text { Volatility } \\
\text { Persistence }\end{array}$ & 1.074 & 0.741 \\
\hline Log Likelihood & & 1348.3 & & Log Likelihood & & \\
\hline
\end{tabular}

Since the coefficients are nonlinear functions of the BEKK parameters the standard deviations are estimated based on a Taylor Series approximation around the mean (Greene, 2000). Additionally, because of the large sample approximation z-statistics are reported in parentheses. Asterisks indicate significance at $*_{--} 0.10, *_{-} *_{-} 0 . .05, *^{*} *_{--} 0.01$ level. 
Spillover effects are significant both in terms of past innovation spillovers and past volatility spillovers. They are exhibited both directly and indirectly, i.e. in terms of direct volatility and innovation influences and co-volatility and co-innovations affects, respectively. The indirect influence is larger than the direct influence of primary to scrap prices, especially in GARCH terms. For copper, the direct and indirect information spillover in the primary market from the scrap markets are of relatively similar importance. In the case of lead, volatility spillover comes mostly indirectly, both for scrap and primary prices.

In the copper market, the coefficients of volatility spillover in terms of past variance and covariance from the scrap to the primary market are substantial, ranging from1.08 $\left(\mathrm{h}_{\mathrm{s} 2 \mathrm{~s} 2}\right)$ to -0.36 $\left(h_{\mathrm{S} 2 \mathrm{~s} 1}\right)$. The GARCH spillovers of primary to scrap prices range from $0.004\left(\mathrm{~h}_{\mathrm{PP}}\right.$ on $\left.\mathrm{h}_{\mathrm{S1S1}}\right)$ to 0.37 $\left(h_{\mathrm{s} 1 \mathrm{P}}\right.$ on $\left.h_{\mathrm{s} 2 \mathrm{~s} 2}\right)$. Volatility spillover from primary to scrap prices is higher in terms of innovations, ranging from $0.136\left(\varepsilon_{\mathrm{p}}^{2}\right.$ on $\left.\mathrm{h}_{\mathrm{s} 1 \mathrm{~s} 1}\right)$ to $0.615\left(\varepsilon_{\mathrm{p}} \varepsilon_{\mathrm{s} 2}\right.$ on $\left.\mathrm{h}_{\mathrm{s} 2 \mathrm{~s} 2}\right)$. However, the ARCH effects of scrap on primary copper volatility are again more considerable, extending from $0.25\left(\varepsilon_{\mathrm{S} 2}^{2}\right)$ to $0.67\left(\varepsilon_{\mathrm{S} 1} \varepsilon_{\mathrm{s} 2}\right)$. Old and new scrap covariance spillover is substantial in the new scrap volatility as well. In the lead market, transmission of shocks passes from the scrap to the primary market; coinnovations have only a small effect on primary volatility. GARCH spillovers, exhibited though covariances, are more significant: 0.11 in the primary market and 0.31 in the scrap market.

Measuring both positive and negative spillovers by summation of the absolute spillover coefficients, 91 percent of primary copper volatility movements comes from scrap price spillovers, while 87 percent of primary lead volatility is explained by its own past volatility. Spillovers from the primary market explain 27 percent of lead scrap price volatility. In the case of new copper scrap, spillover accounts for 65 percent of volatility, of which only 11 percent comes from primary market information and another 11 percent comes from primary and old 
scrap price comovements. Old copper volatility exhibits a higher degree of influence from the market at 83 percent of which 33 percent comes from primary price influences, 41 percent comes from new scrap price influences and 25 percent comes from primary and new scrap price comovements.

Table 11 also includes estimates of the volatility persistence for primary and scrap prices. Volatility persistence is measured by adding up the coefficients in each volatility equation. This provides information about the importance of past shocks and volatility in the formation of future conditional variance. The smaller the persistence, the faster the volatility returns to its unconditional variance. No persistence, as in the case of zinc, means that the long-run (unconditional) variance of the series constitutes the forecasts of future volatility.

The results show that the effects of shocks are more persistent in the case of primary prices relative to the case of new scrap prices, but less persistent relative to old scrap prices. For lead, volatility is not only more persistent in primary prices relative to scrap prices, but in the case of primary lead, it is equal to one. This means that primary lead has an integrated GARCH (IGARCH) process, which implies that the volatility of a series is permanently affected by shocks and the unconditional volatility is infinite. To formally test nonstationarity of the lead volatility system, the eigenvalues of the estimated $A \otimes A+G \otimes G$ are computed. Table 12 shows that one eigenvalue is greater than unity: thus, the system is weakly non-stationary. Nelson (1990), however, notes that strict stationarity exists, and thus the IGARCH can be estimated like any other GARCH model. 
Table 12. Weak Stationarity Test for the Lead Volatility Model

\begin{tabular}{lrr}
\hline \multicolumn{3}{c}{$\begin{array}{c}\text { Moduli of Eigenvalues } \\
\text { for } \mathrm{A} \otimes \mathrm{A}+\mathrm{G} \otimes \mathrm{G}\end{array}$} \\
\hline$\lambda 1$ & & 1.0059 \\
$\lambda 2$ & & $0.9543+0.8797 \mathrm{i}$ \\
$\lambda 3$ & & $0.9543-0.8797 \mathrm{i}$ \\
$\lambda 4$ & & 0.9513 \\
\hline
\end{tabular}

\section{Conclusions}

This investigation empirically assessed the direction of influence between primary and scrap prices in terms of both levels and volatility. The first result is that primary and scrap prices hold a long run relationship and cannot wander arbitrarily far away from each other. In the long run, primary prices are found to be weakly exogenous. This means that scrap prices do not aid in long run primary price forecasting. In the cases of lead and zinc, the results also imply that scrap prices follow primary prices. Since the fundamentals of primary markets direct the market, this implication is in accordance with the demand pull theory. For copper, exogeneity of the primary price does not suffice for it to lead the market since old scrap prices are weakly exogenous as well; the copper market is driven by both primary and secondary components.

The fact that scrap prices hold a long run relationship to primary prices also implies that unusual short run interactions between scrap and primary prices are only transitory. This implication is significant in combination with the fact that the rate of adjustment of scrap prices to their long run relationship with primary prices is relatively slow: short run conditions can persist and create misguiding signals for market participants. The impressive rise of prices in the period of 1994 to 1995 and the spikes of 1995 that occurred in all recycled material markets led to many hopeful investments in the recycling business. The optimism created by these market movements was deceptive and led to many bankruptcies (Ackerman and Gallagher, 2002) as 
recycled material prices eventually return to their co-integrating relationship to primary prices. Decisions for investments in recycling should be based on the long run role of recycled materials in the primary markets, not on temporary phenomena.

Short run price spillovers were evaluated as well. The results indicate that short run effects are not necessarily the same as long run influences. Although short run primary lead price changes "Granger cause" scrap price changes, price spillovers in the zinc market are contradirectional. Information spillovers in the short run copper market are directed from the primary to the new and old scrap market and from the new scrap market to the primary market. However, short run Granger causality holds only from primary to new scrap prices and from new scrap prices to old scrap prices. Additionally, since price spillovers are not statistically important over one lag, the results show that information assimilation is rapid in both the primary and scrap prices.

These results show that the direction of price spillovers is unrelated to the recycling rate in the market. Prices of scrap zinc, which provides only 25 percent of apparent zinc supply, lead primary prices in the short run, whereas prices of scrap lead, which constitutes 70 percent of apparent lead supply, is "Granger caused" by primary lead prices. That scrap prices may lead short run primary prices does not signify that scrap metal is the primary force in the market. In the case of zinc, for example, recycling constitutes only a very small portion of the market. A phenomenon of scrap prices leading primary prices could imply that secondary prices are more sensitive to changes in the market, capture these influences earlier than primary prices, and later transmit this information to the primary market which in turn reacts with primary price changes.

Interactions between primary and scrap prices were found to differ in the three markets examined. Although the results for some markets support the assumption of price spillovers only 
from the primary to the scrap market (an assumption used in many past studies of primary and scrap price interactions), the results obtained indicate that such an assumption a priori would lead to substantial information loss.

Past studies of primary and scrap interrelations have assumed that market signals are transmitted only through prices and ignored volatility influences (Ross, 1989). This analysis shows that information transmission between primary and scrap markets occurs in terms of both prices and volatility spillovers in the cases of copper and lead. In the zinc market, information spillover within and between the primary and scrap markets is captured only in terms of price levels spillovers.

Volatility spillovers are exhibited both directly and indirectly, i.e. in terms of direct volatility and innovation influences and covolatility and coinnovations affects, respectively. The indirect influence is larger than the direct influence of primary to scrap prices, especially in terms of past covariance. Additionally, information comes from both past innovation spillovers and past volatility spillovers. However, there is a distinct pattern in the time it takes for shocks in the primary market to pass to the scrap market. In the copper market, a specific shock in the primary market increases the scrap market volatilities through ARCH spillovers; therefore the rate of transmission is rapid. In the lead market, an unanticipated event in the primary market does not have a significant effect on the scrap market; however, as the volatility in the primary market increases because of the anticipated event, this increase in volatility is later transmitted to scrap prices. Moreover, with the exception of old copper scrap, the study finds volatility persistence to be higher for primary than for scrap markets.

In the copper market, volatility and shock spillovers from the scrap to the primary prices is higher than the spillovers that flow from the primary to the scrap prices. For lead, volatility 
spillovers explain the conditional volatility of prices to a lower degree, but the pattern and degree of spillovers is more uniform between the primary and the scrap markets. The findings on volatility transmission also suggest that when taking into account both first and second price moments, information transmission is bidirectional - price influences are experienced from the primary to the secondary market, as well as from the secondary to the primary market even when transmission is unidirectional in terms of price levels. In other words, any change affecting the primary or scrap market sets in motion reactions in both primary and secondary components of the metal market. These results are especially important when one considers that the rate of transmission of information to a market is primarily indicated by the volatility of its price (Ross, 1989).

Finally, given that modeling time-varying volatility can produce more accurate price forecasts, incorporating volatility links between primary and scrap prices could provide significant information for anticipating primary and secondary price changes in the cases where volatility transmission is substantial. As an example, around ninety percent of primary copper price volatility is explained by volatility in the scrap market which means that primary copper market participants can benefit from following what is happening in the scrap market. 


\section{References}

Ackerman, F. and K. Gallagher. 2002. Mixed Signals: Market Incentives, Recycling, and the Price Spike of 1995. Resources, Conservation and Recycling 35:275-295.

Adrangi, B., A. Chatrath, K. Raffiee, and R.D. Ripple. 2001. Alaska North Slope Crude Oil Price and the Behaviour of Diesel Prices in California. Energy Economics 23:29-42.

Asche, F., O. Gjolberg, and T. Völker. 2003. Price Relationships in the Petroleum Market. An Analysis of Crude Oil and Refined Product Prices. Energy Economics 25:289-301.

Bauwens, L., S. Laurent, and J. Rombouts. 2003. Multivariate GARCH Models: A Survey. CORE Discussion Paper No. 2003/31. Louvain-La-Neuve, Belgium.

Brown, M.S. and J. Butler. 1968. The Production, Marketing and Consumption of Copper and Aluminum. The Economist Intelligence Unit :160-164.

Chan, K., K.C. Chan, and G.A. Karolyi. 1991. Intraday Volatility in the Stock Index and Stock Index Futures Markets. The Review of Financial Studies 4(4):657-684.

Dickey, D.A. and W.A. Fuller. 1981. Likelihood Ratio Statistics for Autoregressive Time Series with a Unit Root. Econometrica (49):1057-1072.

Edgren J.A. and K.W. Moreland. 1990. An Econometric Analysis of Paper and Wastepaper Markets. Resources and Energy 11(3):299-319.

Edwards, J. and P. Robbins. 1979. Guide to Non-Ferrous Metals and their Markets. New York: Kogan Page, London: Nichols Publishing Company.

Engle, R.F. 1982. Autoregressive Conditional Heteroskedasticity with Estimates of the Variance of U.K. Inflation. Econometrica 50:987-1008.

Engle, R.F. and C.W.J. Granger. 1987. Co-integration and Error Correction: Representation, Estimation, and Testing. Econometrica, 55:251-276. 
Engle, R.F. and F.K. Kroner. 1995. Multivariate Simultaneous Generalized ARCH. Econometric Theory 11:122-150.

Engle, R.F., T. Ito, and W.L. Lin. 1990. Meteor Showers or Heat Waves? Heteroskedastic IntraDaily Volatility in the Foreign Exchange Market. Econometrica 58:525-542.

Eviews (version 5.1). 2005. Irvire, CA: Quantitative Micro Software.

Ewing, B.T., F. Malik, and O. Ozfidan. 2002. Volatility Transmission in the Oil and Natural Gas Markets. Energy Economics 24(6):525-538.

Figuerola-Ferretti, I. and C.L. Gilbert. 2001. Price Variability and Marketing Method in Nonferrous Metals: Slade's Analysis Revisited. Resources Policy 27(3):169-177.

Fisher, L.A. and A.D. Owen. 1981. An Econometric Model of the US Aluminum Market. Resources Policy 7(3):150-160.

Girma, P., and A. Paulson. 1999. Risk Arbitrage Opportunities in Petroleum Futures Spreads. Journal of Future Markets 19, 931-955.

Gjolberg, O., and T. Johnsen. 1999. Risk Management in the Oil Industry: Can Information on Long-run Equilibrium Prices Be Utilized? Energy Economics 21:517-527.

Goodwin, B.K., T.J. Grennes, and M.K. Wohlgenannt. 1990. A Revised Test of the Law of One Price Using Rational Price Expectations. American Journal of Agricultural Economics 72:682-693.

Granger, C.W.J. 1969. Investigating Causal Relations by Econometric Models and CrossSpectral Methods. Econometrica 37:424-438.

Greene, W.H., 2000. Econometric Analysis. Englewood Cliffs, NJ: Prentice-Hall, Inc.

Hashimoto, H. 1983. Modeling Price Fluctuations of Ferrous Scrap. Resources Policy 9(2):122139. 
Johansen, S. 1995. Likelihood-based Inference in Cointegrated Vector Autoregressive Models. Oxford: Oxford University Press. .1991. Estimation and Hypothesis Testing of Cointegration Vectors in Gaussian Vector Autoregressive Models. Econometrica 59:1551-1580.

Johansen, S. and K. Juselius. 1990. Maximum Likelihood Estimation and Inference on Cointegration- with Applications to the Demand for Money. Oxford Bulletin of Economics and Statistics 52:169-210.

Karolyi G.A. 1995. A Multivariate GARCH Model of International Transmission of Stock Returns and Volatility: The Case of the United States and Canada. Journal of Business and Economic Statistics 13:11-25.

Kearney C. and A.J. Patton. 2000. Multivariate GARCH Modeling of Exchange Rate Volatility Transmission in the European Monetary System. Financial Review 41:29-48.

Labys, W.C. 1980. Modelling Disequilibrium Dynamics and Adjustment Processes in the Copper Industry. Department Working Paper No. 14. Morgantown, WV: Department of Mineral and Energy Economics, West Virginia University. Photocopied.

Labys, W.C. and M. Kaboudan. 1980. A Short Run Disequilibrium Model of the Copper Market. Department Working Paper No. 16. Morgantown, WV: Department of Mineral and Energy Economics, West Virginia University. Photocopied.

Labys, W.C., J.B. Lesourd, and D. Badillo. 1998. The Existence of Metal Price Cycles. Resources Policy 24(3):147-155.

Labys, W. C., H. B. Rees, and C. M. Elliott. 1971. Copper Price Behavior and the London Metal Exchange. Applied Economics 3:99-113. 
Lanza, A., M. Manera, and M. Giovannini. 2005. Modeling and Forecasting Cointegrated Relationships among Heavy Oil and Product Prices. Energy Economics 27(6):831-848.

MacKinnon, J.G. 1996. Numerical Distribution Functions for Unit Root and Cointegration Tests. Journal of Applied Econometrics 11:601-618.

MacKinnon, J.G., A.A. Haug, and L. Michelis. 1999. Numerical Distribution Functions of Likelihood Ratio Tests for Cointegration. Journal of Applied Econometrics 14:563-577.

Matlab (version 6.5). 2002. Natick, MA: The Mathworks.

American Metal Market. 1984-2003. Metal Statistics. New York: American Metal Market.

Metals Today. 1965. Zurich: Economic Research Department, Union Bank of Switzerland. Bulletin 314:17

Meyer, J and Stephan von Cramon-Taubadel. 2004. Asymmetric Price Transmission: A Survey. Journal of Agricultural Economics 55(3):581-611.

Nelson, D.B. 1990. Stationarity and Persistence in the GARCH $(1,1)$ Model. Econometric Theory 6:318-334

Phillips, P.C.B. and P. Perron. 1988. Testing for a Unit Root in Time Series Regression. Biometrika 75:335-346.

Rezitis, A. 2003. Volatility Spillover Effects in Greek Consumer Meat Prices. Agricultural Economics Review 4(1):29-36.

Ross, S. 1989. Information and Volatility: the No-Arbitrage Martingale Approach to Timing and Resolution Irrelevancy. Journal of Finance 44:1-17.

Serletis, A. 1994. An Integration Analysis of Petroleum Futures Prices. Energy Economics 16:93-97. 
Slade, M.E. 1980. An Econometric Model of the US Secondary Copper Industry: Recycling Versus Disposal. Journal of Environmental Economics and Management 7:123-141.

Stollery, K.R. 1983. Secondary Supply of Copper and Ferrous Metals and Canadian Metal Markets. Technical Paper No. 3. Kingston, Ontario: Center for Resource Policies, Queens University.

Taylor, C.A. 1979. A Quarterly Domestic Copper Industry Model. The Review of Economics and Statistics 61(3):410-422.

Commodity Research Bureau. 1984-2003. The CRB Commodity Yearbook. Chicago: Commodity Research Bureau.

Tilton, J. and A.W. Vogely. 1981. Market Instability in the Metal Industries. Special Issue of Materials and Society 5(3).

UCSD GARCH Toolbox for Matlab. 2004. Sheppard, K. K.<http://www.kevinsheppard.com/ research/ucsd_garch/ucsd_garch.aspx> (February 10, 2005).

USGS. 2002. Recycling-Metals; Minerals Yearbook. Washington D.C: US Geological Survey, US Department of Interior.

USGS. 2003. Recycling-Metals; Minerals Yearbook. Washington D.C: US Geological Survey, US Department of Interior.

Van Beukering P. and M.N. Bouman. 2001. Empirical Evidence on Recycling and Trade of Paper and Lead in Developed and Developing Countries. World Development 29(10):1717-1737.

Weaver, R. and W. Natcher. 2000. Has Market Reform Exposed Farmers to Greater Price Volatility? State College, PA: Farm Economics, Cooparative Extension Service, U.S. Department of Agriculture, The Penn State University. 


\title{
CHAPTER 4: ESSAY 3 \\ Time-Varying Ratios of Primary and Scrap Metal Prices: \\ The Importance of Inventories
}

\begin{abstract}
Although metal markets are subject to short run disequilibria and metal prices follow an adjustment mechanism over time, the links between primary and scrap metal prices have been assumed constant. This study explores potential primary and scrap price relationships using time series methodology applied to aluminum, copper, lead, and zinc prices for the period 1984-2000. The results show that even though a long run equilibrium between primary and scrap prices exists, persistent short run dynamics lead to unstable relationships in the short run. The short run relationships between primary and scrap prices, expressed through the ratios of primary and scrap prices, are stronger in some periods than others. A model which relates the ratio of primary and scrap prices to levels of primary metal stocks is proposed and evaluated. The model shows that inventories are positively related to the ratios of primary to scrap prices and provides a key to understanding the adjustment mechanisms between scrap and primary prices.
\end{abstract}




\section{Introduction}

Recycled materials act both as inputs into the production of and as substitutes for refined primary materials. As a consequence, fluctuations in demand and supply in the recycled material markets both influence and are influenced by the primary material markets. These links are evident in terms of prices which express the market information available at every point in time.

In the seventies and eighties, many studies examined links between primary and scrap metal fundamentals, including prices, through structural modeling. Fisher and Owen (1981) expressed explicit structural relationships for scrap and primary aluminium and indicated a connection between primary and scrap prices. Employing a traditional structural analysis, Hashimoto (1983) argued that steel price fluctuations and co-movements of primary and scrap steel prices are due to the industry's inherent inelasticities and its sensitivity to the business cycle. Stollery (1983) modeled the demand and supply relationships between scrap, primary input, and primary output for copper and steel. His empirical model of copper showed that the scrap price varies in direct proportion to the primary London Metal Exchange (LME) price.

Although some studies found intertemporal linkages between primary and scrap prices, they assumed that the relationship was stable. The majority of studies examining primary and scrap price links have been based on the concept of rapid market clearing. To the contrary, metal markets are known to be inelastic in the short run and to follow flow and stock adjustment processes towards equilibrium. As a consequence, disequilibrium between primary and scrap prices has, to a great extent, been overlooked in the literature. It has been acknowledged only in Stollery's (1983) and Taylor's (1979) studies of the difference between primary and scrap copper prices - mostly as an investigation of the refiner's margin - and in the annual studies of copper 
recycling from USGS $^{1}$ which also include an examination of the difference between primary and scrap copper prices.

Understanding the changing character of primary and scrap price links is very important, not only for those involved in the recycling sector but for those involved with the primary metal market since greater than 50 percent of the industry's supply comes from recycling (USGS, 2000). This study revives the interest in primary and scrap market links and shows, through time series methods, that the relationship between primary and scrap prices is not constant over time but dependent upon market forces.

The study shows that primary and scrap prices hold a long run equilibrium relationship, but that their short run interaction is unstable. This information should be invaluable to metal products manufacturers as well as to dealers in scrap metal because their optimal long run and short run choices are often different. The changing relationship of the spread between primary and scrap prices is described in terms of their price ratios. Price ratios reflect both equilibrium and disequilibrium adjustments and are closely related to price differences ${ }^{2}$ which have provided the only reference to short run disequilibrium between primary and scrap prices in past studies. Price ratios vary over time but the price ratio series are mean-reverting in many cases. The mean reversion of primary to scrap price ratios is important for scrap metal markets since it implies that policies which try to promote recycling through price manipulations may be able to decrease the spread between primary and scrap prices in the short term but may not lead to sustainable results.

In addition, the analysis demonstrates that price ratio fluctuations are related to market conditions and to the physical availability of metal in the market as reflected in inventory levels.

\footnotetext{
${ }^{1}$ Multiple years.

${ }^{2}$ For example $P S-a P P=0$ is identical to $P S / P P=a$.
} 
Thus, increasing the role of scrap in metal markets through technological improvements and higher market integration could have a stronger impact on scrap demand and supply than pricebased policies. The theoretical explanation for the relationship between price ratios and inventories is provided by the production-smoothing incentives of metal producers which lead to tighter connections between primary and scrap prices when inventories are lower than when inventories are higher. In a tight market, the spread between primary and scrap prices becomes smaller. When supply is ample, as indicated by high inventory accumulation, the spread between primary and scrap prices becomes wider. Establishment of this relationship provides market participants with valuable insight into the relative behaviour of the primary and scrap metal sectors by allowing them to anticipate and forecast primary to scrap price spreads.

\section{Primary and Scrap Price Behavior}

\section{II. a. Primary and Scrap Prices}

Four metal markets are analyzed - aluminium, copper, lead, and zinc - utilizing United States average monthly prices for the period of $1984-2000^{3}$. Primary prices represent values for refined metal which can be produced either from primary ore/concentrate or scrap metal. The primary prices used are the producer price of primary aluminum (PPA), the producer price of delivered copper cathode (PPC), the New York delivery prices of the primary producers' pig lead (PPL), and the domestic and foreign producer prices for primary zinc slab delivered in the United States (PPZ) $)^{4}$

Commercial scrap metal can be divided into new and old scrap. New scrap, such as cuttings and turnings, is generated during processing and fabrication of metal products and is

\footnotetext{
${ }^{3}$ The case of aluminum is studied for the period of 1985-2000, and the case of zinc for the period 1984-1996.

${ }^{4}$ PPA and PPC were obtained from the United States Geological Survey specialists P. Plunkert and D.L Edelstein respectively. PPL is published in the Commodity Research Bureau Commodity Yearbook, and PPZ is available in the Metal Statistics publication of the American Metal Market. The length of each time series is determined by data availability and compatibility.
} 
usually denoted as No.1 scrap. It is desirable for its higher quality and for its consistency in terms of content and supply. New scrap prices included in the study are for aluminum clippings (PS1A), for brass mills No. 1 copper scrap (PS1C), and for new zinc clippings (PSZ). Old scrap, usually labelled No. 2 scrap, is metal incorporated in post-consumer products, obsolete manufactured products, or spent materials. Old scrap prices in the study are for old sheet and cast aluminum (PS2A), the producer price for aluminum used beverage can scrap (PS3A), the price for refiners' No.2 copper scrap (PS2C), and the smelters' buying price for heavy soft scrap lead $(\mathrm{PSL})^{5}$.

The primary and scrap prices in each market are presented in figure 1 while table 1 shows their time series characteristics including Phillips and Perron [P-P] (1988) unit root tests that indicate that the price series are integrated of order one, i.e. I(1). Appendix A provides an explanation of the relationship between primary and scrap prices by averaging their mean and volatility over three-year periods. Primary and scrap prices move in the same direction but are not always in correspondence.The degree of variation is higher for scrap prices in terms of coefficients of variation with the exception of aluminium cans and new scrap copper. Primary and scrap prices are interrelated. However, in contrast to past studies which assume instantaneous and simultaneous reactions, this description indicates that the links between primary and secondary prices are not constant over time. The differing degree of price variation for primary and scrap metals is an indication that the short-term primary and secondary price changes are not always synchronous. Both primary and secondary markets adjust to exogenous and endogenous changes with time lags and can be subject to disequilibrium conditions in their

\footnotetext{
${ }^{5}$ The Metal Statistics publication of the American Metal Market is the source for PS1A, PS2A, PSL, and PSZ. We obtained PS1C and PS2C from the United States Geological Survey specialist D.L. Edelstein, and PS3A from the Commodity Research Bureau Commodity Yearbook. The length of each time series is determined by data availability and compatibility.
} 
own market or in relation to each other, at least in the short term. As can be seen in figure 2 , the price ratios of primary and secondary metals show that the relationship between primary and scrap prices is not constant over time.

Table 1. Characteristics of Primary and Scrap Prices by Metal

\begin{tabular}{|c|c|c|c|c|c|c|c|c|c|c|c|}
\hline \multirow[t]{3}{*}{ Characteristic } & \multicolumn{11}{|c|}{ Price Series } \\
\hline & \multicolumn{4}{|c|}{ Aluminum } & \multicolumn{3}{|c|}{ Copper } & \multicolumn{2}{|c|}{ Lead } & \multicolumn{2}{|c|}{ Zinc } \\
\hline & PPA & PS1A & PS2A & PS3A & PPC & PS1C & $\mathrm{PS} 2 \mathrm{C}$ & PPL & PSL & $\mathrm{PPZ}$ & PSZ \\
\hline Mean & 70.66 & 49.74 & 43.45 & 50.30 & 98.43 & 88.80 & 75.02 & 37.96 & 15.61 & 53.58 & 31.30 \\
\hline $\begin{array}{l}\text { Standard } \\
\text { Deviation }\end{array}$ & 16.16 & 13.29 & 12.36 & 11.38 & 24.86 & 22.00 & 19.73 & 9.24 & 4.86 & 13.45 & 10.44 \\
\hline Coef. of Variation & 0.229 & 0.267 & 0.284 & 0.226 & 0.253 & 0.248 & 0.263 & 0.243 & 0.312 & 0.251 & 0.334 \\
\hline Skewness & 1.005 & 0.161 & -0.056 & 0.260 & 0.284 & 0.003 & 0.019 & -0.519 & -0.159 & 0.997 & 0.277 \\
\hline Kurtosis & 4.116 & 2.759 & 2.456 & 2.196 & 2.089 & 1.783 & 1.665 & 2.306 & 2.534 & 3.477 & 2.680 \\
\hline Jarque-Bera (J-B) & 42.26 & 1.29 & 2.47 & 7.34 & 9.80 & 12.60 & 15.16 & 13.24 & 2.70 & 27.32 & 2.66 \\
\hline Probability (J-B) & 0.000 & 0.524 & 0.291 & 0.025 & 0.007 & 0.002 & 0.001 & 0.001 & 0.259 & 0.000 & 0.264 \\
\hline \multicolumn{12}{|c|}{ P-P Unit Root Test } \\
\hline Levels & -2.262 & -2.220 & -2.244 & -2.244 & -2.251 & -2.063 & -2.081 & -1.614 & -2.017 & -1.888 & -1.939 \\
\hline Probability* & 0.186 & 0.200 & 0.192 & 0.192 & 0.189 & 0.260 & 0.253 & 0.474 & 0.280 & 0.337 & 0.314 \\
\hline First Differences & -10.55 & -10.17 & -9.84 & -9.21 & -10.56 & -12.08 & -11.90 & -10.86 & -11.60 & -7.50 & -10.07 \\
\hline Probability* & 0.000 & 0.000 & 0.000 & 0.000 & 0.000 & 0.000 & 0.000 & 0.000 & 0.000 & 0.000 & 0.000 \\
\hline 1\% Critical Value & -3.465 & -3.465 & -3.465 & -3.465 & -3.462 & -3.462 & -3.462 & -3.462 & -3.462 & -3.473 & -3.473 \\
\hline $5 \%$ Critical Value & -2.877 & -2.877 & -2.877 & -2.877 & -2.876 & -2.876 & -2.876 & -2.876 & -2.876 & -2.880 & -2.880 \\
\hline
\end{tabular}

*MacKinnon (1996) one-sided p-values for rejection of hypothesis of a unit root 

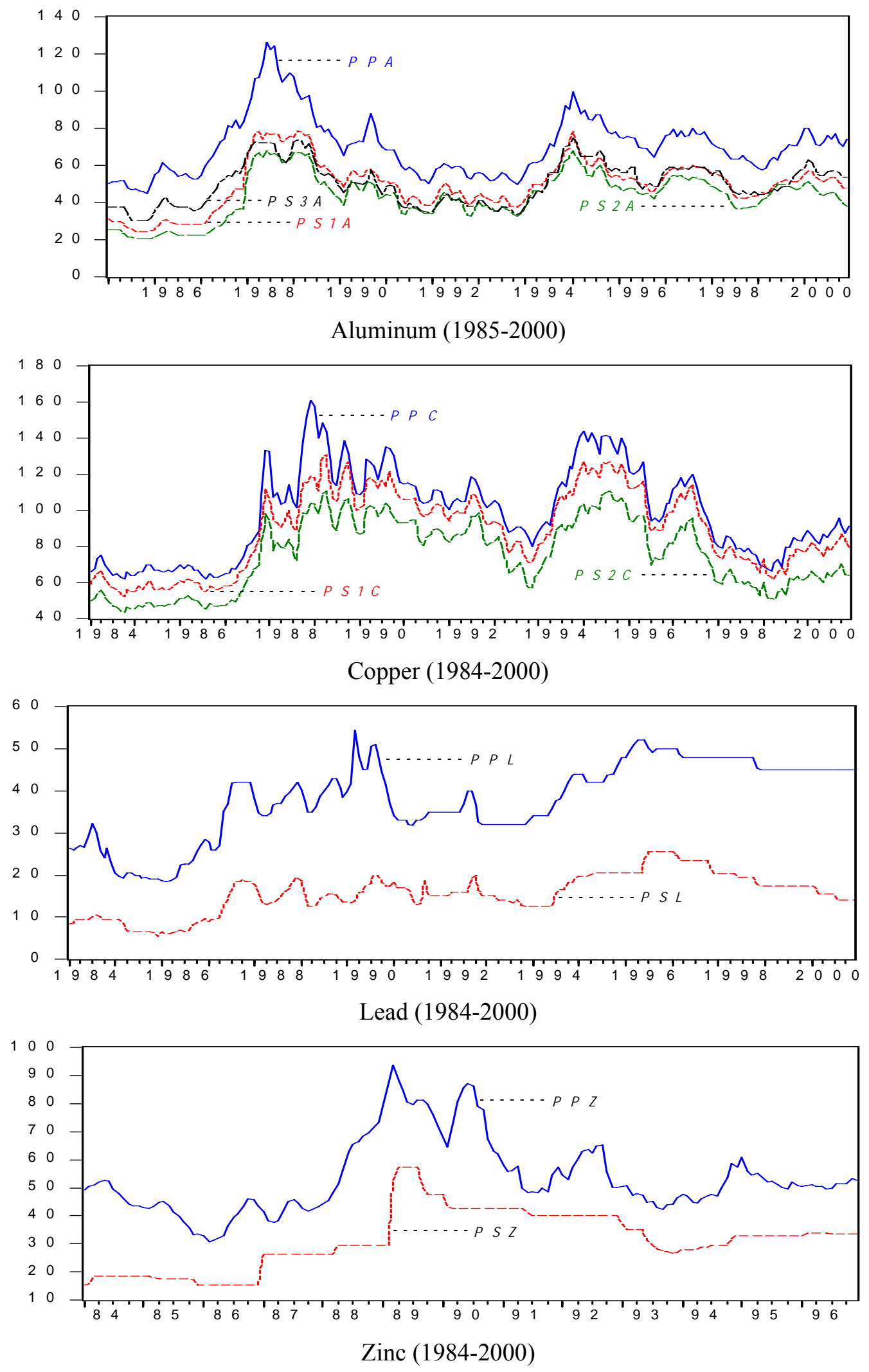

Figure 1. Primary and Scrap Price Series by Metal 

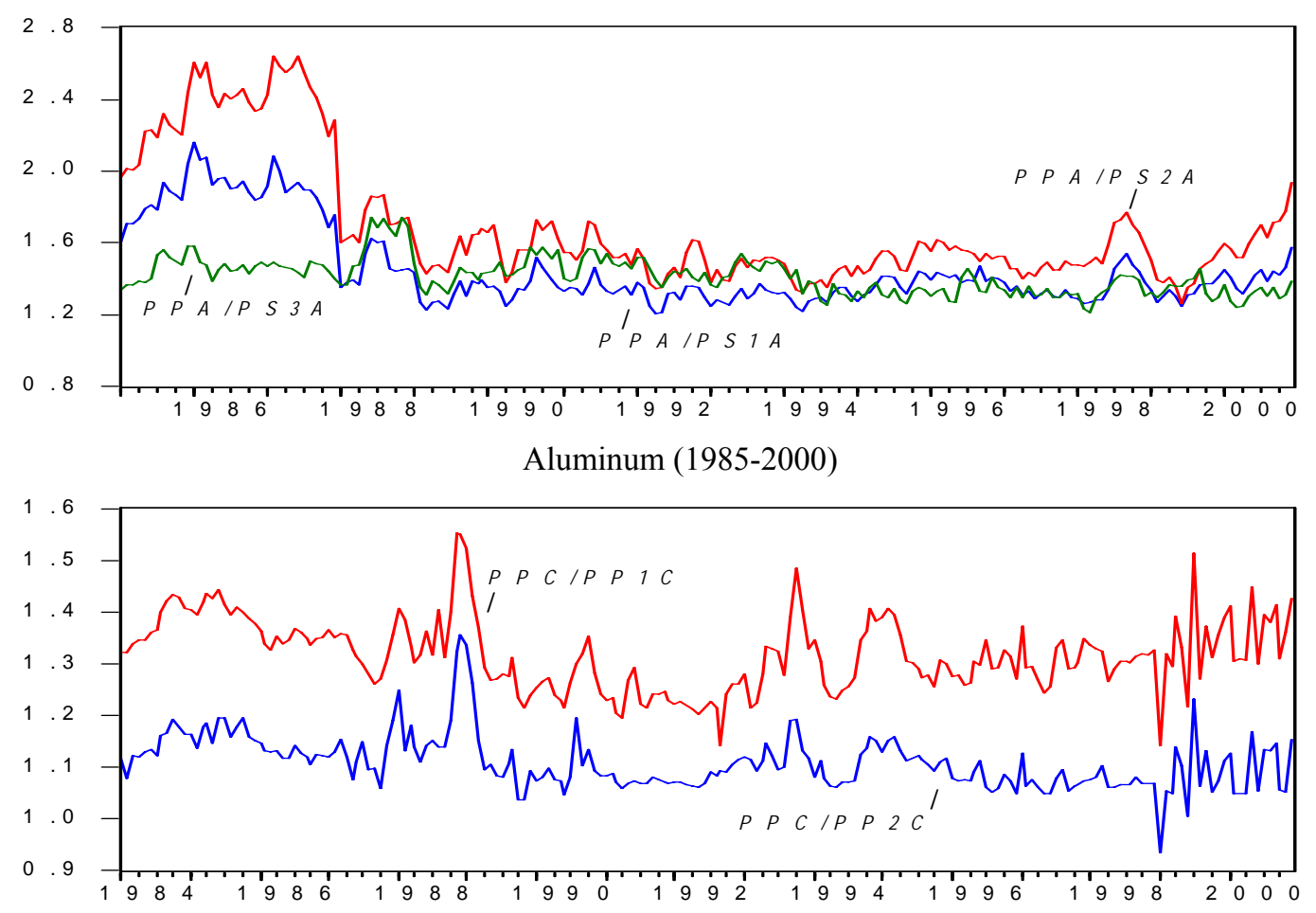

Copper (1984-2000)
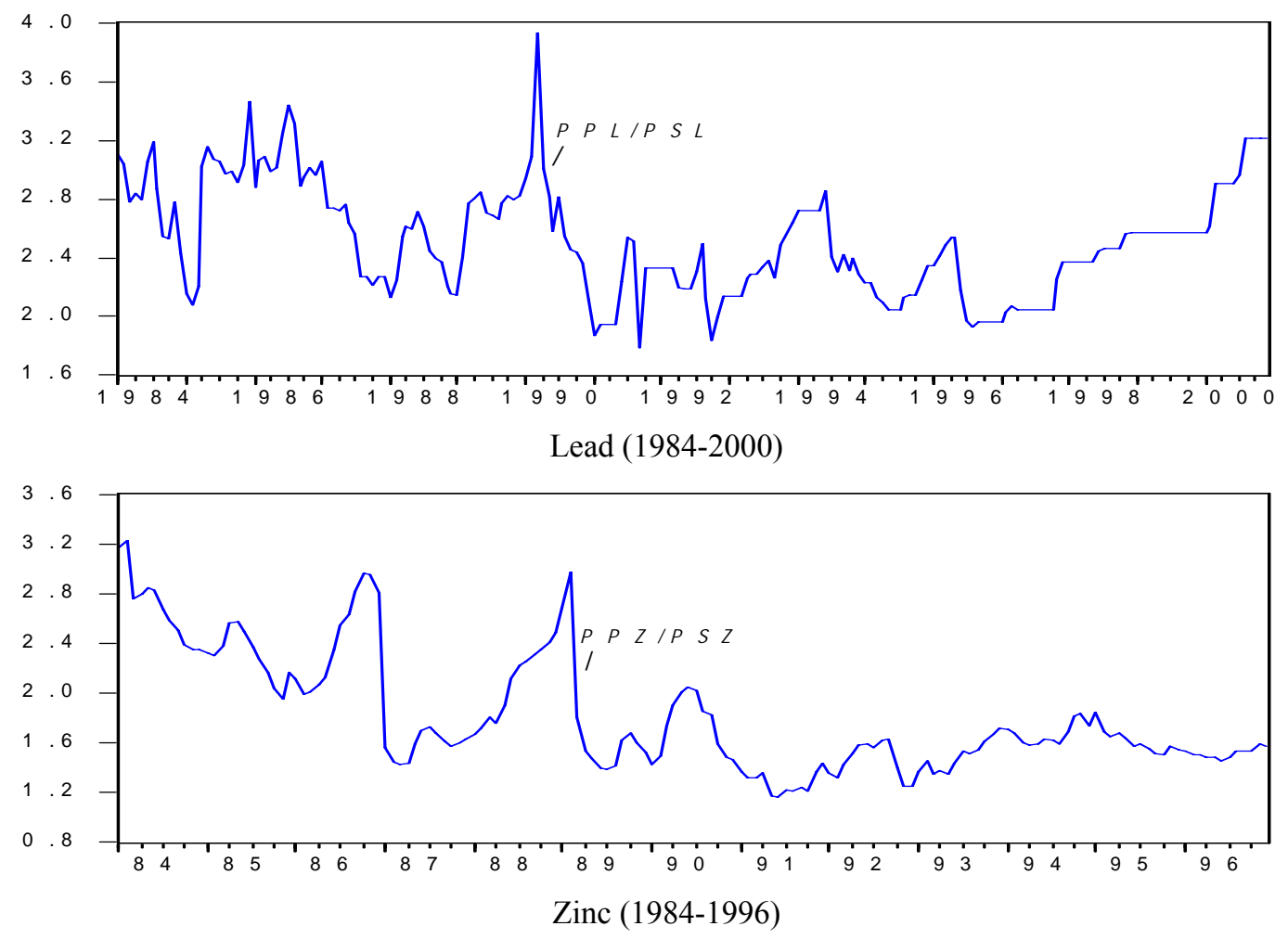

Figure 2. Primary and Scrap Price Ratios by Metal 


\section{II. b. Primary and Secondary Price Relationships}

On average, one would expect the spread between the primary price and the scrap price to simply reflect the refinery margin. In the short run, however, changes in the primary prices may not completely explain changes in the scrap prices because constraints do not always allow market clearing (Taylor, 1979). Cointegration analysis has established that variables may have an equilibrium relationship in the long run as explained by economic theory even though disequilibria in the short term are possible. Specifically, Engle and Granger (1987) point out that a linear combination of two or more non-stationary series may be stationary. If such a stationary linear combination exists, the non-stationary time series are said to be cointegrated. The stationary linear combination is called the cointegrating equation and is interpreted as a long-run equilibrium relationship between the variables. If two variables are cointegrated, they cannot move too far away from each other. In contrast, a lack of cointegration suggests that such variables have no long run link and can wander arbitrarily far away from each other.

Since the primary and scrap prices in each market are non-stationary of order one [I(1)] (table 1), cointegration testing allows for the establishment of a long run equilibrium relationship between primary and scrap prices even though short run price dynamics may reflect disequilibrium. The Johansen $(1991,1995)$ cointegration tests reveal not only the long run relationship but also short run dynamic information based on the Vector Error Correction (VECM) models that are produced.

Johansen's method tests the restrictions imposed by cointegration on the unrestricted Vector Autoregression (VAR) model involving $\mathrm{k}$ series. For primary and scrap prices the unrestricted VAR is

$$
P_{t}=A_{1} P_{t-1}+\ldots+A_{p} P_{t-p}+\varepsilon_{t},
$$


where $P_{t}$ is a vector including one primary and one scrap price series (both non-stationary I(1) variables), and $\varepsilon_{t}$ is a vector of innovations. The VAR is transformed in the following VECM:

$$
\Delta P_{t}=\Pi P_{t-1}+\sum_{i=1}^{p-1} \Gamma_{i} \Delta P_{t-i}+\varepsilon_{t}, \quad \text { where } \Pi=\sum_{i=1}^{p} A_{i}-I_{i}, \quad \Gamma_{i}=-\sum_{j=i+1}^{p} A_{j}
$$

Granger's representation theorem (Johansen, 1991; Engle and Granger, 1987) asserts that if the coefficient matrix $\Pi$ has reduced rank $r<2$ for the bivariate case, then there exist $2 \times r$ matrices $\alpha$ and $\beta$ each with rank r such that $\Pi=\alpha \beta^{\prime}$ and $\beta^{\prime} P_{\mathrm{t}-1}$ is stationary. In the bivariate case there can be at most one independent combination of the variables in $P_{t}\left(\beta^{\prime} P_{\mathrm{t}-1}\right)$ that is stationary. The variable, $r$, is the number of cointegrating relations; in the bivariate case the cointegrating rank cannot be larger than one. Each column of $\beta$ is the cointegrating vector (characterizing the long run relationship between the primary and scrap price), and the elements of $\alpha$ are known as the adjustment parameters of primary and scrap prices to their cointegrating (long run) relationship.

The cointegrating term is also known as the error correction term since the deviation from long run equilibrium between primary and scrap prices is corrected gradually through a series of short run price adjustments towards this equilibrium. The adjustment rates measure the speed of adjustment of the short run changes of prices to their long-run relationship and show the persistence of short run disequilibrium conditions.

The cointegration analysis ${ }^{6}$ is presented in table 2 . The first five columns show the cointegration test results. The sixth column shows the long run relationship between the primary and scrap price for each pair. The last two columns show the adjustment rates of the price changes to their cointegrating relationship. Primary prices are found to hold a long run

\footnotetext{
${ }^{6}$ Eviews (version 5.1) was used for parameter estimation.
} 
relationship to scrap prices with the exception of old and new aluminum prices. The primary products of old and new scrap aluminum, cast aluminum products, are sold in markets that are separate from those of primary aluminum and, as a consequence, it is not inconsistent that these scrap prices are not found to have a long run relationship to primary aluminum prices.

Table 2. Evidence of Cointegration between Primary and Scrap Prices by Metal

\begin{tabular}{|c|c|c|c|c|c|c|c|c|}
\hline \multirow[t]{2}{*}{ Prices } & \multirow[t]{2}{*}{ Ho: $\mathrm{r}=\mathrm{p}$} & \multicolumn{2}{|c|}{ Max. Eigenvalue Test } & \multicolumn{2}{|c|}{ Trace Test } & \multirow{2}{*}{$\begin{array}{c}\text { Cointegrating } \\
\text { Relationship }\left(\beta^{\prime} P_{t-1}\right)\end{array}$} & \multicolumn{2}{|c|}{ Adjustment Rates $(\alpha)$} \\
\hline & & Statistic & Prob.^^ & Statistic & Prob.^^ & & Primary Price & Scrap Price \\
\hline \multicolumn{9}{|l|}{ Aluminum } \\
\hline \multirow[t]{2}{*}{ PPA,PS1A } & $\mathrm{p}=0$ & 10.28 & 0.310 & 16.99 & 0.133 & & & \\
\hline & $\mathrm{p} \leq 1$ & 6.71 & 0.142 & 6.71 & 0.142 & & & \\
\hline \multirow[t]{2}{*}{ PPA,PS2A } & $\mathrm{p}=0$ & 6.66 & 0.711 & 11.47 & 0.498 & & & \\
\hline & $\mathrm{p} \leq 1$ & 4.81 & 0.305 & 4.81 & 0.305 & & & \\
\hline \multirow[t]{2}{*}{ PPA,PS3A } & $\mathrm{p}=0$ & $15.35^{\wedge}$ & 0.009 & $15.38^{\wedge}$ & 0.015 & $\mathrm{PPA}_{\mathrm{t}-1}-1.41 \mathrm{PS} 3 \mathrm{~A}_{\mathrm{t}-1}$ & -0.06 & 0.06 \\
\hline & $\mathrm{p} \leq 1$ & 0.03 & 0.892 & 0.03 & 0.892 & $(-51.43)^{* * *}$ & $(-1.39)$ & $(1.89)^{*}$ \\
\hline \multicolumn{9}{|l|}{ Copper } \\
\hline \multirow[t]{2}{*}{ PPC,PS1C } & $\mathrm{p}=0$ & $28.33^{\wedge}$ & 0.000 & $28.36^{\wedge}$ & 0.000 & $\mathrm{PS}_{1 C_{\mathrm{t}-1}}-0.9 \mathrm{PPC}_{\mathrm{t}-1}$ & 0.16 & -0.16 \\
\hline & $\mathrm{p} \leq 1$ & 0.04 & 0.871 & 0.04 & 0.871 & $(-124.18)^{* * *}$ & $(1.49)$ & $(-1.84)^{*}$ \\
\hline \multirow[t]{2}{*}{ PPC,PS2C } & & $26.63^{\wedge}$ & 0.001 & $30.73^{\wedge}$ & 0.001 & $P S 2 C_{t-1}-0.82 P P_{t-1}+5.66$ & 0.15 & -0.14 \\
\hline & & 4.1 & 0.398 & 4.1 & 0.398 & $(-26.77)^{* * *}(1.83)^{*}$ & $(1.37)$ & $(-1.76)^{*}$ \\
\hline \multicolumn{9}{|l|}{ Lead } \\
\hline \multirow[t]{2}{*}{ PPL,PSL } & $\mathrm{p}=0$ & $26.13^{\wedge}$ & 0.005 & $32.10^{\wedge}$ & 0.007 & $\operatorname{PSL}_{t-1}-0.65 * \mathrm{PPL}_{\mathrm{t}-1}+0.03 \mathrm{t}+5.4$ & -0.01 & -0.14 \\
\hline & $\mathrm{p} \leq 1$ & 5.96 & 0.465 & 5.96 & 0.465 & $(-7.99)^{* * *} \quad(2.23)^{* *}$ & $(-0.11)$ & $(-5.02)^{* * *}$ \\
\hline \multicolumn{9}{|l|}{ Zinc } \\
\hline \multirow[t]{2}{*}{ PPZ,PSZ } & $\mathrm{p}=0$ & $18.09^{\wedge}$ & 0.022 & $20.87 \wedge$ & 0.041 & $\mathrm{PPZ}_{\mathrm{t}-1}-1.24 * \mathrm{PSZ}_{\mathrm{t}-1}-13.86$ & -0.02 & 0.08 \\
\hline & $\mathrm{p} \leq 1$ & 2.78 & 0.622 & 2.78 & 0.622 & $(-6.28)^{* * *}(-2.14)^{* *}$ & $(-0.87)$ & $(4.15)^{* * *}$ \\
\hline
\end{tabular}

$\wedge$ denotes rejection of the hypothesis at the 0.05 level

$\wedge \wedge$ MacKinnon-Haug-Michelis (1999) p-values

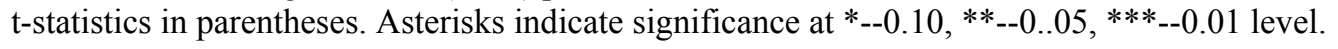


In relation to the short run disequilibrium between primary and scrap prices, results show that the adjustment rates of primary and scrap prices to their cointegrating relationship are not high $^{7}$. This suggests that short run disequilibrium movements can be persistent and denotes the importance of understanding the short-term relationships between primary and scrap prices. In addition, adjustment rates are statistically significant only for scrap prices. This means that most of the adjustment towards the long run relationship between primary and scrap prices is borne by adjustments in the scrap market.

\section{Primary to Scrap Price Ratios}

To examine the time-varying spread between primary and secondary prices, the analysis relies on price ratios. Cointegration analysis separates the disequilibrium dynamics from the equilibrium adjustments of the primary and scrap prices. By using price ratios it is possible to include both disequilibrium and equilibrium adjustments that occur between primary and scrap prices. The close relationship between price ratios and price differentials provides the connection of the vector error correction models of the primary and scrap prices analyzed above to their price ratios. As Granger indicated in his 2003 Nobel Prize Lecture, "a potentially useful property of forecasts based on cointegration is that when extended some way ahead, the forecasts of the two series will form a constant ratio" (Granger, 2004: p. 362).

The secondary/primary price ratio indicates the relative attractiveness of choosing secondary versus primary inputs in the production process and is an explanatory factor for recycling rates (Van Beukering and Bouman, 2001). Price ratios are also important for secondary smelters and refineries (producing primary metal mainly from scrap) since their profitability and survival depends on the price margin between scrap and the refined primary output. In this

\footnotetext{
${ }^{7}$ The speed of adjustment can range from zero to one.
} 
context, Taylor (1979) used the relative scrap to primary price ratio in explaining primary prices. The time varying relationship between primary and scrap prices was analysed by Fowler (1937), who took an interest in iron ore and steel scrap price ratios relative to their consumption ratios for producing steel and found that there were differences in the elasticity of substitution between different periods.

The primary to scrap price ratios are presented in figure 2. Appendix A includes a summary of the price ratios data by averaging over three-year periods. Table 3 shows their time series characteristics, including Phillips and Perron (1988) unit root tests. The following conclusions can be drawn for primary to scrap price ratios:

(i). The means of the price ratios are not consistent over the twenty-year period. In some periods scrap prices are closer, indicating a stronger relationship to the primary metal prices relative to other periods.

(ii). The price ratios are stationary in many cases and the evidence favors a constant mean. This supports the finding already indicated through cointegration analysis that the primary and scrap prices tend to revert to a long run relationship.

(iii). The temporal patterns of price ratio means and volatility differ between markets. In addition, the temporal patterns of the price ratios within each market are similar for different types of scrap. This would suggest that a market specific explanation of the price ratio behaviour is indicated. 
Table 3. Characteristics of Primary to Scrap Price Ratios by Metal

\begin{tabular}{|c|c|c|c|c|c|c|c|}
\hline \multirow[t]{4}{*}{ Characteristic } & \multicolumn{7}{|c|}{ Price Ratio Series } \\
\hline & \multicolumn{3}{|c|}{ Aluminum } & \multicolumn{2}{|c|}{ Copper } & \multirow{2}{*}{$\begin{array}{c}\text { Lead } \\
\text { PPL }\end{array}$} & \multirow{2}{*}{$\begin{array}{c}\text { Zinc } \\
\text { PPZ }\end{array}$} \\
\hline & PPA & PPA & PPA & PPC & PPC & & \\
\hline & $\overline{\mathrm{PS} 1 \mathrm{~A}}$ & $\overline{\mathrm{PS} 2 \mathrm{~A}}$ & $\overline{\mathrm{PS} 3 \mathrm{~A}}$ & $\overline{\mathrm{PS} 1 \mathrm{C}}$ & $\overline{\mathrm{PS} 2 \mathrm{C}}$ & $\overline{\mathrm{PSL}}$ & $\overline{\mathrm{PSZ}}$ \\
\hline Mean & 1.456 & 1.692 & 1.411 & 1.11 & 1.319 & 2.517 & 1.821 \\
\hline Standard Deviation & 0.223 & 0.35 & 0.1 & 0.053 & 0.071 & 0.381 & 0.477 \\
\hline Coef. of Variation & 0.153 & 0.207 & 0.071 & 0.048 & 0.054 & 0.151 & 0.262 \\
\hline Skewness & 1.46 & 1.431 & 0.824 & 1.313 & 0.463 & 0.487 & 1.046 \\
\hline Kurtosis & 3.905 & 3.77 & 4.013 & 7.304 & 3.523 & 2.965 & 3.154 \\
\hline Jarque-Bera (J-B) & 74.743 & 70.283 & 29.919 & 216.126 & 9.603 & 8.069 & 28.626 \\
\hline Probability (J-B) & 0.000 & 0.000 & 0.000 & 0.000 & 0.008 & 0.018 & 0.000 \\
\hline \multicolumn{8}{|l|}{ P-P Unit Root Test } \\
\hline Levels & -1.853 & -1.783 & -4.086 & -6.623 & -5.839 & -3.410 & -1.468 \\
\hline Probability* & 0.354 & 0.388 & 0.001 & 0.000 & 0.000 & 0.012 & 0.133 \\
\hline First Differences & -14.75 & -13.50 & - & - & - & - & -10.17 \\
\hline Probability* & 0.000 & 0.000 & - & - & - & - & 0.000 \\
\hline $1 \%$ Critical Value & -3.465 & -3.465 & -3.465 & -3.462 & -3.462 & -3.462 & -2.58 \\
\hline $5 \%$ Critical Value & -2.877 & -2.877 & -2.877 & -2.876 & -2.876 & -2.876 & -1.943 \\
\hline
\end{tabular}

*MacKinnon (1996) one-sided p-values for rejection of hypothesis of a unit root

\section{III. a. Inventory Influences}

Market fundamentals allow an understanding of the behaviour of primary to scrap price ratios. Low price ratios seeming to reflect tight supply/demand balances (low stock levels) suggest that market fundamentals do influence the spread between primary and scrap prices. The graphs and time series characteristics of the inventory series (in logarithmic form) for the period 1984-2000 are presented in figure 3 and table 4 respectively ${ }^{8}$. Periods of low price ratios coincided with periods of low market inventories. For aluminium, the price ratio was low during 1988, 1990, 1993, 1996-1997, and 1999-2000, all periods of low inventories. For lead, low price

\footnotetext{
${ }^{8}$ The inventories used are United States stocks at the end of each month. Aluminum stock data was available only for North America. The source for the North American Aluminium stocks, denoted in the paper, as USAS, is the International Aluminum Institute. The Copper stocks (USCS) where estimated from segregated US copper stocks compiled by the United States Geological Survey specialist, D.L. Edelstein. The Metal Statistics publication of the American Metal Markets provided the source for lead (USLS) and zinc (USZS) stocks. The length of each time series is determined by data availability and compatibility.
} 
ratios were experienced in the low inventory periods of 1984-1985, 1988, 1991. In contrast, the periods of 1985-1986, 1986-1987, and 1995-96 had high inventory accumulation with high lead price ratios. Examination of the effect of supply influences on the spread between primary and scrap prices brings to light that short zinc supply in 1987-1989 was accompanied by low price ratios while worldwide supply shortages of aluminium in 1986-1988 coincided with high price ratios. The reason for this inconsistency in the relation of price ratios to supply is that supply shortages for aluminium during 1986-1988 where buffered by drawing from the industry's high inventories. Shortages for zinc in 1987-1989, however, coincided with low zinc inventories. Furthermore, it is noted that reduced demand in 2000 was accompanied by increased ratios, except in the case of aluminium, where the period was characterised by a reduction in inventories and the price ratios were low.

Table 4. Characteristics of US Metal Stocks

\begin{tabular}{lcccc}
\hline Characteristic & \multicolumn{4}{c}{ Inventory Series } \\
\hline & InUSAS & InUSCS & InUSLS & InUSZS \\
\hline Mean & 7.390 & 4.377 & 3.360 & 9.165 \\
Standard Deviation & 0.167 & 0.449 & 0.795 & 0.693 \\
Coef. of Variation & 0.023 & 0.102 & 0.237 & 0.076 \\
Skewness & 0.059 & 1.391 & -0.017 & 1.250 \\
Kurtosis & 3.356 & 4.211 & 2.035 & 3.168 \\
Jarque-Bera (J-B) & 1.117 & 75.151 & 7.929 & 40.782 \\
Probability (J-B) & 0.572 & 0.000 & 0.019 & 0.000 \\
& & & & \\
Phillips-Perron Unit Root Test & & & & \\
Levels & -1.666 & -2.916 & -2.641 & -1.828 \\
$\quad$ Probability* & 0.763 & 0.045 & 0.087 & 0.366 \\
First Difereences & -11.19 & - & - & -11.98 \\
$\quad$ Probability* & 0.000 & - & - & 0.000 \\
1\% Critical Value & -4.007 & -3.464 & -3.462 & -3.473 \\
5\% Critical Value & -3.434 & -2.876 & -2.876 & -2.880 \\
\hline
\end{tabular}

*MacKinnon (1996) one-sided p-values for rejection of hypothesis of a unit root 

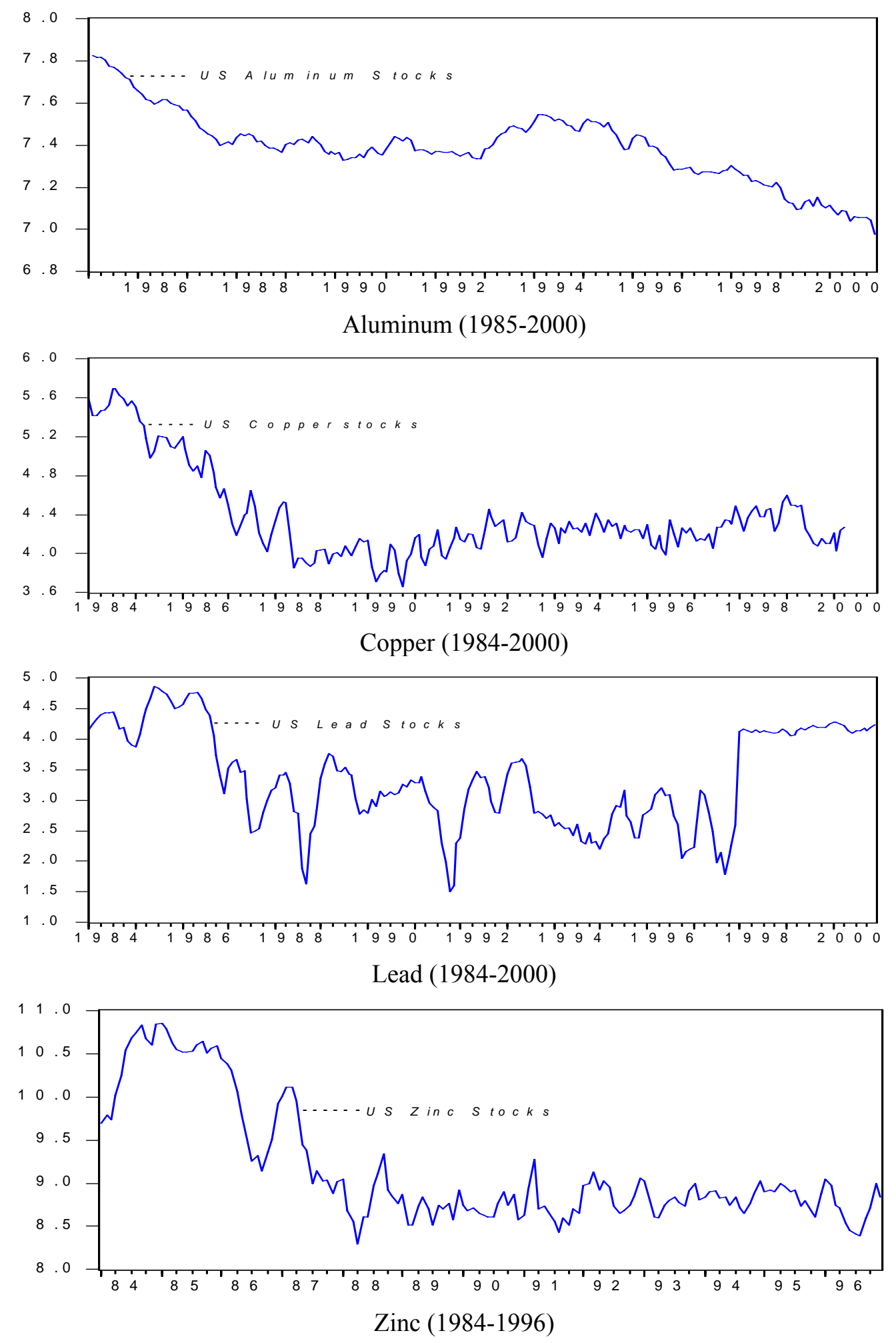

Figure 3. Metal Stocks (in logarithmic form) 
It appears that the major determinant of price ratios is the tightness in the market, represented by inventory availability. Scatter plots of price ratios to United State inventories presented in figures 4-7 attest to a positive relationship between price ratios and inventories. The plots also include a line of fit to improve interpretation of the relationship that connects them.

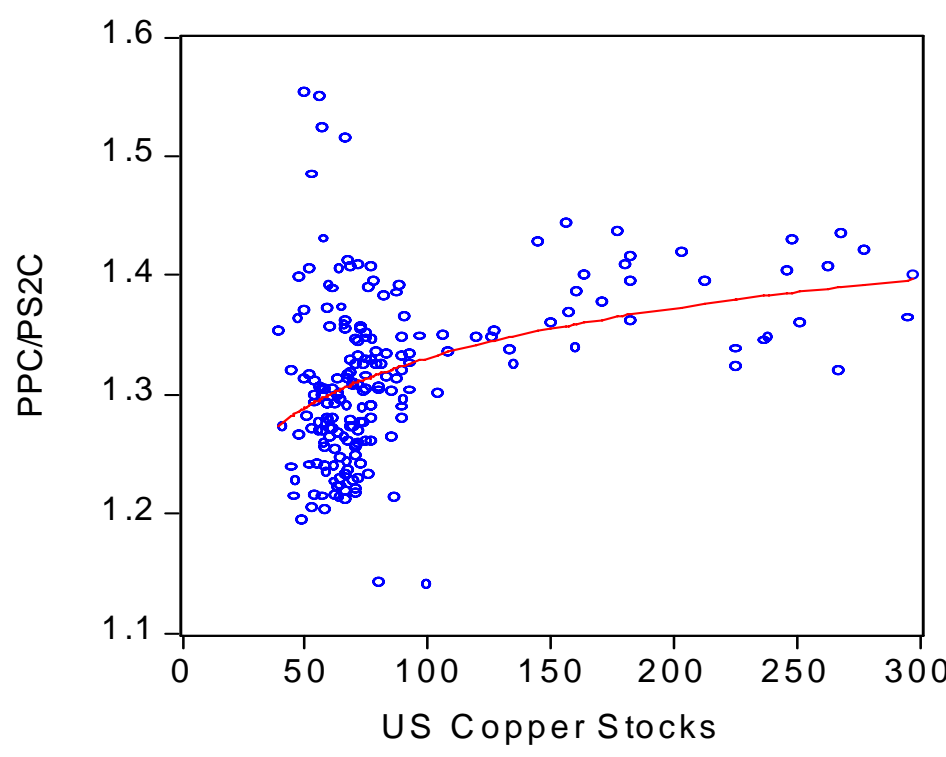

Figure 4. Scatter Plot of the Price Ratio of Primary to Old Scrap Copper (PPC/PS2C) to Copper Inventories 


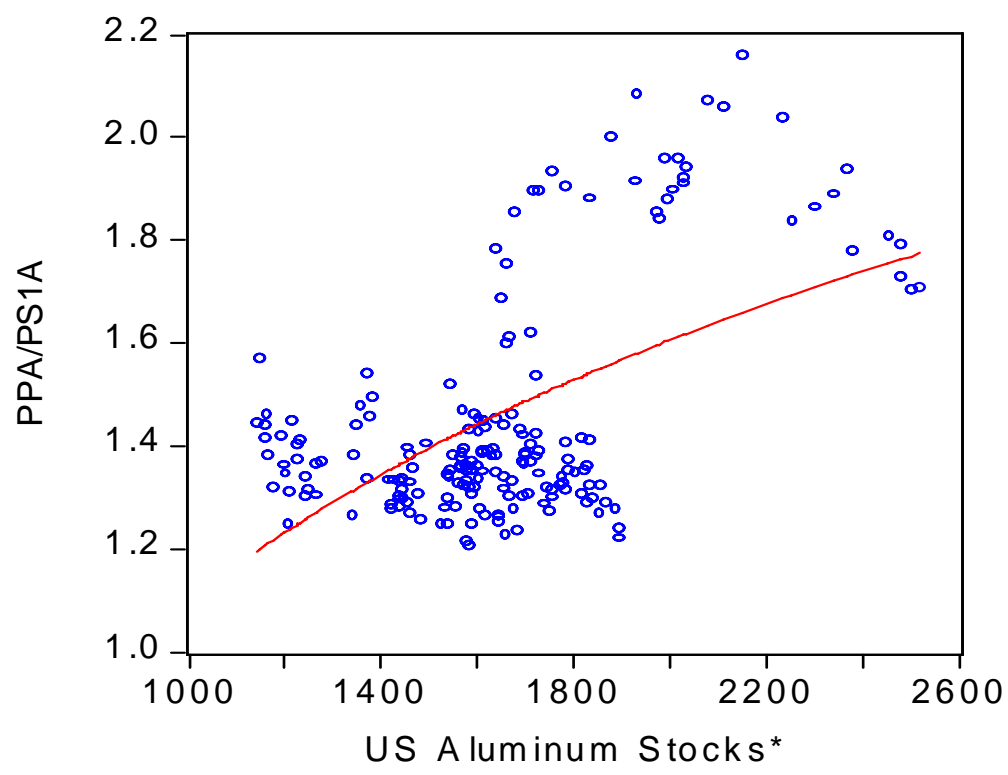

Figure 5. Scatter Plot of the Price Ratio of Primary to New Scrap Aluminum (PPA/PS1A) to Aluminum Inventories*

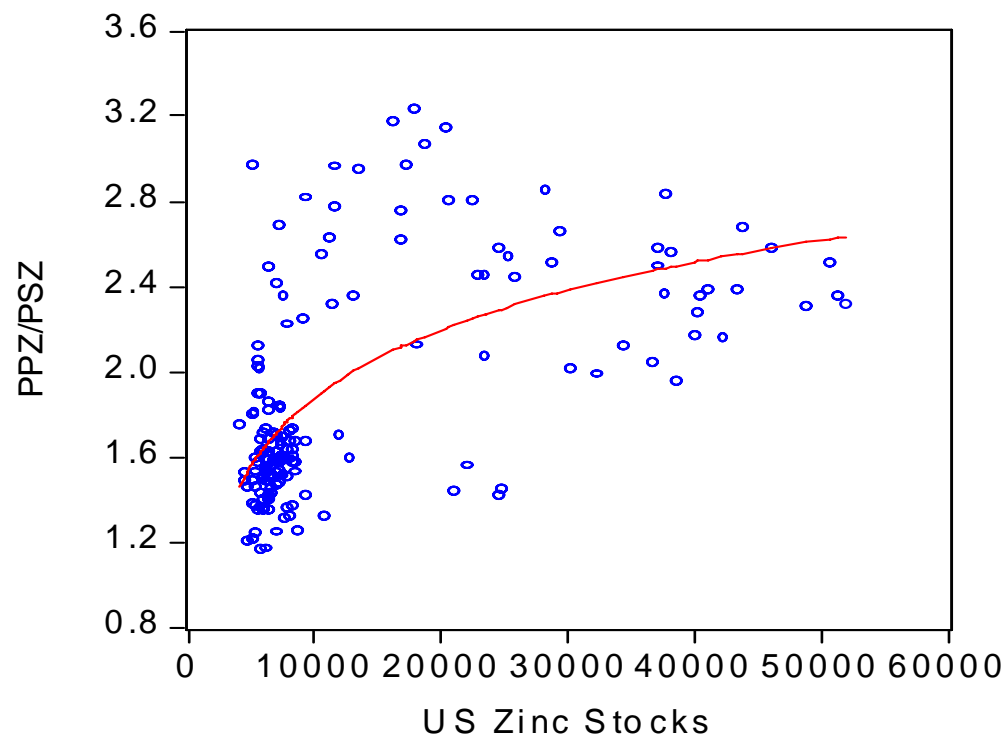

Figure 6. Scatter Plot of the Price Ratio of Primary to New Scrap Zinc (PPZ/PSZ) to Zinc Inventories

\footnotetext{
${ }^{*}$ lagged by one month.
} 


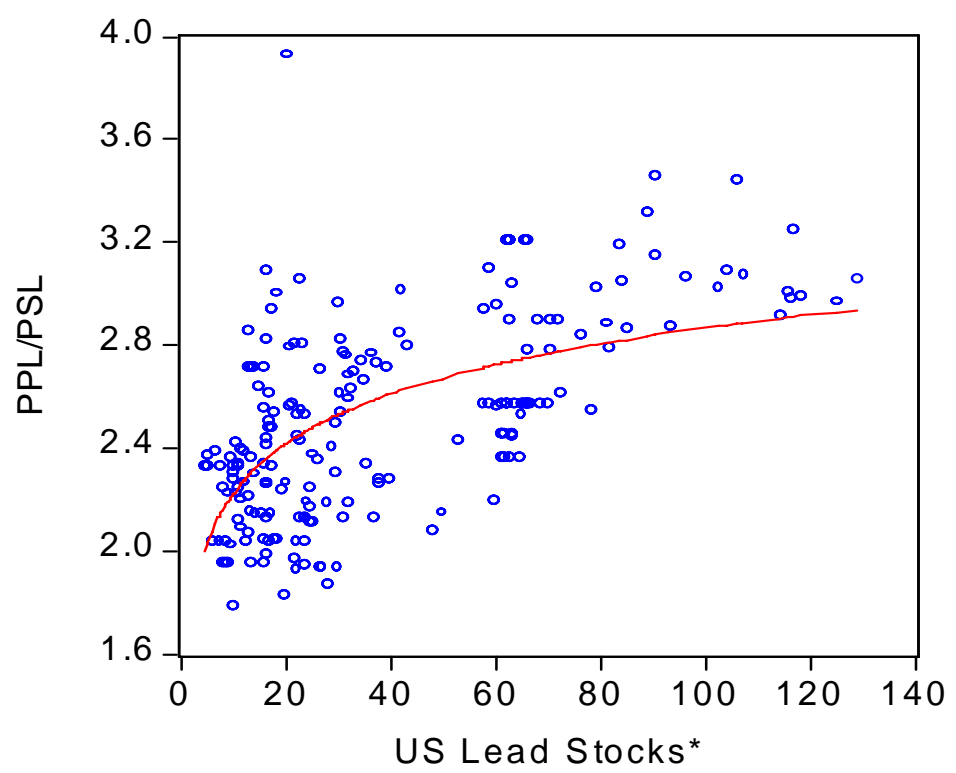

Figure 7. Scatter Plot of the Price Ratio of Primary to Old Scrap Lead (PPL/PSL) to Lead Inventories

\section{Modeling Price Ratios}

\section{IV. a. Nature of Inventories}

Stocks are a major factor in metal markets. They provide the intertemporal link in dynamic commodity systems and form the basis of price adjustment since demand and supply are inelastic (Labys and Kaboudan, 1980). Primary and scrap metal demand and supply do not always clear $(D=S)$ in the short-term due to technological, institutional and psychological constraints. The discrepancy between supply and demand is then carried over to the subsequent period through inventory changes. When the market is in a period of excess supply, in which metal production exceeds metal demand, the excess is added to the accumulated stocks. When demand exceeds supply, stocks are drawn down to cover the excess demand. Current inventories are defined as the summation of supply and demand changes as well as inventory accumulation carried over from the past periods:

\footnotetext{
* lagged by one month.
} 


$$
I_{p, t}=I_{p, t-1}+S_{p, t}-D_{p, t}
$$

Thus, inventories express market conditions, both as current flow changes and as past accumulation of stocks. Consequently, they can allow inferences about how market conditions influence primary and secondary prices.

The role of inventories emphasizes the dynamic character of metal markets and indicates the disequilibrium forces that are embodied in the market. It would be expected that the disequilibrium between primary and scrap prices be related to a variable (such as inventories) that embodies disequilibrium conditions. In addition, stocks are a determinant of both primary and scrap prices.

When demand and supply are inelastic, as is the case in metal markets, a stock adjustment process determines primary metal price behaviour. Taylor (1979) introduced the influence of stocks on scrap prices as well in his short run model of the copper industry. Since both primary and scrap prices are explained by inventories, the ratio of primary to scrap prices should also be influenced by inventories. This is especially obvious if it is taken into account that the reactions of primary and scrap prices to market forces will be different and come with different adjustment rates.

\section{IV. b. The Production Smoothing Model}

Production smoothing is an explanation for the use of stocks in inelastic markets. It points out that adjusting production to changes of demand would be accompanied by high adjustment costs. This stems from the high investment cost in production expansion and the rigidity of electricity, primary input and labor contracts. In addition, it acknowledges that firms face convex production cost curves and fluctuating market demand. Under such conditions, firms 
have incentives to use inventories to buffer demand shocks and smooth production (Holt et al., 1960) or production costs (Eichenbaum, 1984, 1989).

In the presence of low demand, excess supply is stored as inventory in order to avoid production cuts and consequent adjustment cost; in periods of high demand, difficulties and increased costs resulting from higher production can be avoided by absorbing buffer stocks. Capacity is unlikely to be expanded or contracted in the short run; expansion (contraction) would occur only when clear (but often misleading) signals of long-term increasing (decreasing) prices unfold. Based on the incentives for production smoothing, low stocks, indicating high demand and short supply in the market, would also lead to the utilization of relatively more scrap than usual as a metal input or substitute. The cost of disrupting the flow of operations is linked to the use of primary ore and concentrate: scrap, which is a more flexible input than primary ore, can be used to smooth production and production costs.

In periods of excess demand, increased supply orders can easily be covered by scrap, and higher marginal costs from the use of primary ore can be avoided. The relative use of scrap directly from metal consumers, as a substitute for primary metal, also increases as the market tightens and the primary metal industry is not able to respond swiftly to demand. Thus, when inventories are low, the ratio of primary to secondary demand decreases, leading subsequently to a smaller primary to scrap price ratio. In contrast during low demand, when stocks are high, production and production cost-smoothing implies that relatively less scrap is used as input to primary production. Ore and concentrate are preferred to scrap in order to avoid the idling of production capacity. Although both primary and scrap demand are low when inventories are high, their demand ratio widens and so does the primary to scrap price ratio. The first hypothesis that arises from this analysis is that the ratio of primary to scrap metal prices is positively linked 
to inventories. However, technological, psychological, and institutional constraints in the market, as well as the influence of expectations, could mean that the ratio of primary to scrap prices adjusts to inventories over time. Therefore, it is expected that the positive relationship between the ratios of primary to secondary metal prices and inventories occurs with time lags.

\section{IV. c. Time Series Models}

Since metal markets are characterized by stock adjustments and expectation functions, the hypotheses are tested under a dynamic framework with autoregressive (ARMAX) models as described in equation 2. Current and past inventories as well as lagged price ratios incorporate information about the fundamentals of the market. The scatter plots in graphs 4-7 indicate that the relationship between price ratios and inventories is asymmetric. Higher stocks lead to higher ratios at a decreasing rate since the difference between the primary and scrap prices is constrained by their technological and market relations. To express this asymmetry, inventories are transformed into logarithms.

$$
(P p / P s)_{t}=c+\phi_{k} \sum_{1}^{k}(P p / P s)_{t-k}+\gamma \ln I_{t}+\delta \ln I_{t-1}+\varepsilon_{t}
$$

The ARMAX models explain the movement of a variable through time in terms of its own past values as well as current and past values of other explanatory variables. Time and relationships through time are an explicit part of the formulation. The lagged values of the price ratios and inventories appear as a consequence of the theoretical basis of the model, which takes into account past market information and allows economic agents to respond not only to current values but to past values as well.

When price ratios and inventories are stationary, the number of lags is chosen based only on the goodness of fit. When the price ratios are stationary, but inventories contain a unit root $[\mathrm{I}(1)]$, as in the case of modeling the ratio of aluminum primary to used aluminum can prices, 
regression equations including only current inventories or only inventories lagged by one period are meaningless because the error term contains a trend component. Including current and past values allows the individual coefficients of $\log I_{t}, \log I_{t-1}$ to be written as coefficients of stationary variables which implies that a t-statistic is appropriate for testing the influence of $\log I_{t}, \log I_{t-1}$ individually on the price ratios (Sims, Stock and Watson, 1990). Specifically, the distributions of the estimated coefficients $\gamma$ and $\delta$ each converges at a rate corresponding to $\sqrt{T}$ to a Gaussian distribution. An F test of the joint hypothesis that $\gamma$ and $\delta$ are both zero has a nonstationary limiting distribution and cannot be conducted, but it is possible to test the hypothesis of $\gamma=0$ and $\delta=0$ being asymptotically $\mathrm{N}(0,1)$ separately for each variable (Hamilton, 1994) .

When both price ratios and inventories are non-stationary [I(1)] it is necessary to check whether a long run relationship exists between them. If cointegration is present, a Vector Error Correction model is produced. This approach is followed for the primary to scrap zinc price ratio as well as the ratios of primary to new and old aluminum scrap prices. The model of the price ratios under this formulation is described by:

$$
\Delta(P p / P s)_{t}=c+a\left[(P p / P S)_{t-1}+\beta \ln I_{t-1}\right]+\sum_{1}^{k} \phi_{k} \Delta(P p / P S)_{t-k}+\sum_{1}^{k} \gamma_{k} \Delta \ln I_{t-1}+\varepsilon_{t}
$$

In this model the relationship of inventories to price ratios is examined both in the long term and in the short term.

\section{Empirical Results}

The empirical results of the price ratio models are presented in Table $5^{9}$. The coefficients differ considerably between metal markets. The functions of all the price ratios have significant

\footnotetext{
${ }^{9}$ The tests for cointegration between primary/scrap price ratios and inventories for zinc and aluminum and their full Vector Error Correction models are presented in appendix B. All computations were performed with E-views (version 5.1)
} 
autoregressive coefficients. For the price ratios that are non-stationary, the autoregressive coefficient is one. The significance of the autoregressive coefficients testifies to the dynamic adjustment behavior of the metal markets.

Table 5. Models of Primary to Scrap Price Ratios

\begin{tabular}{|c|c|}
\hline $\begin{array}{l}\begin{array}{l}\Delta(\mathrm{PPA} / \mathrm{PS} 1 \mathrm{~A})_{\mathrm{t}}=-0.065\left[\mathrm{PPA} / \mathrm{PS} 1 \mathrm{~A}_{\mathrm{t}-1}-0.58 \operatorname{lnUSAS}_{\mathrm{t}-1}+2.622\right]-0.0007+\varepsilon_{\mathrm{t}} \\
(-2.682)^{*}\end{array} \\
\begin{array}{c}(-2.235)^{\circ} \\
\text { Adj. } \mathrm{R}^{2}=0.032, \text { AIC }=-2.67\end{array}\end{array}$ & $(4.1)$ \\
\hline $\begin{aligned} \begin{array}{l}\Delta(\mathrm{PPA} / \mathrm{PS} 2 \mathrm{~A})_{\mathrm{t}}=-0.046\left[\mathrm{PPA} / \mathrm{PS} 2 \mathrm{~A}_{\mathrm{t}-1}-0.809 \operatorname{lnUSAS} \mathrm{S}_{\mathrm{t}-1}+4.295\right]-0.0003+\varepsilon_{\mathrm{t}} \\
(-2.216)^{\circ}\end{array} \\
\begin{aligned} \text { Adj. } \mathrm{R}^{2}=0.020, \mathrm{AIC}=-2.03 & (-1.730)^{\wedge}\end{aligned}\end{aligned}$ & $(4.2)$ \\
\hline 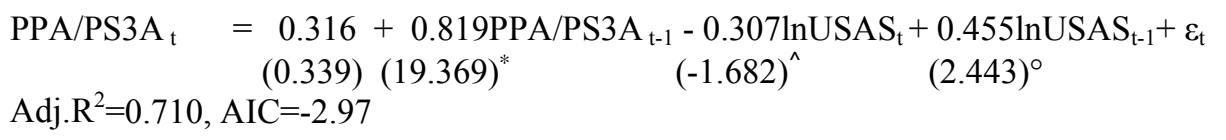 & $(4.3)$ \\
\hline 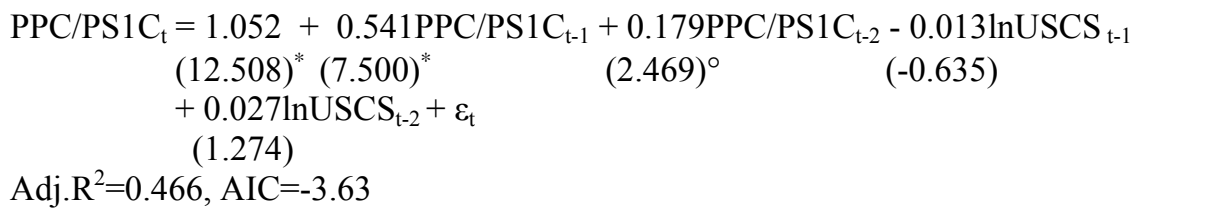 & $(4.4)$ \\
\hline 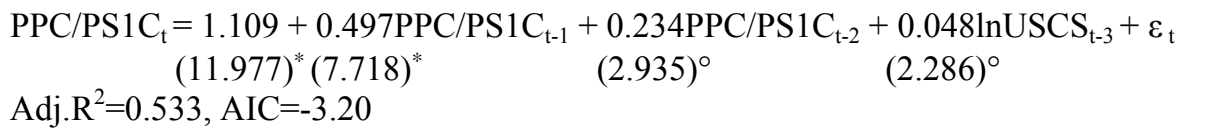 & $(4.5)$ \\
\hline $\begin{aligned} \mathrm{PPL} / \mathrm{PSL}_{\mathrm{t}} & =2.049+0.841(\mathrm{PPC} / \mathrm{PS} 1 \mathrm{C})_{\mathrm{t}-1}+0.141(\operatorname{lnUSLS})_{\mathrm{t}-1}+\varepsilon_{\mathrm{t}} \\
& (11.044)^{*}(21.569)^{*}\end{aligned}$ & $(4.6)$ \\
\hline 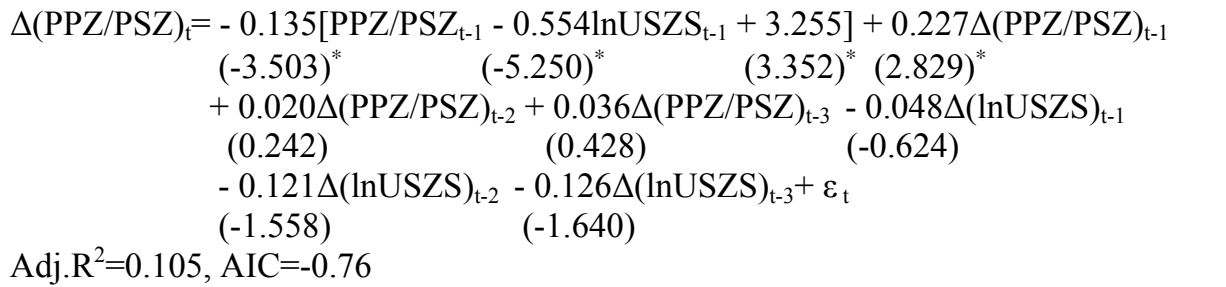 & (4.7) \\
\hline
\end{tabular}

t-statistics in parentheses: ${ }^{\wedge}$ indicates significance at 0.10 level, ${ }^{\circ}$ indicates significance at 0.05 level, ${ }^{*}$ indicates significance at 0.01 level. 
The effect of inventories on the primary/secondary price ratios is positive. Even though present inventory levels have a negative effect on the ratio of primary to used aluminum can prices, past values of inventories have a positive effect which surpasses the effect exerted by current inventories. The influence of stocks to price ratios is weakest in the copper market and is significant only for the ratio of primary to old scrap prices. Considerable inventory influence on the price ratios comes from past lags. Thus, the ratio of primary to secondary data does adjust to the changing market conditions with time lags.

In the cases of zinc price ratios and aluminum primary to old and new scrap price ratios, inventories hold a positive long run relationship to price ratios. Short run changes in price ratios also hold a positive relationship to inventories for aluminum. In the case of zinc, price ratios are influenced positively by the lagged inventory levels but are negatively affected by short run inventory changes although the short run influence is not statistically significant. Last, short run dynamics in these markets can be persistent since the adjustment rates to the long run relationship that exists between the price ratios and inventories are not high ${ }^{10}$.

The ratio of primary to scrap metal prices is not constant since market conditions influence primary and secondary metal prices to differing degrees. Price ratios increase as inventories increase and decrease when inventories decline. This positive relationship of the primary/scrap price ratio to metal market inventories suggests that scrap prices react more violently to market condition changes than primary prices do. In times of ample supply, both primary and scrap prices decrease, but the fall in scrap prices is greater. In periods of excess demand and tight supply both primary and scrap prices increase, with scrap price increases being relatively higher.

\footnotetext{
${ }^{10}$ The speed of adjustment can range from zero to one.
} 
Secondary smelters and refineries depend fully on scrap for metal production and are greatly affected by this phenomenon. These producers may find themselves at a disadvantage in relation to primary smelters and refineries because their input costs are more volatile than their sales and they have to engage in a great deal of market speculation. This may be the reason for many suggestions in the copper industry to link scrap prices to LME copper prices (Blomberg and Hellmer, 2000; Labys et al., 1971).

Finally, to the extent that price reactions to surface stocks could represent price adjustments to reduced underground stocks, long term downward sloping trends of the primary and scrap price ratio would indicate resource exhaustion. This is a possible direction for future research which may be able to produce more conclusive results about resource exhaustion than the study of primary resource prices alone. It is important to note that the positive long run relationship found between price ratios and inventories for zinc and aluminium validates this approach.

\section{Conclusions}

This study describes interrelations between primary and scrap markets in terms of price ratios. Understanding the relative behaviour of primary and scrap prices can be valuable to metal market participants, especially in the decision making process of managers of secondary smelters and refineries. In examining the dynamic relationship of primary and scrap metal prices through time series methods, the results show that a long run equilibrium ties primary to scrap prices. However, short run dynamics include movements away and adjustments towards equilibrium. This unstable short run relationship between primary and scrap prices is verified by the timevarying ratios of primary to scrap prices. The fact that primary and scrap prices hold a long run relationship in most markets suggests that policies that aim to increase recycling rates by 
decreasing the primary to scrap price ratio will not be able to sustain long term results. Such policies could have a more significant effect in the old and new aluminium scrap markets where a long run relationship between primary and scrap prices is not present. In addition, knowledge that a long run equilibrium relationship exists between primary and scrap prices should make scrap market participants cautious about their reaction to short run fluctuations of scrap prices.

In the latter part of the paper, it is shown that price ratios are related to market fundamentals. The level of inventories in the market influences price ratios positively. In the case of zinc, as well as the cases of new and old aluminum, this relationship is more pronounced in the long run than the short run. Moreover, considerable inventory influence on price ratios comes from past lags, since the ratio of primary to secondary prices adjusts to the changing market conditions. The dynamic adjustment of price ratios to market information is also established by the significant autoregressive coefficients of price ratios. These results can help metal market participants anticipate or forecast relative changes in primary and scrap prices.

The theoretical explanation of the positive relationship between primary and scrap price ratios to inventories found in this paper is provided by the production smoothing incentives of metal producers. These lead to tighter connections between primary and scrap prices when inventories are lower than when inventories are higher. In a tight market, the spread between primary and scrap prices becomes smaller, whereas ample supply, as indicated by high accumulation of inventories, means wider spreads between primary and scrap prices. Although the empirical results attest to this structure for aluminium, zinc, and lead, the evidence is weaker in the case of copper. Understanding the reasons why this relationship is not as pronounced in the case of copper could provide additional insights into the structural relations between primary and scrap prices. It should also be noted that production smoothing incentives are a short run 
phenomenon and the long run equilibrium between inventories and price ratios, found in the case of zinc and new and old aluminium scrap, could suggest there may be other forces that lead to this relationship as well.

Finally, the positive relationship between the price ratios and the level of metal inventories found in this study indicates that as inventories increase (decrease), both primary and secondary prices increase (decrease), but scrap price reactions to market conditions are more pronounced. The flexibility of scrap as an input to primary metal production is the reason the ratio of primary to secondary prices is expected to hold a positive relationship to inventory levels. It is important to note that the estimated Vector Error Correction models of primary and scrap prices show that the partial adjustment towards the long run relationship between primary and scrap prices is achieved through scrap price movements. This indicates both the higher flexibility of scrap prices and the stabilizing force of the scrap sector for the metal markets. 


\section{References}

Blomberg, J. and S. Hellmer. 2000. Short-run Demand and Supply Elasticities in the West European Market for Secondary Aluminium. Resources Policy 26:39-50.

Eichenbaum, M. 1984. Rational Expectations and the Smoothing Properties of Inventories of Finished Goods. Journal of Monetary Economics 14:71-96.

. 1989. Some Empirical Evidence on the Production Level and Production Smoothing

Models of Inventory Investment. The American Economic Review 79 (4):853-864.

Engle, Robert F. and C.W.J. Granger. 1987. "Co-integration and Error Correction: Representation, Estimation, and Testing,” Econometrica 55:251-276.

Eviews (version 5.1). 2005. Irvine, CA: Quantitative Micro Software.

Fisher, L.A. and A.D. Owen. 1981. An Econometric Model of the US Aluminum Market. Resources Policy 7(3):150-160.

Fowler, R.F. 1937. The Substitution of Scrap for Pig-Iron in the Manufacture of Steel. The Quarterly Journal of Economics 52(1):129-154.

Granger, C.W.J. 2004. Time Series Analysis, Cointegration, and Application. Nobel Lecture, December 8, 2003. The Nobel Prizes 2003:360-366.

Hamilton, James D. 1994. Time Series Analysis. Princeton: Princeton University Press.

Hashimoto, H. 1983. Modeling Price Fluctuations of Ferrous Scrap. Resources Policy (June):122-139.

Holt, C. C., F. Modigliani F, J.F. Muth, and H.A. Simon. 1960. Planning Production, Inventories, and Work Force. Englewood Cliffs, NJ: Prentice-Hall Inc.

International Aluminum Institute. 2003. Statistics. <http://www.world-aluminium.org/> (March 24, 2004). 
Johansen, S. 1995. Likelihood-based Inference in Cointegrated Vector Autoregressive Models. Oxford: Oxford University Press.

. 1991. Estimation and Hypothesis Testing of Cointegration Vectors in Gaussian Vector Autoregressive Models. Econometrica 59:1551-1580.

Labys, W.C. and M. Kaboudan. 1980. A Short Run Disequilibrium Model of the Copper Market. Department Working Paper No. 16. Morgantown, WV: Department of Mineral and Energy Economics, West Virginia University. Photocopied.

Labys, W.C., H.B. Rees, and C.M. Elliott. 1971. Copper Price behavior and the London Metal Exchange. Applied Economics 3:99-113.

MacKinnon, J.G. 1996. Numerical Distribution Functions for Unit Root and Cointegration Tests. Journal of Applied Econometrics 11:601-618.

MacKinnon, J.G., A.A. Haug, and L. Michelis. 1999. Numerical Distribution Functions of Likelihood Ratio Tests for Cointegration. Journal of Applied Econometrics 14:563-577.

American Metal Market. 1984-2003. Metal Statistics. New York: American Metal Market.

Phillips, P.C.B. and P. Perron. 1988. Testing for a Unit Root in Time Series Regression. Biometrika 75:335-346.

Sims, C.A., James H.S., and M.W. Watson. 1990. Inference in Linear Time Series Models with Some Unit Roots. Econometrica 58 (1):161-82.

Stollery, K.R. 1983. Secondary Supply of Copper and Ferrous Metals and Canadian Metal Markets. Center for Resource Policies, Technical Paper n3. Kingston, Ontario: Queens University.

Taylor, C. A. 1979. A Quarterly Domestic Copper Industry Model. The Review of Economics and Statistics 61(3):410-422. 
Commodity Research Bureau. 1984-2003. The CRB Commodity Yearbook. Chicago: Commodity Research Bureau.

USGS. 2000. Recycling-Metals; Minerals Yearbook. Washington DC: US Geological Survey, US Department of Interior.

USGS. 1955-. Copper; Minerals Yearbook. Washington DC: US Geological Survey, US Department of Interior.

Van Beukering, P. and M.N. Bouman. 2001. Empirical Evidence on Recycling and Trade of Paper and Lead in Developed and Developing Countries. World Development 29(10):1717-1737. 


\section{Appendix A}

Table A1. Primary and Scrap Prices and Volatility by Metal (1985-1999)

\begin{tabular}{|c|c|c|c|c|c|c|c|c|c|c|}
\hline \multirow[t]{3}{*}{ Series } & \multicolumn{10}{|c|}{ Prices } \\
\hline & \multicolumn{5}{|c|}{ Means } & \multicolumn{5}{|c|}{ Standard Deviations } \\
\hline & $1985-87$ & 1988-90 & 1991-93 & 1994-96 & 1997-99 & 1985-87 & 1988-90 & 1991-93 & 1994-96 & $1997-99$ \\
\hline \multicolumn{11}{|c|}{ Aluminum } \\
\hline PPA & 58.99 & 90.67 & 56.77 & 76.14 & 69.45 & 11.67 & 17.76 & 4.86 & 10.62 & 6.72 \\
\hline PS1A & 31.47 & 65.21 & 43.05 & 56.16 & 51.87 & 6.79 & 10.53 & 4.10 & 8.15 & 5.95 \\
\hline PS2A & 24.98 & 55.80 & 37.87 & 51.25 & 46.82 & 4.68 & 9.39 & 3.88 & 7.33 & 5.92 \\
\hline PS3A & 40.52 & 60.57 & 39.08 & 57.00 & 52.17 & 8.24 & 10.00 & 4.07 & 9.14 & 5.91 \\
\hline \multicolumn{11}{|c|}{ Copper } \\
\hline PPC & 71.81 & 124.88 & 102.77 & 119.47 & 87.16 & 13.87 & 15.74 & 10.09 & 18.38 & 16.30 \\
\hline PS1C & 63.08 & 109.85 & 94.17 & 108.56 & 81.19 & 12.10 & 11.03 & 11.04 & 14.63 & 15.30 \\
\hline $\mathrm{PS} 2 \mathrm{C}$ & 53.00 & 94.41 & 82.09 & 91.36 & 66.50 & 11.18 & 9.70 & 11.25 & 13.19 & 13.09 \\
\hline \multicolumn{11}{|l|}{ Lead } \\
\hline PPL & 25.92 & 40.65 & 33.74 & 43.86 & 46.98 & 8.49 & 5.14 & 2.13 & 5.86 & 1.64 \\
\hline PSL & 9.62 & 15.67 & 15.32 & 19.51 & 20.11 & 4.33 & 2.22 & 1.82 & 4.07 & 2.62 \\
\hline \multicolumn{11}{|l|}{ Zinc } \\
\hline PPZ & 40.10 & 72.27 & 52.44 & 51.21 & - & 4.63 & 12.57 & 6.61 & 3.60 & - \\
\hline PSZ & 19.84 & 40.33 & 37.45 & 32.01 & - & 4.87 & 10.46 & 5.07 & 2.09 & - \\
\hline
\end{tabular}

Table A2. Price Ratios by Metal for Selected Time Periods

\begin{tabular}{lccccc}
\hline Series & \multicolumn{5}{c}{ Price Ratios } \\
\hline \multicolumn{1}{l}{$\mathbf{1 9 8 5 - 8 7}$} & $\mathbf{1 9 8 8 - 9 0}$ & $\mathbf{1 9 9 1 - 9 3}$ & $\mathbf{1 9 9 4 - 9 6}$ & $\mathbf{1 9 9 7 - 9 9}$ \\
\hline Aluminum & & & & & \\
PPA/PS1A & 1.883 & 1.387 & 1.321 & 1.358 & 1.343 \\
PPA/PS2A & 2.363 & 1.623 & 1.504 & 1.488 & 1.493 \\
PPA/PS3A & 1.459 & 1.495 & 1.456 & 1.341 & 1.335 \\
Copper & & & & & \\
PPC/PS1C & 1.139 & 1.137 & 1.094 & 1.098 & 1.074 \\
PPC/PS2C & 1.360 & 1.323 & 1.260 & 1.307 & 1.314 \\
Lead & & & & & 2.365 \\
PPL/PSL & 2.820 & 2.621 & 2.224 & 2.296 & \\
Zinc & & & & & \\
PPZ/PSZ & 2.112 & 1.861 & 1.412 & 1.602 & - \\
\hline
\end{tabular}




\section{Appendix B}

Table B1. VECM Models for Price Ratios and Inventories

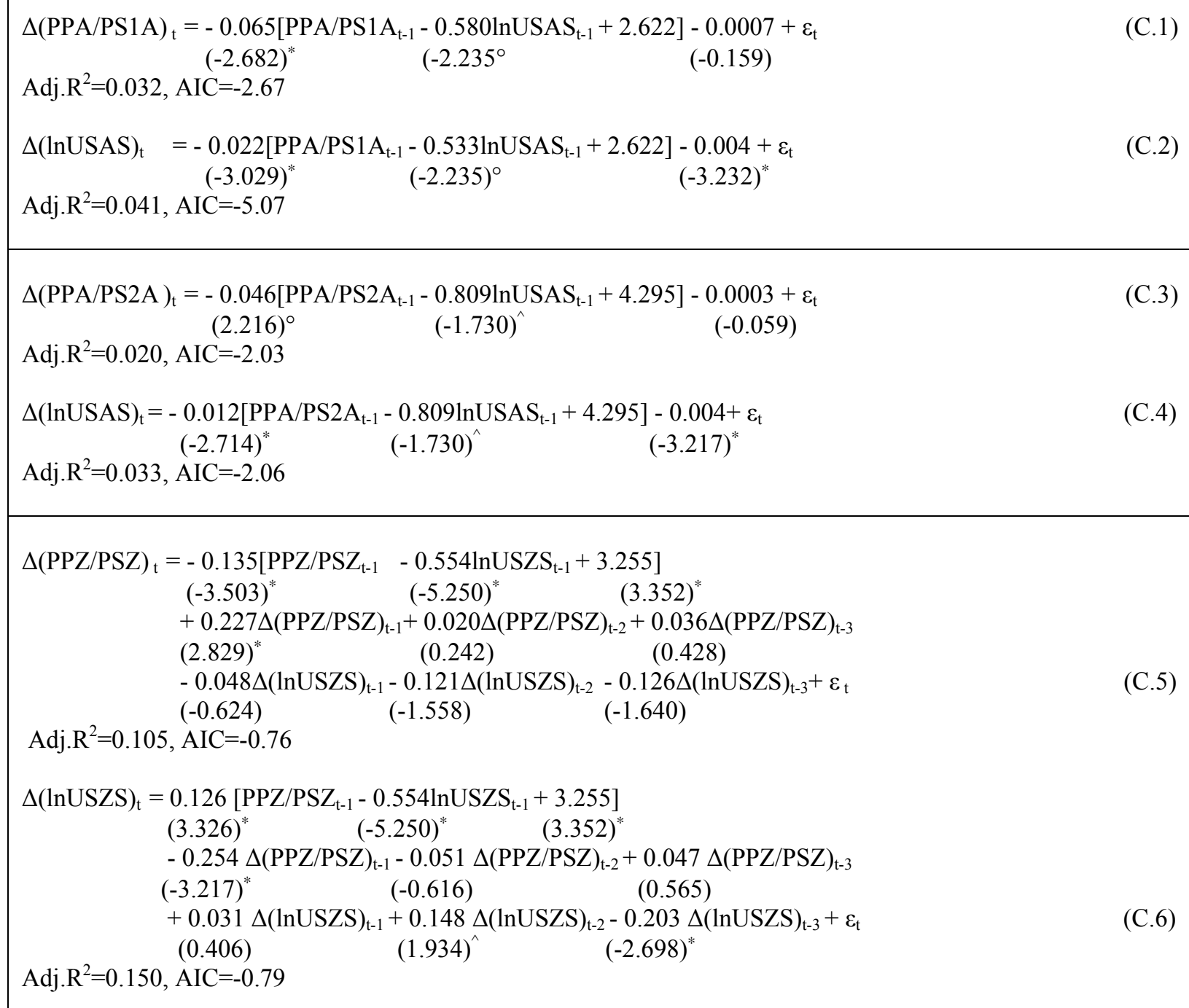

t-statistics in parentheses: ${ }^{\wedge}$ indicates significance at 0.10 level, ${ }^{\circ}$ indicates significance at 0.05 level, ${ }^{*}$ indicates significance at 0.01 level. 
Table B2. Tests for Cointegration between Price Ratios and Inventories

\begin{tabular}{|c|c|c|c|c|c|c|c|}
\hline \multirow[t]{2}{*}{ Prices } & \multirow[t]{2}{*}{ Ho: $r=p$} & \multicolumn{3}{|c|}{ Maximum Eigenvalue Test } & \multicolumn{3}{|c|}{ Trace Test } \\
\hline & & Statistic & 5\% Crit.Val. & Prob.** & Statistic & 5\% Crit.Val. & Prob.** \\
\hline \multicolumn{8}{|l|}{ Aluminum } \\
\hline PPA/PS1A, & $\mathrm{p}=0$ & $19.108^{*}$ & 14.265 & 0.008 & $19.843^{*}$ & 15.495 & 0.010 \\
\hline USAS & $\mathrm{p} \leq 1$ & 0.735 & 3.841 & 0.391 & 0.735 & 3.841 & 0.391 \\
\hline PPA/PS2A, & $\mathrm{p}=0$ & $15.234^{*}$ & 14.265 & 0.035 & $15.925^{*}$ & 15.495 & 0.043 \\
\hline USAS & $\mathrm{p} \leq 1$ & 0.692 & 3.841 & 0.406 & 0.692 & 3.841 & 0.406 \\
\hline Zinc & & $22.500^{*}$ & 15.892 & 0.004 & $26.475^{*}$ & 20.262 & 0.006 \\
\hline PPZ/PSZ, & $\mathrm{p}=0$ & 3.975 & 9.165 & 0.416 & 3.975 & 9.165 & 0.416 \\
\hline USZS & $\mathrm{p} \leq 1$ & & & & & & \\
\hline
\end{tabular}

*denotes rejection of the hypothesis at the 0.05 level

**MacKinnon-Haug-Michelis (1999) p-values 


\section{CURRICULUM VITAE}

\section{EDUCATION}

WEST VIRGINA UNIVERSITY

Ph.D.Natural Resource Economics

Majors:

- Environmental and Natural Resource Economics

- Public Economics (Department of Economics)
Morgantown, West Virginia

2001-2006

Dissertation Title:

Three Essays in Environmental Markets: Dynamic Behavior, Market Interactions, and Policy Implications

WEST VIRGINA UNIVERSITY

M.S. Agricultural and Natural Resource Economics

Major: Environmental Economics and Policy

\section{ATHENS UNIVERSITY OF ECONOMICS AND BUSINESS}

B.A. Economics

Major: Applied Economics

UNIVERSITE DE MONTPELLIER I

Erasmus Exchange Program (Economics)

INSTITUTE FRANCAISE D' ATHENES

Sorbonne II (French Foreign Language Degree)

Awarded by UNIVERSITE PARIS SORBONNE
Morgantown, West Virginia

$2001-2003$

Athens, Greece

$1996-2001$

Montpellier, France

Spring 1999

Athens, Greece

2000

\section{PROFESSIONAL EXPERIENCE}

\section{WEST VIRGINA UNIVERSITY}

Research Assistant:

Compiled an extensive dataset of Scrap and Primary Metal Prices

Compiled an extensive dataset of Metal Inventories

Research in the area of Recycling

Research in the area of Voluntary Policies

\section{WEST VIRGINA UNIVERSITY}

Teaching Assistant:

Teaching Assistant for "Principals of Microeconomics"

(ECON 201) (125 students)

Instructor of the course "Introduction to Environmental Economics"(ARE 220), full teaching responsibilities (40 students)

Guest lecturer for sections in "Agricultural, Environmental, and Resource

Policy" (ARE 633) and "International Economics" (ECON 451), WVU,

2002

\section{WEST VIRGINA UNIVERSITY}

Research Assistant:

Compilation of the Anti-degradation Policies and Efforts in the US
Morgantown, West Virginia

Summer 2004-Summer 2005

Morgantown, West Virginia

Fall 2003-Spring 2004

Spring 2001, Fall 2002

Morgantown, West Virginia

Fall 2001-Summer 2003 
Analysis of the Economic Implications of the Antidegradation Policy in the

Water Quality Standards of West Virginia

Contributed to the formulation of West Virginia's Antidegradation Policy

Investigated Economic Effects of Ship Recycling

Compiled a dataset of cost and price factors in the steel industry

WEST VIRGINA UNIVERSITY HOSPITALS

International Patients Program:

Morgantown, West Virginia

Program Assistant

Summer 2005-Fall 2005

\section{PROFESSIONAL PARTICIPATION}

- Selected Paper Session Moderator, 2005 Annual Meetings of the Northeastern Agricultural and Resource Economics Association-NAREA; Annapolis, Maryland, June 2005

- Book Review "Environmental Economics and Management; Theory Policy and Application; Third Edition, Scott Callan and Janet Thomas", Summer 2004

- Participant of the ERS academic focus group for improving ERS's Agricultural Resource Management Survey (ARMS) and its distribution to academia and the general public, after invitation from ERS, USGS; Washington, DC, August 2003

- President of the Graduate Resource Economics Club (GREC) in WVU, 2002-2003

\section{PUBLICATIONS AND PRESENTATIONS}

Xiarchos I. M. 2005. Scientific Abstract Publication. "The Influence of Inventories on the Relative Prices of Primary and Secondary Metals," Agricultural and Resource Economics Review, 34 (2) (October).

- The 2005 Annual Meeting of the Northeastern Agricultural and Resource Economics Association NAREA; Annapolis, Maryland, June 2005

Xiarchos, I. M. 2005. Scientific Abstract Publication. "Relationships between Primary and Secondary Markets: An Examination of Prices for the Case of Steel," Journal of Agricultural and Applied Economics, 37(1)(April)

- The 2005 Annual Meeting of the Southern Agricultural Economics Association-SAEA; Little Rock, Arkansas, February 2005. http://agecon.lib.umn.edu/cgi-bin/pdf_view.pl?paperid=15703\&ftype=.pdf

Xiarchos, I. M., and R. Childs. 2004. "Spatial Considerations on the Effect of Smoking Regulations on Restaurant Employment: The Case of West Virginia", Electronic Proceedings of the 2004 UCGIS (University Consortium for Geographic Information Science) Annual Assembly.

http://65.61.12.151/UCGISFall2004/studentpapers/files/xiarchos.pdf

- The Student Poster Session of the 2004 UCGIS Assembly, held in conjunction with the Third International Conference on Geographic Information Science, GIScience 2004; University of Maryland Conference Center, MD, October 2004

- The Eighth Annual Davis College Graduate Student Research Conference, WVU, April 2004, as a preliminary version of the paper

Xiarchos, I. M., and T. T. Phipps. 2003. Scientific Abstract Publication. "An Environmentally Conscious Firm in a Dynamic Framework,"Agricultural and Resource Economics Review, 32 (2) (October).

- The 2003 Annual Meeting of the Northeastern Agricultural and Resource Economics Association NAREA; Portsmouth, NH, June 2003 


\section{RESEARCH IN PROGRESS}

- Xiarchos, I.M. and T. T. Phipps "An Environmentally Conscious Firm: Dynamic Behavior and Policy Considerations" (Dissertation Essay)

- Xiarchos, I.M. and W.C. Labys "Price and Volatility Transmission between Primary and Scrap Metal Markets" (Dissertation Essay)

- Xiarchos I.M. and W.C. Labys "Time-Varying Ratios of Primary and Scrap Metal Prices: The Importance of Inventories" (Dissertation Essay)

- Xiarchos, I.M. "Spatial Considerations for the Effect of Smoking Regulations on Restaurant Employment"

- Crompton, P., Labys, W.C., and I.M. Xiarchos. "Metal Prices and the Supply of Storage"

- Xiarchos, I.M. "Creating a Market: The Effect of Waste Exchanges on Recycling Rates"

- Xiarchos, I.M. and R. Sobel. "Tax Evasion, Self Employment and Tax Rates"

\section{HONORS AND AWARDS}

- Travel award, NAREA; Paper Presentation at the 2005 NAREA Annual Meetings

- Member of Honor Society of Agriculture, Gamma Sigma Delta $(\Gamma \Sigma \Delta)$

- Travel award, UCGIS; Poster Presentation at the 2004 UCGIS Annual Assembly

- Ph.D. Preliminary Comprehensive Exams: Distinction, 2002

- Recipient of Socrates/Erasmus grant; Erasmus Exchange Program, Spring 1999

- $18^{\text {th }}$ Session of the European Youth Parliament at Götenborg, Sweden. Representative in the Greek Delegation, 1995

\section{PROFESSIONAL ASSOCIATIONS}

- Honor Society of Agriculture, Gamma Sigma Delta ( $\Gamma \Sigma \Delta)$

- Association of Environmental Resource Economists (AERE)

- European Association of Environmental Resource Economists (EAERE)

- Latin American and Caribbean Association of Environmental Resource Economists (EAERE)

- Southern Agricultural Economics Association (SAEA)

- Northeastern Agricultural and Resource Economics Association (NAREA)

\section{SKILLS}

\section{Languages}

- Greek (fluent)

- English (fluent)

- French (fluent)

- Italian (basic) $\underline{\text { Technology Skills }}$

$\begin{array}{ll}\text { Basic Skills } & \begin{array}{l}\text { Econometric } \\ \text { Packages }\end{array} \\ \text { Word } & \text { SPSS } \\ \text { Excel } & \text { SAS } \\ \text { PowerPoint } & \text { Eviews } \\ \text { Access } & \text { Matlab } \\ & \text { Limdep }\end{array}$

Spatial Software ArcGIS GeoDa Matlab 